\title{
The effects of constituents and the food matrix of dairy products postprandial metabolism in overweight subjects
}

Citation for published version (APA):

Masson, C. J. (2013). The effects of constituents and the food matrix of dairy products postprandial metabolism in overweight subjects. [Doctoral Thesis, Maastricht University]. Uitgeverij BOXPress. https://doi.org/10.26481/dis.20130906cm

Document status and date:

Published: 01/01/2013

DOI:

$10.26481 /$ dis.20130906cm

Document Version:

Publisher's PDF, also known as Version of record

\section{Please check the document version of this publication:}

- A submitted manuscript is the version of the article upon submission and before peer-review. There can be important differences between the submitted version and the official published version of record.

People interested in the research are advised to contact the author for the final version of the publication, or visit the DOI to the publisher's website.

- The final author version and the galley proof are versions of the publication after peer review.

- The final published version features the final layout of the paper including the volume, issue and page numbers.

Link to publication

\footnotetext{
General rights rights.

- You may freely distribute the URL identifying the publication in the public portal. please follow below link for the End User Agreement:

www.umlib.nl/taverne-license

Take down policy

If you believe that this document breaches copyright please contact us at:

repository@maastrichtuniversity.nl

providing details and we will investigate your claim.
}

Copyright and moral rights for the publications made accessible in the public portal are retained by the authors and/or other copyright owners and it is a condition of accessing publications that users recognise and abide by the legal requirements associated with these

- Users may download and print one copy of any publication from the public portal for the purpose of private study or research.

- You may not further distribute the material or use it for any profit-making activity or commercial gain

If the publication is distributed under the terms of Article $25 \mathrm{fa}$ of the Dutch Copyright Act, indicated by the "Taverne" license above, 
THE EFFECTS OF CONSTITUENTS AND THE FOOD MATRIX OF DAIRY PRODUCTS ON POSTPRANDIRL METRBOLISM IN OUERWEIGHT SUBJECTS

CHRISTIARN J. MASSON 

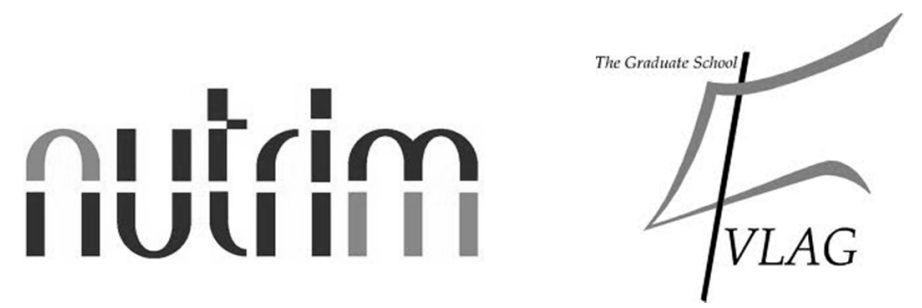

The studies presented in this thesis were performed at the School for Nutrition, Toxicology and Metabolism (NUTRIM), which participates in the Graduate School VLAG (Food Technology, Agrobiotechnology, Nutrition and Health Sciences), accredited by the Royal Netherlands Academy of Arts and Sciences (KNAW).

Cover design: Kevin Reumkens and Audrey Kawarmala Layout: Chris Masson

Printed by: Proefschriftmaken.nl | | Uitgeverij BOXpress

(C) CJ Masson, Heerlen 2013

ISBN: 978-90-8891-672-4 


\title{
THE EFFECTS OF CONSTITUENTS PND THE FOOD MATRIX OF DAIRY PRODUCTS ON POSTPRANDIRL METRBOLISM IN QUERWEIGHT SUBJECTS
}

\author{
Proefschrift
}

ter verkrijging van de graad van doctor aan de Universiteit Maastricht, op gezag van de Rector Magnificus, Prof. dr. L.L.G. Soete, volgens het besluit van het College van Decanen,

in het openbaar te verdedigen op

vrijdag 6 september 2013 om 14.00u

$$
\text { door }
$$

Christiaan Josef Masson

geboren te Heerlen op 18 november 1983 


\section{Promotor}

Prof. dr. ir. R.P. Mensink

\section{Beoordelingscommissie}

Prof. dr. M.A. van Baak (voorzitter)

Prof. dr. E.E. Blaak

Prof. dr. E.C.M. Mariman

Prof. dr. C.G. Schalkwijk

Dr. P.L. Zock (Unilever Research \& Development, Vlaardingen)

The research in this thesis was carried out at the department of Human Biology from Maastricht University and was funded by the Dutch Dairy Association 


\section{HOUD UDL, WANT RLLE MOEILIJKE DINGEN IN HET LEUEN LIJKEN ONMOGELIJK, TOTDRT ZE ZIJN UDLBRACHT UOOR KELLY}





\section{CONTENTS}

Chapter 1

9

General introduction

Chapter 2

The effects of macronutrients on postprandial lipemic, inflammatory and endothelial responses

Chapter 3

Fatty acid- and cholesterol transporter protein expression along the human intestinal tract

Chapter 4

Exchanging saturated fatty acids for ( $n-6)$ polyunsaturated fatty acids in a mixed meal may decrease postprandial lipemia and markers of inflammation and endothelial activity in overweight men

Chapter 5

The effects of milk and milk constituents provided with a high-fat meal on postprandial markers for inflammation in overweight men

Chapter 6

Milk homogenization and postprandial metabolism in overweight men: a randomized study

Chapter 7

General discussion

Summary

Samenvatting

Dankwoord

List of publications 



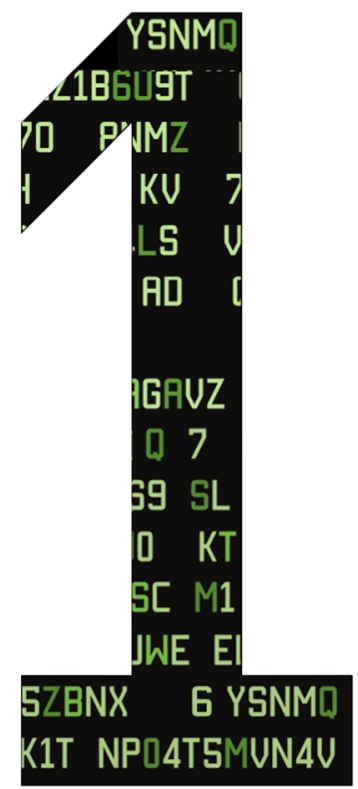

GENERAL INTRODUCTION 


\section{INTRODUCTION}

The incidence of the metabolic syndrome, a cluster of metabolic risk markers including elevated plasma glucose levels, an atherogenic lipid profile (i.e. increased triacylglycerols (TAG) and decreased high-density lipoprotein (HDL) cholesterol concentrations), abdominal obesity, low-grade systemic inflammation, and elevated blood pressure (1) has increased dramatically during the last decades (2). It is frequently diagnosed based on criteria formulated by the National Cholesterol Education Program's Adult Treatment Panel III (NCEP-ATP III; Table 1.1). If three or more of these conditions are present, people are diagnosed as suffering from the metabolic syndrome, which is a major risk factor for developing cardiovascular disease (CVD) and type 2 diabetes mellitus $(3,4)$.

Table 1.1: NCEP-ATP III criteria for the diagnosis of metabolic syndrome (5)

\begin{tabular}{ll}
\hline Criteria & Cut-off values \\
\hline Waist circumference, $\mathrm{cm}$ & $>102$ (men) \\
& $>88$ (women) \\
Blood pressure, $\mathrm{mm} \mathrm{Hg}$ & $\geq 130 / \geq 85$ \\
Triacylglycerols, $\mathrm{mmol} \cdot \mathrm{L}^{-1}$ & $\geq 1.7$ \\
$\mathrm{HDL}$ cholesterol, $\mathrm{mmol} \cdot \mathrm{L}^{-1}$ & $<1.03$ (men) \\
& $<1.30$ (women) \\
Fasting glucose, $\mathrm{mmol} \cdot \mathrm{L}^{-1}$ & $\geq 6.1$ \\
\hline
\end{tabular}

\section{Cardiovascular disease}

Although the term CVD classifies all diseases of the heart and blood vessels, e.g. heart failure, stroke and myocardial infarction, it is generally used to describe atherosclerosis. Atherosclerosis is the continuous process of hardening of the arteries, which already starts at an early age, and is the leading cause of stroke, infarction and peripheral vascular disease (6). The trigger for this process is endothelial damage, which is often induced by - but not restricted to - high circulating concentrations of low-density lipoprotein (LDL) cholesterol, proinflammatory cytokines, glucose, and non-esterified fatty acids. The inflicted damage increases the permeability of the endothelium and stimulates endothelial cells to induce chemotaxis by the release of chemokines, e.g. monocyte chemotactic protein (MCP)-1 (Figure 1.1). In addition, the increased permeability may lead to extravasation of atherogenic LDL particles and TAG-rich lipoproteins (TRL), which may undergo oxidation and stimulate endothelial cells to express cellular adhesion molecules (CAM). As a result of both chemotaxis and the expression of CAM, monocytes are drawn to the damage site, resulting in diapedesis and 
extravasation of monocytes. Once migrated into the intima layer, monocytes differentiate into macrophages, producing an array of proinflammatory cytokines, including interleukin (IL)-6, IL-8 and tumor necrosis factor (TNF)- $\alpha$. Additionally, these macrophages are capable of scavenging large amounts of oxidized LDL and TRL inside the intima layer through scavenger receptors, hereby transforming into lipid-laden foam cells and drastically increasing the production of proinflammatory cytokines. The endothelial cells and smooth muscle cells surrounding the affected area are stimulated to produce proinflammatory cytokines and growth factors, stimulating the proliferation of smooth muscle cells and the formation of a fibrous cap. At this stage the formation of the mature atherosclerotic plaque is completed, which may partially or completely block arterial blood flow. Eventually, this atherosclerotic plaque may rupture and result in a thrombus, which may obstruct a cerebral artery (cerebrovascular infarction) or coronary artery (myocardial infarction).

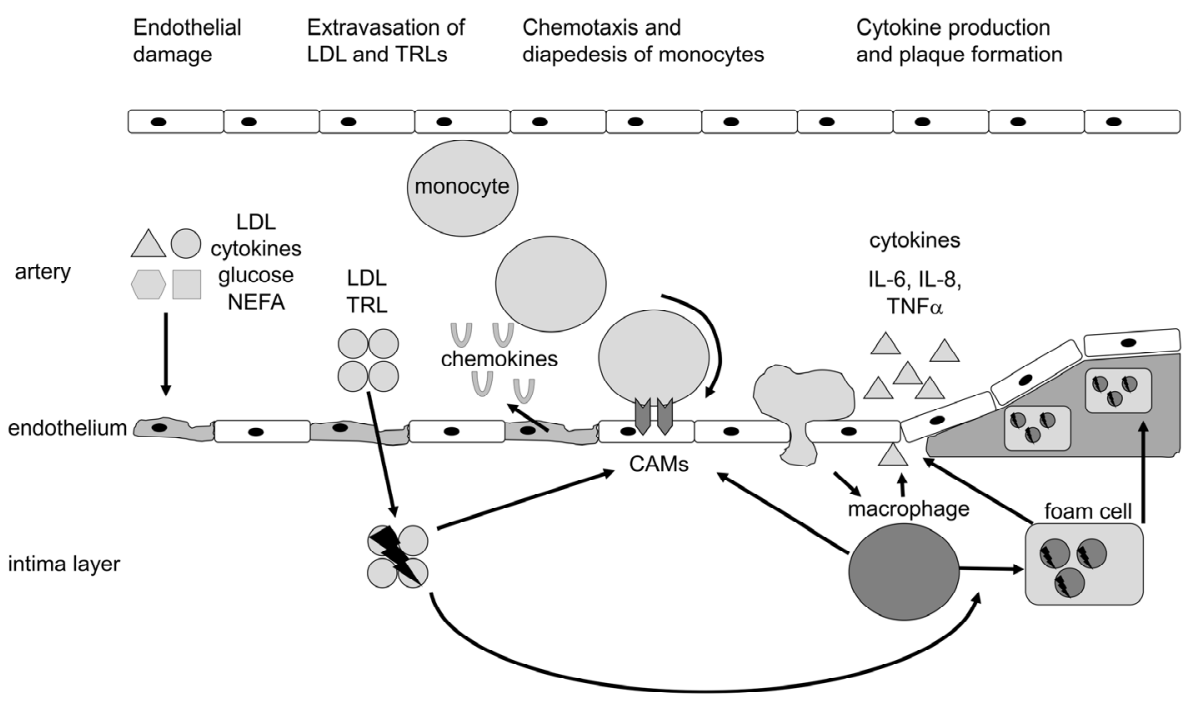

Figure 1.1: Schematic overview of the atherosclerotic process. LDL: low density lipoprotein, TRL: triacylglycerol-rich lipoprotein, CAM: cellular adhesion molecule, IL-6/8: interleukin-6/8, TNFa: tumor necrosis factor $\alpha$. 


\section{DAIRY CONSUMPTION AND METABOLIC SYNDROME AND CVD}

Several epidemiological studies (7-10) have found that a high intake of dairy products, such as milk, cheese, cream, butter and yogurt is associated with a reduced risk of developing the metabolic syndrome. Some studies $(11,12)$, however, have found a protective health effect only for low-fat dairy products. In addition, these protective effects were less pronounced compared to those of other studies (7-10). Moreover, consumption of dairy products was negatively related with the development of cardiovascular disease (CVD) and type 2 diabetes mellitus in case-control studies and prospective cohort studies $(13,14)$.

\section{Dairy components and disease risk}

The neutral to beneficial effects of the consumption of full-fat dairy products in relation to disease risk are surprising, because dairy products contain high amounts of cholesterol and saturated fatty acids, which are well known for their adverse effects on the serum lipoprotein profile. Saturated fatty acids increase LDL cholesterol concentrations by down-regulation of LDL-receptor mediated catabolism $(15,16)$, which may ultimately increase the risk of cardiovascular disease $(17,18)$. On the other hand, dairy products also contain high amounts of calcium and protein. Dietary calcium is well-known for its beneficial blood pressure modulation, showing on average a decrease of $0.5 \mathrm{~mm} \mathrm{Hg}$ or $0.4 \mathrm{~mm} \mathrm{Hg}$ in diastolic blood pressure in women and men respectively from one quartile of calcium intake to the next (19). In that study (19), calcium intake ranged between 688 and $1826 \mathrm{mg} /$ day, with an average consumption of $1109 \mathrm{mg} / \mathrm{day}$ for men and $980 \mathrm{mg} /$ day for women. Moreover, higher intakes of calcium were associated with a lower prevalence of the metabolic syndrome in middle-aged and older US women (20). In addition, calcium is known for its intestinal fat binding capacity, inducing the formation of insoluble calcium soaps thereby reducing intestinal fat absorption and increasing fecal fat excretion $(21,22)$. By this, calcium may positively affect lipoprotein metabolism.

Dairy products are also an important source of dietary protein. It has been shown that replacing dietary carbohydrates by proteins favorably reduced the total:HDL cholesterol ratio $(23,24)$. One of the most important characteristics of dietary protein is probably its potential of modifying body composition in relation to weight loss. Because of its satiating properties, dietary protein decreases energy intake and as a result fat mass, whilst sparing fat free mass thereby inducing a shift in body composition.

From the overview presented above it is clear that dairy products are complex food products and that their health effects may not be assigned to single dairy constituents alone. The findings that also high-fat dairy products may 
decrease the risk for the metabolic syndrome suggest that the composition of dairy products may play a role.

\section{POSTPRANDIAL METABOLISM OF DIETARY FAT}

After food intake, dietary fat, which is mainly composed of TAG, is partially digested into free fatty acids and monoacylglycerol by gastric lipase in the stomach and later in the duodenum and jejunum by pancreatic lipase. Fatty acids can be divided into short-chain (less than 6 carbon atoms (C)), mediumchain (6-12 C), long-chain (13-20 C), and very long-chain fatty acids (more than $20 \mathrm{C}$ ). Short-chain and medium-chain fatty acids are absorbed passively in the intestine and released directly from the intestinal capillaries into the portal circulation. The release of these fatty acids into the portal circulation does not result in a lipemic response. In contrast, long-chain and very longchain fatty acids are at least partially absorbed actively by specific fatty acid transport proteins, including Fatty Acid Transport Protein-4, Fatty Acid Translocase/CD36 and plasma membrane-bound Fatty Acid Binding Protein (25).

After absorption, the long-chain and very long-chain fatty acids are reesterified into TAG and incorporated into apolipoprotein B-48-rich chylomicrons in the intestine. These chylomicrons travel through the lymphatic vessels and enter the circulation in the vena subclavia. Whilst the intestinally formed chylomicrons travel through the circulation towards the liver, the TAG content is hydrolyzed by lipoprotein lipase (LPL). The released fatty acids are delivered either as an energy source to fat-utilizing tissues, e.g. muscle tissue, or to fat-storing tissues, for example adipose tissue, where these fatty acids are re-esterified to TAG. Hydrolysis, in combination with exchange of TAG between chylomicrons and the free fatty acid pool, leads to the formation of chylomicron remnants (26). The chylomicron remnants, which predominantly contain intestinally absorbed cholesterol after TAG clearance by LPL, are removed from the circulation mainly by the $L D L$ receptor and $L D L$ receptorrelated protein (LRP) (27-29).

Due to the increased flux of free fatty acids towards the liver and the rise of cholesterol levels inside the liver cells as a consequence of TRL clearance, very low-density lipoproteins (VLDL) synthesis increases. Inside the endoplasmatic reticulum, cholesteryl esters and TAG are incorporated into a growing particle. This particle also contains apolipoprotein B-100 and is exocytosed into the circulation as VLDL. 


\section{Importance of postprandial metabolism and food matrix}

By far most of the nutritional intervention studies are carried out in the fasted state. However, the evaluation of postprandial responses is of great importance, since people spend most of the day in a postprandial state. Considering that in Western countries on average at least three meals per day are consumed and that the duration of postprandial lipemia is on average 6-8 hours depending on the fat content of the meal, people spend most of the day in the postprandial state. Many studies have shown a positive correlation between the level and duration of postprandial lipemia and cardiovascular disease (30-32). Postprandial inflammation is tightly related to postprandial lipemia, since TRL augment cytokine production ex vivo by endothelial cells and in vitro by macrophages $(33,34)$. Atherosclerosis may therefore also be a postprandial process. It is thought that the most important particles involved in the interactions between postprandial lipemia, inflammation and endothelial activation are chylomicron remnants (35) and VLDL particles (33).

Besides the proposed effects on the long-term, as discussed in the paragraph above, dairy constituents may also alter the direct responses after meal consumption. In this, dairy protein, which consists mainly of casein, may decrease postprandial TAG concentrations (36) and as a result inflammatory responses. Moreover, in addition to its hypothesized effects on fat absorption, calcium may also decrease the formation of reactive oxygen species by altering mitochondrial uncoupling status through the suppression of calcitriol (37).

Since dairy products are complex food products, also the food matrix, which consists of the structure of the dairy product as a whole, the molecular arrangement and also the interrelationship between its constituents may play a substantial role in the postprandial responses. For instance, for carbohydrate-rich foods it is known that the physical structure of the food product determines postprandial glucose and insulin responses $(38,39)$, which may arguably also be the case for lipemic responses to fat-rich foods. For example, when different dairy products, e.g. milk, butter and cheese, are compared, differences in the food matrix may play a crucial role on the postprandial lipemic response, because differences in the physical state of the dairy fat might affect absorption kinetics and bioavailability. Therefore, the postprandial response to a specific dairy product may not be the net effect of all its constituents, but may be modified by the matrix in which it is consumed. 


\section{OUTLINE OF THE THESIS}

This thesis describes the results of several human intervention studies addressing the role of dairy products, their components and their food matrix on postprandial metabolic risk markers for CVD, including postprandial lipemia, and markers for inflammation and endothelial activation. In chapter 2 , an overview of the literature on the effects of macronutrients on the different stages of digestion, absorption and metabolism, and postprandial risk markers is presented. The observational study in chapter $\mathbf{3}$ was designed to measure the protein distribution profiles of the prominent cholesterol and fatty acid transport proteins along the human gastrointestinal tract, to gain insight in the main loci of transporter-mediated uptake of cholesterol and fatty acids. The human intervention study in chapter $\mathbf{4}$ was designed to compare postprandial responses in TAG and markers for inflammation and endothelial activation between saturated and ( $n-6)$ polyunsaturated fatty acids in overweight men. In chapter 5 the effects of milk and its main constituents - total milk protein and calcium - on postprandial inflammatory and endothelial responses in overweight men are described, while chapter 6 presents the results of a human intervention study on the effects of the food matrix of milk on postprandial risk markers. Finally, the main findings and conclusions based on the studies described in this thesis are discussed in chapter 7. 


\section{REFERENCES}

1. Executive Summary of The Third Report of The National Cholesterol Education Program (NCEP) Expert Panel on Detection, Evaluation, And Treatment of High Blood Cholesterol In Adults (Adult Treatment Panel III). JAMA 2001;285:2486-97.

2. Zimmet P, Alberti KG, Shaw J. Global and societal implications of the diabetes epidemic. Nature 2001;414:782-7.

3. Gogia A, Agarwal PK. Metabolic syndrome. Indian J Med Sci 2006;60:72-81.

4. Grundy SM. Cardiovascular and metabolic risk factors: how can we improve outcomes in the high-risk patient? Am J Med 2007;120:S3-8; discussion S9.

5. Grundy SM, Brewer HB, Jr., Cleeman JI, Smith SC, Jr., Lenfant C. Definition of metabolic syndrome: Report of the National Heart, Lung, and Blood Institute/American Heart Association conference on scientific issues related to definition. Circulation 2004;109:433-8.

6. Ross R. Atherosclerosis--an inflammatory disease. N Engl J Med 1999;340:115-26.

7. Azadbakht L, Mirmiran P, Esmaillzadeh A, Azizi F. Dairy consumption is inversely associated with the prevalence of the metabolic syndrome in Tehranian adults. Am J Clin Nutr 2005;82:523-30.

8. Pereira MA, Jacobs DR, Jr., Van Horn L, Slattery ML, Kartashov AI, Ludwig DS. Dairy consumption, obesity, and the insulin resistance syndrome in young adults: the CARDIA Study. JAMA 2002;287:2081-9.

9. Ruidavets JB, Bongard V, Dallongeville J, et al. High consumptions of grain, fish, dairy products and combinations of these are associated with a low prevalence of metabolic syndrome. J Epidemiol Community Health 2007;61:810-7.

10. Elwood PC, Pickering JE, Fehily AM. Milk and dairy consumption, diabetes and the metabolic syndrome: the Caerphilly prospective study. J Epidemiol Community Health 2007;61:695-8.

11. Choi HK, Willett WC, Stampfer MJ, Rimm E, Hu FB. Dairy consumption and risk of type 2 diabetes mellitus in men: a prospective study. Arch Intern Med 2005;165:997-1003.

12. van Dam RM, Hu FB, Rosenberg L, Krishnan S, Palmer JR. Dietary calcium and magnesium, major food sources, and risk of type 2 diabetes in U.S. black women. Diabetes Care 2006;29:2238-43.

13. Mann JI. Diet and risk of coronary heart disease and type 2 diabetes. Lancet 2002;360:783-9.

14. Kontogianni MD, Panagiotakos DB, Chrysohoou C, Pitsavos C, Stefanadis C. Modelling dairy intake on the development of acute coronary syndromes: the CARDIO2000 study. Eur J Cardiovasc Prev Rehabil 2006;13:791-7.

15. Nicolosi RJ, Stucchi AF, Kowala MC, Hennessy LK, Hegsted DM, Schaefer EJ. Effect of dietary fat saturation and cholesterol on LDL composition and metabolism. In vivo studies of receptor and nonreceptor-mediated catabolism of LDL in cebus monkeys. Arteriosclerosis 1990;10:119-28.

16. Spady DK, Bilheimer DW, Dietschy JM. Rates of receptor-dependent and -independent low density lipoprotein uptake in the hamster. Proc Natl Acad Sci U S A 1983;80:3499503.

17. Kromhout D, Menotti A, Bloemberg B, et al. Dietary saturated and trans fatty acids and cholesterol and 25-year mortality from coronary heart disease: the Seven Countries Study. Prev Med 1995;24:308-15.

18. Sacks FM, Katan M. Randomized clinical trials on the effects of dietary fat and carbohydrate on plasma lipoproteins and cardiovascular disease. Am J Med 2002;113 Suppl 9B:13S-24S.

19. Drouillet $\mathrm{P}$, Balkau B, Charles MA, et al. Calcium consumption and insulin resistance syndrome parameters. Data from the Epidemiological Study on the Insulin Resistance Syndrome (DESIR). Nutr Metab Cardiovasc Dis 2007;17:486-92.

20. Liu S, Song Y, Ford ES, Manson JE, Buring JE, Ridker PM. Dietary calcium, vitamin D, and the prevalence of metabolic syndrome in middle-aged and older U.S. women. Diabetes Care 2005;28:2926-32.

21. Denke MA, Fox MM, Schulte MC. Short-term dietary calcium fortification increases fecal saturated fat content and reduces serum lipids in men. J Nutr 1993;123:1047-53. 
22. Jacobsen R, Lorenzen JK, Toubro S, Krog-Mikkelsen I, Astrup A. Effect of short-term high dietary calcium intake on 24-h energy expenditure, fat oxidation, and fecal fat excretion. Int J Obes (Lond) 2005;29:292-301.

23. Krauss RM, Blanche PJ, Rawlings RS, Fernstrom HS, Williams PT. Separate effects of reduced carbohydrate intake and weight loss on atherogenic dyslipidemia. Am J Clin Nutr 2006;83:1025-31.

24. Katan MB. Alternatives to low-fat diets. Am J Clin Nutr 2006;83:989-90.

25. Tso P, Nauli A, Lo CM. Enterocyte fatty acid uptake and intestinal fatty acid-binding protein. Biochem Soc Trans 2004;32:75-8.

26. Hultin M, Savonen R, Olivecrona T. Chylomicron metabolism in rats: lipolysis, recirculation of triglyceride-derived fatty acids in plasma FFA, and fate of core lipids as analyzed by compartmental modelling. J Lipid Res 1996;37:1022-36.

27. Brown MS, Goldstein JL. A receptor-mediated pathway for cholesterol homeostasis. Science 1986;232:34-47.

28. Herz J, Qiu SQ, Oesterle A, DeSilva HV, Shafi S, Havel RJ. Initial hepatic removal of chylomicron remnants is unaffected but endocytosis is delayed in mice lacking the low density lipoprotein receptor. Proc Natl Acad Sci U S A 1995;92:4611-5.

29. Out R, Kruijt JK, Rensen PC, et al. Scavenger receptor BI plays a role in facilitating chylomicron metabolism. J Biol Chem 2004;279:18401-6.

30. Bansal S, Buring JE, Rifai N, Mora S, Sacks FM, Ridker PM. Fasting compared with nonfasting triglycerides and risk of cardiovascular events in women. JAMA 2007;298:309-16.

31. Patsch JR, Miesenbock G, Hopferwieser T, et al. Relation of triglyceride metabolism and coronary artery disease. Studies in the postprandial state. Arterioscler Thromb 1992;12:1336-45.

32. Nordestgaard BG, Benn M, Schnohr P, Tybjaerg-Hansen A. Nonfasting triglycerides and risk of myocardial infarction, ischemic heart disease, and death in men and women. JAMA 2007;298:299-308.

33. Mohrschladt MF, Weverling-Rijnsburger AW, de Man FH, et al. Hyperlipoproteinemia affects cytokine production in whole blood samples ex vivo. The influence of lipidlowering therapy. Atherosclerosis 2000;148:413-9.

34. Sampedro MC, Motran C, Gruppi A, Kivatinitz SC. VLDL modulates the cytokine secretion profile to a proinflammatory pattern. Biochem Biophys Res Commun 2001;285:393-9.

35. Cabezas MC, de Bruin TW, Westerveld HE, Meijer E, Erkelens DW. Delayed chylomicron remnant clearance in subjects with heterozygous familial hypercholesterolaemia. J Intern Med 1998;244:299-307.

36. Westphal S, Kastner S, Taneva E, Leodolter A, Dierkes J, Luley C. Postprandial lipid and carbohydrate responses after the ingestion of a casein-enriched mixed meal. Am J Clin Nutr 2004;80:284-90.

37. Sun X, Zemel MB. Calcium and 1,25-dihydroxyvitamin D3 regulation of adipokine expression. Obesity (Silver Spring) 2007;15:340-8.

38. O'Dea K, Nestel PJ, Antonoff L. Physical factors influencing postprandial glucose and insulin responses to starch. Am J Clin Nutr 1980;33:760-5.

39. Bjorck I, Granfeldt Y, Liljeberg H, Tovar J, Asp NG. Food properties affecting the digestion and absorption of carbohydrates. Am J Clin Nutr 1994;59:699S-705S. 



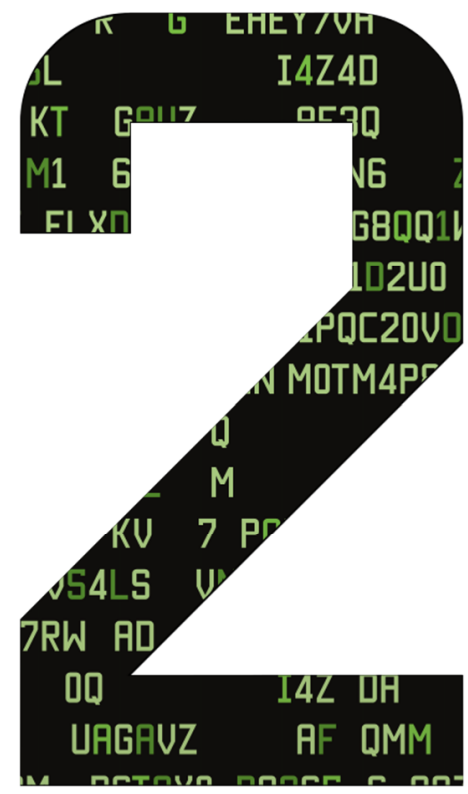

\section{THE EFFECTS OF MACRD- NUTRIENTS ON PDSTPRANDIAL LIPEMIC, INFLAMMATORY AND ENDOTHELIRL RESPONSES}




\section{ABSTRACT}

Postprandial lipemia is positively associated with cardiovascular disease risk. Moreover, the importance of postprandial inflammatory and endothelial processes is becoming more and more evident. Obviously, dietary fatty acids are a prerequisite for a postprandial lipemic response, and since postprandial lipemia and the inflammatory and endothelial responses are related, fatty acids may also affect these processes. Fat-specific determinants of lipemia include the amount of fat and the fatty acid composition, e.g. chain length, degree of saturation, triacylglycerol structure and solid fat content. Additionally, both dietary protein and carbohydrates may affect postprandial metabolism at various steps of digestion, absorption, and metabolic processing. Considerable effects may be found on fatty acid handling, mainly through insulinotropic effects, hereby decreasing the hepatic output of very low density lipoprotein (VLDL) particles. Regarding the inflammatory and endothelial responses, there are clear indications that meal consumption can result in activated endothelium and inflammatory signaling. However, data on macronutrient-specific differences is limited. This review presents an overview of the literature on the influence of the different macronutrients on postprandial lipemic, inflammatory and endothelial responses in human subjects. 


\section{INTRODUCTION}

Many intervention studies have examined the effects of diets on fasting concentrations of metabolic risk markers. However, it may take 6-8 hours to process a meal and many people in Western societies consume at least three meals a day. Thus, we spend most time of the day in the postprandial state. In fact, obese subjects and people suffering from diabetes mellitus and the metabolic syndrome (MetS) often display increased postprandial triacylglycerol (TAG) concentrations(1-4) which are positively associated with cardiovascular disease (CVD). Therefore, many recent studies have focused on postprandial metabolism, concentrating on lipemic, glycemic and inflammatory responses and on endothelial function. Postprandial metabolism is influenced by many factors including the macronutrient composition of the diet, which may affect the absorption and clearance rate of TAG-rich lipoproteins (TRLs). For fat, chain length, degree of saturation, the TAG structure, and the solid fat content might be important (5-9). Also, the composition of the habitual diet may influence the postprandial response by increasing fasting TAG levels, which are positively associated with postprandial TAG responses $(10,11)$.

Information on the role of macronutrients on postprandial inflammatory and endothelial responses is scarce. We therefore decided to review human studies on the influence of macronutrients on postprandial lipemia and inflammatory and endothelial processes, which might be involved in the etiology of the MetS and CVD.

\section{METABOLISM OF MACRONUTRIENTS IN RELATION TO TRI- ACYLGLYCEROL-RICH LIPOPROTEIN FORMATION}

\section{Digestion and absorption of macronutrients}

After food intake, dietary fat, which is mainly composed of TAG, is partially digested into free fatty acids and monoacylglycerol by gastric lipase in the stomach and later in the duodenum and jejunum by pancreatic lipase. The concentrations of the digestive enzyme gastric lipase may depend on the amount of fat in the diet. This was suggested by Armand et al. (12), who measured levels of gastric lipase in the gastric fluid of healthy subjects after an overnight fast, following 2-week-periods of either a high-fat diet $(50 \%$ of energy (En\%) from fat) or a low-fat diet (25 En\% fat). Levels of gastric lipase were increased after the high-fat diet. This indicates that enzyme synthesis and secretion adapt to habitual fat consumption. 
Digestion and absorption of dietary fatty acids varies according to type and chain length of the fatty acids involved. Fatty acids can be divided into shortchain (less than 6 carbon atoms (C)), medium-chain (6-12 C), long-chain (13$20 \mathrm{C}$ ), and very long-chain fatty acids (more than $20 \mathrm{C}$ ). Short-chain and medium-chain fatty acids are absorbed passively in the intestine and released directly from the intestinal capillaries into the portal circulation. The release of these fatty acids into the portal circulation does not result in a lipemic response. In contrast, long-chain and very long-chain fatty acids are at least partially absorbed actively by specific fatty acid transport proteins, including Fatty Acid Transport Protein-4, Fatty Acid Translocase/CD36 and plasma membrane-bound Fatty Acid Binding Protein (13) .

After absorption, the long-chain and very long-chain fatty acids are reesterified into TAG and incorporated into apolipoprotein B-48-rich chylomicrons in the intestine. These chylomicrons travel through the lymphatic vessels and enter the circulation in the vena subclavia.

Dietary oligosaccharides and polysaccharides are hydrolyzed into monosaccharides by pancreatic and intestinal glycosidases. In the intestine, several transporters are responsible for carbohydrate uptake (reviewed in (14)). The intestinal sodium/glucose cotransporter (SGLT-1), which has the highest affinity for glucose and galactose, is responsible for the majority of the uptake of monosaccharides from the intestine into the enterocyte, a process that depends on extracellular sodium. On the other hand, fructose absorption occurs by glucose transporter-5 (GLUT-5) facilitated diffusion. After absorption, the monosaccharides are released into the circulation by basolateral membrane-located glucose transporter-2 (GLUT-2) or GLUT-5.

For protein absorption, proteases, peptidases and specific peptide and amino acid transporters are involved (15). Proteins are degraded into amino acids and taken up by the enterocytes. From here, the amino acids are released into the circulation. However, the postprandial amino acid composition in plasma does not necessarily resemble the composition of the protein ingested, due to differences in the absorption rate and rate of release of the different amino acids into the circulation (16). Additionally, the amino acids from ingested protein are mixed with endogenously synthesized proteins and amino acids, and amino acids derived from proteins of shed intestinal mucosa cells (17).

\section{Formation and clearance of triglyceride-rich lipoproteins}

Whilst the intestinally formed chylomicrons travel through the circulation towards the liver, the TAG content is hydrolyzed by lipoprotein lipase (LPL), which is the main enzyme for chylomicron clearance and therefore partially determines the extent of postprandial lipemia. The released fatty acids are 
delivered either as an energy source to fat-utilizing tissues, e.g. muscle tissue, or to fat-storing tissues, for example adipose tissue, where these fatty acids are re-esterified to TAG. LPL activity is thought to depend mainly on plasma TAG levels (18). Hydrolysis, in combination with exchange of TAG between chylomicrons and the free fatty acid pool, leads to the formation of chylomicron remnants (19). The chylomicron remnants, which predominantly contain intestinally absorbed cholesterol after TAG clearance by LPL, are removed from the circulation mainly by the LDL receptor and LDL receptor-related protein (LRP) (20-22).

Due to the increased flux of free fatty acids towards the liver and the rise of cholesterol levels inside the liver cells as a consequence of TRL clearance, very low-density lipoproteins (VLDL) synthesis increases. Inside the endoplasmatic reticulum, cholesteryl esters and TAG are incorporated into a growing particle. This particle also contains apolipoprotein B-100 and is exocytosed into the circulation as VLDL. Insulin plays an important role in this process, since it acutely suppresses the production of hepatic apolipoprotein B-100-containing lipoproteins (23-25) and intestinally-derived lipoproteins (26), partly by its suppressive effects on free fatty acid concentrations, but also when free fatty acids are not affected $(27,28)$. This may occur by rerouting the free fatty acids towards adipose tissue and by increasing its clearance into tissues (29). Therefore, due to insulin-stimulating effects, also dietary carbohydrates and proteins may affect these processes.

There is evidence that TAG in TRLs directly after the consumption of a meal originates from the previous meal and that chylomicron TAG may therefore peak twice after a meal $(30,31)$. Evans et al. (31) have shown that after a standardized high-fat breakfast ( $54 \mathrm{En} \%$ fat; $4.3 \mathrm{MJ}$ ), the early TAG response (45-60 $\mathrm{min}$ ) after a consecutive lunch, which was consumed 5 hours after the breakfast, was comparable after a low-fat (1 En\% fat; $1.4 \mathrm{MJ}$ ) and a high-fat (60 En\% fat; $3.5 \mathrm{MJ}$ ) lunch, while no response was observed after water ingestion or saline infusion. The second peak after $120 \mathrm{~min}$, however, was much more pronounced after the high-fat than after the low-fat lunch. These findings indicate that the postprandial TAG response is primed by the previous meal and therefore comparisons between test meals may be confounded by the previous meal. Whether this also applies to the meal consumed on the previous day remains unclear. The exact mechanism by which the fat from the previous meal appears in chylomicrons of the subsequent meal, is not fully understood. It has been suggested that the subsequent meal triggers an increase in intestinal lymph flow, which may accelerate the entry of pre-formed chylomicrons into the circulation (31). 


\section{FATTY-ACID RELATED FACTORS INFLUENCING FATTY ACID META-BOLISM}

\section{Amount of intake}

Various studies have shown that postprandial TAG concentrations are linearly related to the amount of fat in the meal. Relatively low intakes of fat in the meal of 5-15 g did not significantly increase postprandial TAG concentrations (32), whereas intakes varying between 30-80 g stimulated postprandial lipemia dose-dependently (32-35). Cohen et al. (35) measured serum TAG concentrations after consumption of $40 \mathrm{~g}, 80 \mathrm{~g}$ or $120 \mathrm{~g}$ fat from cream and found that the increase in postprandial lipemia from $40 \mathrm{~g}$ to $80 \mathrm{~g}$ was larger than that from 80 to $120 \mathrm{~g}$. However, since TAG concentrations had not reached baseline concentrations after 8 hours, the effects calculated as the area under the curve (AUC) might have been underestimated, especially at the higher intakes (35). Compared with the intake of $40 \mathrm{~g}$ fat, the maximum serum TAG concentration was twice as high after the intake of $80 \mathrm{~g}$, but was only 2.4 times higher after the consumption of $120 \mathrm{~g}$ fat. For this observation, no obvious explanation could be given by the authors, since fat absorption, even at high doses (36), is nearly complete. It was however speculated that high-fat loads might increase the clearance rate of TAG from the circulation (35).

\section{Fatty acid type}

Since medium and short-chain fatty acids are secreted into the portal vein and are not incorporated into chylomicrons, these fatty acids have limited effects on postprandial lipemia. Indeed, in healthy subjects (BMI 20.1-27.8 kg/m²) postprandial lipemia (AUC) was lower after a medium-chain TAG (MCT)-rich meal (90 g fat, of which $42 \% \mathrm{MCT}$ ) as compared to long-chain TAG (LCT)rich meals (90 g fat) containing predominantly oleate, elaidate or palmitate (37). Recently, Poppitt et al. (38), however, did not report differences in postprandial lipemia for 3 hours after the intake of short-chain triacylglycerols (SCT), MCT or LCT-rich breakfasts in lean men. However, the postprandial period may have been too short, while the difference in the intake of SCT or MCT vs. that of LCT was only $10 \mathrm{~g}$.

Also, the degree of saturation of long-chain fatty acids may modulate postprandial lipemia, but studies examining differences in postprandial TAG concentrations between saturated fatty acids, monounsaturated fatty acids and n-6 PUFA are conflicting (39). On the other hand, marine n-3 PUFA may reduce postprandial TAG. Beneficial effects of realistic amounts of $n-3$ longchain polyunsaturated fatty acids (LCPUFA) in the diet on fasting TAG concentrations have been found in numerous studies, especially in subjects 
with hypertriacylglycerolemia (reviewed in (40)). Effects of n-3 LCPUFA on postprandial TAG concentrations are less clear. A single evening meal rich in fish oil ( $n-3$ long-chain PUFA) resulted in lower postprandial TAG iAUCs as compared to a saturated fat-rich meal, but not to an n-6 PUFA meal (41). Multiple studies, however, found no reductions in postprandial lipemia, as evaluated by changes in iAUCs, peak changes, peak concentrations (not corrected for baseline) and time to peak, when fish oil (doses varying from 2.3-16.0 g EPA+DHA) was added to a test meal with varying lipid compositions (42-44), while supplementation of the background diet with n-3 LCPUFA from fish oil was shown to decrease postprandial TAG concentrations in healthy subjects (44-47). Moreover, after long-term consumption of diets with varying n-3 or n-6 PUFA contents, decreased fasting TAG concentrations (48), and a decreased postprandial TAG response after a standardized test meal containing $50 \mathrm{~g}$ of fat (49) were found after the n-3 LCPUFA diets as compared to the n- 6 PUFA diets. On average doses of 3-4 g n-3 LCPUFA/day reduce fasting serum TAG concentrations by approximately $25 \%$ (40). Also, changing the $n-6 / n-3$ ratio of fatty acids in the meal during 6 months resulted in decreased fasting TAG and postprandial TAG iAUC in men and post-menopausal women, although postprandial LPL activity was unchanged (49). This finding seems contradictory to the findings by Park et al.(50) that n-3 LCPUFA accelerate postprandial clearance of chylomicrons, which was suggested to be due to increased LPL activity, as an increased preheparin LPL activity was found after n-3 LCPUFA supplementation.

Several other studies have analyzed whether LPL activities did depend on fatty acid type. In one study, lower increases in LPL activity were seen after the consumption of diets high in stearic acid or palmitic acid than after the intake of meals with linoleic acid or trans oleic acid (5). Changes in LPL activity corresponded with changes in TAG (5). LPL activity may be determined by chylomicron size, which in rats is larger after a meal containing mainly LCPUFA than after a meal containing mainly lauric acid or mainly MCT (51). Based on studies in rats, Martins et al. (52) have shown that increased particle size increases the clearance rate, but that the number of particles might be more important than particle size. This was explained through the competition for clearance, since plasma clearance of chylomicrons and remnants is a saturable process (52).

\section{Triacylglycerol structure and solid fat content}

Studies in animals and infants have suggested that TAG structure is important in the process of fat uptake, chylomicron synthesis, and clearance. Since pancreatic lipase preferably hydrolyzes fatty acids at the sn-1 and sn-3 
positions of the TAG structure (53), fatty acids in the sn-2 position are retained in the resulting 2-monoacylglycerol, which is a substrate for the resynthesis of TAG within the enterocyte. The non-esterified fatty acids from the sn-1 and sn-3 positions may form insoluble calcium/magnesium soaps, which may lower the absorption of these fatty acids. In adults, however, TAG structure does not seem to determine the extent of absorption (reviewed in (54)).

Whether TAG structure influences postprandial hyperlipidemia is not known, TAG structure is highly related to the melting curve of a fat and Berry et al.(8, 54) have proposed that a high solid fat content at body temperature lowers the postprandial TAG response. The solid fat particles are suggested to form micelles less readily, thereby delaying the absorption process and consequently lowering postprandial lipemia $(8,9)$.

\section{MACRONUTRIENT-RELATED FACTORS INFLUENCING FATTY ACID METABOLISM}

\section{Acute interaction between dietary carbohydrates and fatty acid meta- bolism}

Carbohydrate-rich meals may lower the absorption of fatty acids in the intestine by changing pancreatic enzyme synthetic rates. In rats, a meal rich in glucose and starch increased the pancreatic synthesis of amylase, but decreased lipase and protease mRNA expression and synthesis (55) (reviewed in (56)). These animal data probably reflect a physiological adaptive response, since a relative increase in carbohydrates coincides with a relative decrease in other macronutrients, resulting in decreased synthesis of their respective catabolic enzymes.

Several studies showed that the addition of carbohydrates to a fat load, resulted in a decreased lipemic response. Decreases in the iAUC for total serum TAG were found after glucose addition to a fat load as compared to a fat load alone, when the amount of glucose was increased from $50 \mathrm{~g}$ to $100 \mathrm{~g}$ (57) or from $50 \mathrm{~g}$ to $75 \mathrm{~g}$ or $100 \mathrm{~g}$ (58). Westphal et al.(58) extended these findings by looking at different lipoproteins. They found comparable concentrations of TAG in chylomicrons after a fat load alone or in combination with $75 \mathrm{~g}$ glucose, though the chylomicron response was delayed due to delayed gastric emptying after the fat load in combination with glucose. Moreover, these authors showed a suppressed postprandial VLDL-TAG increase after the combination of fat with glucose, which was hypothesized to be due to an insulin-mediated decrease in free fatty acid flux towards the liver and an increased flux towards the adipose tissue. 
The type of carbohydrate may also affect postprandial lipemia. In an early study by Cohen et al. (59), the addition of $50 \mathrm{~g}$ of fructose or $100 \mathrm{~g}$ of sucrose, providing $50 \mathrm{~g}$ of fructose and $50 \mathrm{~g}$ of glucose, to a high-fat load increased both the AUC for TAG and the maximum increase, whereas postprandial lipemia was unchanged after the addition of $50 \mathrm{~g}$ glucose. From these findings it was concluded that fructose or fructose-containing carbohydrates increase postprandial lipemia, whereas insulinogenic carbohydrates do not. Increases in postprandial lipemia after fructose addition to a fat load have been confirmed in several other studies $(60,61)$.

\section{Acute interaction between dietary protein and fatty acid metabolism}

It has been suggested that dietary protein may modulate postprandial TAG by affecting hepatic VLDL synthesis through insulinotropic effects, resulting in the rerouting of free fatty acids from the liver towards adipose tissue. However, especially plant proteins, including soy protein $(62,63)$, lupin protein $(64,65)$, chickpea protein and lentil protein (66) decreased serum TAG concentrations as compared to casein protein in rats when included in the habitual diet, while plasma insulin concentrations were comparable or higher after the casein diets as compared to the plant proteins. As LPL activity was either unchanged after 22 days of $200 \mathrm{~g} / \mathrm{kg}$ lupin protein as compared to casein (65), or increased in the liver after 20 days of $50 \mathrm{~g} / \mathrm{kg}$ lupin protein (64) or decreased in adipose tissue after 28 days of $200 \mathrm{~g} / \mathrm{kg}$ chickpea or lentil protein as compared to casein (66), the lower serum TAG concentrations were probably due to the consistently decreased VLDL synthesis after the plant proteins. This decrease may have resulted in, or be caused by, a decreased expression of sterol regulatory element-binding protein (SREBP), which is a key transcription factor for several genes involved in FA synthesis and esterification (67). This reduction may have been caused by the decreased insulin concentrations after the plant proteins, since insulin selectively stimulates SREBP mRNA (68). For humans, information on the effects of dietary protein on postprandial TAG concentrations is limited. Westphal and coworkers (69) have found that the addition of casein to a high-fat meal or to a high-fat meal with oligosaccharides significantly reduced postprandial plasma free fatty acid concentrations, possibly through the insulinotropic effects of amino acids $(70,71)$. Postprandial lipemia, however, was only significantly decreased in the chylomicron TAG fraction in the presence of oligosaccharides, which arguably may have contributed to the decreased lipemic response through inhibition of gastric lipase, as discussed earlier. However, a difference between the meals in gastric emptying and delayed fat absorption due to precipitation by casein may also have contributed to the delay and reduction in TAG response, mainly from the reduced and delayed 
chylomicron TAG response. Due to the decreased flow of free fatty acids to the liver, a decrease in hepatic VLDL synthesis would be expected, resulting in decreased concentrations of VLDL TAG. However, this was not confirmed in the study by Westphal et al. (69), which may indicate that this is an effect in the longer term.

\section{The role of longer-term intake of different macronutrients on fatty acid metabolism}

The effects on postprandial fatty acid metabolism after longer-term consumption of a high-fat diet have also been studied. Sharman et al. (72) switched 12 of in total 20 healthy normolipemic male subjects from their background diet (17 En\% protein, $47 \mathrm{En} \%$ carbohydrate and $32 \mathrm{En} \%$ fat) to a ketogenic, high-fat diet (30 En\% protein, $8 \mathrm{En} \%$ carbohydrate and $61 \mathrm{En} \%$ fat), whereas the remaining 8 subjects remained on their background diet (control group). Whether the background diet was unchanged during the 6week intervention period in the control group was checked by measurement of body weight, which was not changed in the control group but slightly decreased in the intervention group $(-2.2 \pm 1.7 \mathrm{~kg})$. After 3 and 6 weeks of intervention, fasting samples of serum lipids were determined. Compared with the control group, the ketogenic diet significantly decreased fasting TAG concentrations after 3 weeks of intervention, but fasted TAG levels did not further decrease after 3 weeks. After both dietary periods, subjects were postprandially challenged by the same high-fat meal (11 En\% carbohydrate, 2 En\% protein, and $87 \mathrm{En} \%$ fat). Postprandial TAG concentrations were significantly lowered from 3-8 hours after the postprandial challenge in the group on the ketogenic diet as compared to the control group. Based upon these findings it was suggested that a short-term, ketogenic, high-fat diet not only beneficially influences fasting concentrations of TAG, but also postprandial concentrations. It should be noted however that protein intake was also higher on the ketogenic diet. Another study with 10 healthy male subjects (73) showed significant reductions in fasting and postprandial TAG after an 8-week low-carbohydrate, high-fat diet (64 En\% fat, $7 \mathrm{En} \%$ carbohydrates, and $28 \mathrm{En} \%$ protein) in combination with supplementation with n-3 LCPUFA (3291 $\pm 314 \mathrm{mg}$ ) as compared to the habitual diet, which was assessed by 7-day food records (29-39 En\% from fat; $493 \pm 293 \mathrm{mg} \mathrm{n}-3$ PUFA). Unfortunately, it remains unclear what caused the decreases in lipid concentrations, since the high-fat diet was also hypocaloric (8.8 MJ vs. 11.1 $\mathrm{MJ})$. Also, these diets were higher in protein content and higher in MUFA content, which may have influenced the results.

Longer-term intake of carbohydrates increases fasting and postprandial TAG (reviewed in (74)). A role for the habitual high amount of carbohydrates in 
hyperlipidemia was suggested to be due to an increased de novo lipogenesis (75-77), resulting in higher circulating concentrations of TAG. However, when both normolipemic (fasting TAG $<1.13 \mathrm{mmol} / \mathrm{L}$ ) and slightly hyperlipemic (fasting TAG levels $1.13-2.26 \mathrm{mmol} / \mathrm{L}$ ) subjects switched to a 5 -week isocaloric low-fat, high-carbohydrate diet after a 1-week normal diet (35 En\% fat), VLDL-TAG clearance rate was reduced (78). This may suggest a role for this diet on a decreased removal of VLDL-TAG.

Unfortunately, to the best of our knowledge, no studies have been performed regarding the effects of longer-term intake of high-protein diets on postprandial TAG concentrations.

\section{MACRONUTRIENTS AND INFLAMMATORY AND ENDOTHELIAL RESPONSES}

\section{The relation between postprandial lipemia, and postprandial inflamma- tion}

Postprandial inflammation is tightly related to postprandial lipemia, since TAGrich lipoproteins augment cytokine production by endothelial cells and macrophages $(79,80)$. The most important particles involved in the interactions between postprandial lipemia, inflammation and endothelial activation are chylomicron remnants (81) and VLDL particles (79). In vitro studies have further suggested that interactions between chylomicron remnants and monocytes play an important role in atherogenesis $(82,83)$.

Several studies in healthy subjects and type 2 diabetic patients have shown that postprandial lipemia results in increased concentrations of circulating leukocytes, adhesion molecules, proinflammatory cytokines and other inflammatory markers (84-86). Moreover, several prospective cohort studies have shown that markers of inflammation (MOI), including C-Reactive Protein (C-RP) and interleukin-6 (IL-6), predict CVD in healthy individuals and in subjects with MetS (87-89). Additionally, increased concentrations of the Cellular Adhesion Molecules (CAMs) such as soluble Intracellular Adhesion Molecule (sICAM-1) as markers for endothelial activation and early atherosclerosis have been demonstrated to precede CHD several years before its clinical manifestations (90). Markers of inflammation, including CRP, IL-6, Tumor Necrosis Factor $\alpha$ (TNF $\alpha$ ) and TNF receptors, are increased in obesity (91-95) and in subjects with insulin resistance $(96,97)$. 


\section{The influence of dietary fat on inflammatory and endothelial markers}

Postprandial changes in $\mathrm{MOI}$ have been repeatedly found, but results are inconsistent. C-RP is a well-known member of the acute-phase proteins, which is produced as a result of an inflammatory stimulus $(98,99)$. C-RP is suggested to reflect the baseline activity of circulating cytokines $(100,101)$ and is produced in the liver in response to increased cytokine concentrations, mainly IL-6 (102, 103). C-RP levels, however, did not change in healthy subjects after consumption of a high-fat meal (62.5 g fat) and in subjects with MetS (1 g fat/kg body weight) $(104,105)$. In contrast, IL-6 did vary after the consumption of a high-fat meal in obese men $\left(60 \mathrm{~g} \mathrm{fat} / \mathrm{m}^{2}\right)(96)$, trained and untrained subjects ( $80 \mathrm{~g}$ of fat in combination with $80 \mathrm{~g}$ of carbohydrates)(106), and also in healthy subjects and patients with type 2 diabetes (84). In the latter study (84), the postprandial variations in the cytokines IL-6 and TNF $\alpha$, and adhesion molecules ICAM-1 and VCAM-1, were compared between healthy subjects and type 2 diabetic patients after consumption of either a high-fat meal providing $59.2 \mathrm{En} \%$ from fat, $12.3 \mathrm{En} \%$ from protein and $28.5 \mathrm{En} \%$ from carbohydrates with or without vitamins (vitamins $\mathrm{C}$ and $\mathrm{E}$ ), or a highcarbohydrate meal providing $20.6 \mathrm{En} \%$ from fat, $6.5 \mathrm{En} \%$ from protein and $72.9 \mathrm{En} \%$ from carbohydrates. It was found that plasma concentrations of both cytokines and adhesion molecules increased when healthy subjects consumed a high-fat meal, but not when a high-carbohydrate meal was consumed, suggesting that the consumption of a fat-enriched meal is directly associated with endothelial activation. In type 2 diabetic patients, consumption of both meals significantly increased cytokines and adhesion molecule concentrations. When vitamins were consumed directly after the meal, the increments in cytokines and adhesion molecules were no longer found in both subject groups, suggesting that the inflammatory response is either dependent on the oxidation of TRL or that TRL-induced oxidation processes are inhibited by the antioxidant actions of vitamins. Similarly, a high-fat meal increased postprandial $\mathrm{MOI}$ as compared to a high-carbohydrate meal in another study in healthy subjects (107). In this study postprandial serum lipid concentrations were compared during 4 hours and endothelial function during 3 hours after intake of $75 \mathrm{~g}$ of glucose, a high-fat meal (35 En\% fat, with no other macronutrients or energy content specified) or a standard meal (478 kcal, containing 16.4 En\% protein, 32.7 En\% fat and 50.4 En\% carbohydrate. Only the consumption of the high-fat meal increased TAG as compared to the carbohydrate and standard meals. The high-fat meal also significantly lowered forearm blood flow and flow debt repayment, suggesting a deleterious effect of acute fat consumption on endothelial function.

In vitro, it was shown that the n-6 PUFA increase endothelial activation.(108) In vivo, however, these acute n-6 PUFA specific inflammatory effects have not 
been found. Tulk et al. (105) studied the postprandial effects after fat loads with varying $n-6 / n-3$ ratios by blending palm stearin and safflower oil and adding fish oil to the mixture to achieve high or low $n-6 / n-3$ ratios of $20: 1$ or $2: 1$ respectively. Irrespective of this ratio, IL-6 concentrations increased postprandially after the fat loads as compared to a water control.

Consumption of both butter and walnuts increased the activity of postprandial NFKB (109), which is a redox-sensitive transcription factor (110). Olive oil on the other hand, which contains antioxidative polyphenols, did not elicit postprandial $\mathrm{NF \kappa B}$ activation. However, since walnuts also contain polyphenols, it cannot be concluded whether the absence of postprandial $\mathrm{NF} K \mathrm{~B}$ activation after olive oil was due to the difference in the type of fatty acid consumed (MUFA) or to the higher antioxidative capacity (109).

In an intervention study, healthy occasionally-smoking subjects used either no meal, 3 cigarettes, 3 toasts with $50 \mathrm{~g}$ of butter, or the same meal with 3 cigarettes. After the high-fat meals, increased plasma LPS concentrations were found, as compared to when no meal was consumed or only cigarettes were smoked (111). The increased plasma LPS concentrations after the highfat meals were accompanied by a decrease in LPS neutralization capacity, whereas this was not affected by the other two conditions. These findings may indicate a more efficient transport of bacterial LPS from the intestinal lumen into the blood stream with fat. Since LPS has a high affinity for chylomicrons, LPS is possibly incorporated into chylomicrons by the Golgi complex in the enterocytes before exocytosis $(112,113)$. The comparison of two fatty acids, i.e. oleic acid and butyric acid supported this hypothesis (114). Short-chain butyric acid, which is absorbed into the hepatic portal vein and consequently does not lead to chylomicron formation, did not induce an increase in cellassociated LPS release. Long-chain oleic acid on the other hand, which is incorporated into chylomicrons, resulted in significantly higher cell-associated LPS release. Moreover, addition of an inhibitor of chylomicron formation blocked the oleic acid-induced effects on LPS levels. Noteworthy, however, since the methodology on plasma LPS measurements is not widely accepted, these findings are not firmly established.

\section{Dietary carbohydrates and postprandial $\mathrm{MOI}$ and endothelial function}

In a study with lean, young adults, postprandial NFkB activity and concentrations of the oxidative stress marker nitrotyrosine were increased two hours after the consumption of bread with a high glycemic index ( $\mathrm{Gl}$ ) when compared with low $\mathrm{Gl}$ pasta (115). As no correlation was found between $\mathrm{NF} \kappa \mathrm{B}$-activity and postprandial insulin levels, these effects were attributed to the increases in plasma glucose concentrations. However, also no correlation between changes in venous glucose concentrations and $\mathrm{NF} \kappa \mathrm{B}$ activity was 
found. However, since the first venous blood was drawn after $1 \mathrm{~h}$, the timing of blood sampling may be the explanation for the lack of a significant correlation. Currently, there is no strong evidence that the glycemic index or load per se plays a role in postprandial inflammatory processes, since no alterations in inflammatory markers have been shown after a high GI meal as compared to a low $\mathrm{GI}$ meal $(116,117)$. However, these latter findings are hard to interpret, since there were also large differences in fiber content.

It is also believed that dietary fructose, which is a low-Gl carbohydrate, may have pro-inflammatory characteristics as it was previously implicated to contribute to the increased incidence of obesity and MetS $(118,119)$. Unfortunately, no in vivo data is present on the acute effects of fructose on postprandial inflammatory markers in human subjects.

\section{Dietary protein and postprandial $\mathrm{MOI}$ and endothelial function}

The effects of dietary protein on inflammatory and endothelial responses have mainly been attributed to the ratio of lysine:arginine. In this respect, several studies have shown that the process of atherosclerosis is accompanied by a reduction in nitric oxide (NO) production by endothelial nitric oxide synthase (eNOS) in the arterial wall (120-122). Since L-arginine is a precursor of epithelium-derived NO, several recent human studies (123-126) have examined inflammatory and endothelial processes after L-arginine supplementation, showing beneficial effects on flow-mediated dilation (FMD), but not on inflammatory markers. To the best of our knowledge, only three studies $(125,127,128)$ have evaluated the role of dietary protein on postprandial inflammatory and endothelial responses. Two studies found improvements in FMD after acute L-arginine consumption $(125,127)$. In the third study, the addition of $50 \mathrm{~g}$ of either sodium caseinate or soy protein to an acute fat load ( $1 \mathrm{~g}$ fat $/ \mathrm{kg}$ bodyweight) prevented in healthy subjects the decreases in flow-mediated dilation of $58 \%$ caused by the fat load alone (128). The authors suggested that both the increased supply of L-arginine, but also the proteins' insulinotrophy played a role in these improvements, since both proteins increased insulin concentrations and the ratio of L-arginine versus asymmetric dimethylarginine (ADMA), a molecule that inhibits eNOS activity and consequently $\mathrm{NO}$ production in the vessel wall.

Insulin may have both direct and indirect effects, including vasodilatation, and decreased FFA concentrations, resulting in decreased VLDL production and, as a result, decreased lipemia. These positive effects on FMD were not found when glucose was the stimulator of insulin secretion (129), since glucose increased the production of ROS (e.g. peroxidation of $\mathrm{NO}$ by superoxide to form peroxynitrite) (130), which may counteract the beneficial effects of insulin. 


\section{CONCLUSION}

This review presents an overview on the influence of macronutrients on postprandial lipemic, inflammatory and endothelial responses. These processes are closely related at different levels. For lipemia, evidence is present for a relation with increased CVD risk, while the importance of postprandial inflammatory and endothelial processes is becoming more and more evident. Of course, fatty acids are a prerequisite for postprandial lipemia, but dietary protein and carbohydrates have significant modulatory effects. Fatspecific determinants of lipemia include the amount of fat in the diet and its fatty acid composition. In this respect, chain length, degree of saturation, TAG structure and solid fat content result in various effects on the different steps of digestion, absorption, and metabolic processing. Dietary carbohydrates and protein may have considerable effects on fatty acid handling, mainly through insulinotropic effects, hereby decreasing hepatic VLDL output. Compared with glucose, fructose-containing carbohydrates may however increase postprandial TAG. Concerning inflammation and endothelial activity, studies have used various markers and techniques. There are clear indications that diet can result in activated endothelium and inflammatory signaling. However, there is not much data available on macronutrient-specific differences. There is some evidence that mainly high-fat diets induce these processes and that there are differences between fatty acids. Differences between fatty acids in single meals are poorly understood. Moreover, there are some suggestions that high GI carbohydrates may be proinflammatory, while dietary proteins with high L-arginine contents may have beneficial effects on endothelial activity. In general, however, macronutrient-specific effects on postprandial inflammatory processes and endothelial activity have hardly been studied. 


\section{REFERENCES}

1. Bansal S, Buring JE, Rifai N, Mora S, Sacks FM, Ridker PM. Fasting compared with nonfasting triglycerides and risk of cardiovascular events in women. JAMA 2007;298:309-16.

2. Patsch JR, Miesenbock G, Hopferwieser T, et al. Relation of triglyceride metabolism and coronary artery disease. Studies in the postprandial state. Arterioscler Thromb 1992;12:1336-45.

3. Nordestgaard BG, Benn M, Schnohr P, Tybjaerg-Hansen A. Nonfasting triglycerides and risk of myocardial infarction, ischemic heart disease, and death in men and women. JAMA 2007;298:299-308.

4. van Wijk JP, Halkes CJ, Erkelens DW, Castro Cabezas M. Fasting and daylong triglycerides in obesity with and without type 2 diabetes. Metabolism 2003;52:1043-9.

5. Tholstrup T, Sandstrom B, Bysted A, Holmer G. Effect of 6 dietary fatty acids on the postprandial lipid profile, plasma fatty acids, lipoprotein lipase, and cholesterol ester transfer activities in healthy young men. Am J Clin Nutr 2001;73:198-208.

6. Lai HC, Ney DM. Corn oil, palm oil and butterfat fractions affect postprandial lipemia and lipoprotein lipase in meal-fed rats. J Nutr 1995;125:1536-45.

7. Sanders TA, Berry SE, Miller GJ. Influence of triacylglycerol structure on the postprandial response of factor VII to stearic acid-rich fats. Am J Clin Nutr 2003;77:77782.

8. Berry SE, Miller GJ, Sanders TA. The solid fat content of stearic acid-rich fats determines their postprandial effects. Am J Clin Nutr 2007;85:1486-94.

9. Berry SE, Sanders TA. Influence of triacylglycerol structure of stearic acid-rich fats on postprandial lipaemia. Proc Nutr Soc 2005;64:205-12.

10. Lewis GF, O'Meara NM, Soltys PA, et al. Fasting hypertriglyceridemia in noninsulindependent diabetes mellitus is an important predictor of postprandial lipid and lipoprotein abnormalities. J Clin Endocrinol Metab 1991;72:934-44.

11. O'Meara NM, Lewis GF, Cabana VG, Iverius PH, Getz GS, Polonsky KS. Role of basal triglyceride and high density lipoprotein in determination of postprandial lipid and lipoprotein responses. J Clin Endocrinol Metab 1992;75:465-71.

12. Armand M, Hamosh M, DiPalma JS, et al. Dietary fat modulates gastric lipase activity in healthy humans. Am J Clin Nutr 1995;62:74-80.

13. Tso P, Nauli A, Lo CM. Enterocyte fatty acid uptake and intestinal fatty acid-binding protein. Biochem Soc Trans 2004;32:75-8.

14. Thorens B. Glucose transporters in the regulation of intestinal, renal, and liver glucose fluxes. Am J Physiol 1996;270:G541-53.

15. Matthews DM. Intestinal absorption of amino acids and peptides. Proc Nutr Soc 1972;31:171-7.

16. Feigin RD, Beisel WR, Wannemacher RW, Jr. Rhythmicity of plasma amino acids and relation to dietary intake. Am J Clin Nutr 1971;24:329-41.

17. Nasset ES. Role of the digestive system in protein metabolism. Fed Proc 1965;24:9538.

18. Sato N, Deckelbaum RJ, Neeser G, Carpentier YA, Kinney JM. Hydrolysis of mixed lipid emulsions containing medium-chain and long-chain triacylglycerol with lipoprotein lipase in plasma-like medium. JPEN J Parenter Enteral Nutr 1994;18:112-8.

19. Hultin $M$, Savonen $\mathrm{R}$, Olivecrona T. Chylomicron metabolism in rats: lipolysis, recirculation of triglyceride-derived fatty acids in plasma FFA, and fate of core lipids as analyzed by compartmental modelling. J Lipid Res 1996;37:1022-36.

20. Brown MS, Goldstein JL. A receptor-mediated pathway for cholesterol homeostasis. Science 1986;232:34-47.

21. Herz J, Qiu SQ, Oesterle A, DeSilva HV, Shafi S, Havel RJ. Initial hepatic removal of chylomicron remnants is unaffected but endocytosis is delayed in mice lacking the low density lipoprotein receptor. Proc Natl Acad Sci U S A 1995;92:4611-5.

22. Out R, Kruijt JK, Rensen PC, et al. Scavenger receptor BI plays a role in facilitating chylomicron metabolism. J Biol Chem 2004;279:18401-6.

23. Lewis GF, Uffelman KD, Szeto LW, Steiner G. Effects of acute hyperinsulinemia on VLDL triglyceride and VLDL apoB production in normal weight and obese individuals. Diabetes 1993;42:833-42. 
24. Malmstrom R, Packard CJ, Caslake M, et al. Defective regulation of triglyceride metabolism by insulin in the liver in NIDDM. Diabetologia 1997;40:454-62.

25. Malmstrom R, Packard CJ, Caslake M, et al. Effects of insulin and acipimox on VLDL1 and VLDL2 apolipoprotein B production in normal subjects. Diabetes 1998;47:779-87.

26. Pavlic M, Xiao C, Szeto L, Patterson BW, Lewis GF. Insulin acutely inhibits intestinal lipoprotein secretion in humans in part by suppressing plasma free fatty acids. Diabetes 2010;59:580-7.

27. Lewis GF, Uffelman KD, Szeto LW, Weller B, Steiner G. Interaction between free fatty acids and insulin in the acute control of very low density lipoprotein production in humans. J Clin Invest 1995;95:158-66.

28. Malmstrom R, Packard CJ, Watson TD, et al. Metabolic basis of hypotriglyceridemic effects of insulin in normal men. Arterioscler Thromb Vasc Biol 1997;17:1454-64.

29. Bonadonna RC, Groop LC, Zych K, Shank M, DeFronzo RA. Dose-dependent effect of insulin on plasma free fatty acid turnover and oxidation in humans. Am J Physiol 1990;259:E736-50.

30. Fielding BA, Callow J, Owen RM, Samra JS, Matthews DR, Frayn KN. Postprandial lipemia: the origin of an early peak studied by specific dietary fatty acid intake during sequential meals. Am J Clin Nutr 1996;63:36-41.

31. Evans K, Kuusela PJ, Cruz ML, Wilhelmova I, Fielding BA, Frayn KN. Rapid chylomicron appearance following sequential meals: effects of second meal composition. Br J Nutr 1998;79:425-9.

32. Dubois C, Beaumier G, Juhel C, et al. Effects of graded amounts $(0-50 \mathrm{~g})$ of dietary fat on postprandial lipemia and lipoproteins in normolipidemic adults. Am J Clin Nutr 1998;67:31-8.

33. Dubois C, Armand M, Azais-Braesco V, et al. Effects of moderate amounts of emulsified dietary fat on postprandial lipemia and lipoproteins in normolipidemic adults. Am J Clin Nutr 1994;60:374-82.

34. Murphy MC, Isherwood SG, Sethi S, et al. Postprandial lipid and hormone responses to meals of varying fat contents: modulatory role of lipoprotein lipase? Eur J Clin Nutr 1995;49:578-88.

35. Cohen JC, Noakes TD, Benade AJ. Serum triglyceride responses to fatty meals: effects of meal fat content. Am J Clin Nutr 1988;47:825-7.

36. Annegers JH, Boutwell JH, Ivy AC. The effect of dietary fat on fecal fat excretion and subjective symptoms in man. Gastroenterology 1948;10:486-95.

37. Sanders TA, de Grassi T, Miller GJ, Morrissey JH. Influence of fatty acid chain length and cis/trans isomerization on postprandial lipemia and factor VII in healthy subjects (postprandial lipids and factor VII). Atherosclerosis 2000;149:413-20.

38. Poppitt SD, Strik CM, MacGibbon AK, McArdle BH, Budgett SC, McGill AT. Fatty acid chain length, postprandial satiety and food intake in lean men. Physiol Behav 2010;101:161-7.

39. Williams CM. Dietary interventions affecting chylomicron and chylomicron remnant clearance. Atherosclerosis 1998;141 Suppl 1:S87-92.

40. Harris WS. n-3 fatty acids and serum lipoproteins: human studies. Am J Clin Nutr 1997;65:1645S-1654S.

41. Zampelas A, Peel AS, Gould BJ, Wright J, Williams CM. Polyunsaturated fatty acids of the $n-6$ and $n-3$ series: effects on postprandial lipid and apolipoprotein levels in healthy men. Eur J Clin Nutr 1994;48:842-8.

42. Burdge GC, Powell J, Calder PC. Lack of effect of meal fatty acid composition on postprandial lipid, glucose and insulin responses in men and women aged 50-65 years consuming their habitual diets. Br J Nutr 2006;96:489-500.

43. Hall WL, Sanders KA, Sanders TA, Chowienczyk PJ. A high-fat meal enriched with eicosapentaenoic acid reduces postprandial arterial stiffness measured by digital volume pulse analysis in healthy men. J Nutr 2008;138:287-91.

44. Harris WS, Connor WE, Alam N, Illingworth DR. Reduction of postprandial triglyceridemia in humans by dietary n-3 fatty acids. J Lipid Res 1988;29:1451-60.

45. Williams CM, Moore F, Morgan L, Wright J. Effects of $n-3$ fatty acids on postprandial triacylglycerol and hormone concentrations in normal subjects. Br J Nutr 1992;68:65566.

46. Weintraub MS, Zechner R, Brown A, Eisenberg S, Breslow JL. Dietary polyunsaturated fats of the W-6 and W-3 series reduce postprandial lipoprotein levels. Chronic and 
acute effects of fat saturation on postprandial lipoprotein metabolism. J Clin Invest 1988;82:1884-93.

47. Agren JJ, Hanninen O, Julkunen A, et al. Fish diet, fish oil and docosahexaenoic acid rich oil lower fasting and postprandial plasma lipid levels. Eur J Clin Nutr 1996;50:76571.

48. Sanders TA, Sullivan DR, Reeve J, Thompson GR. Triglyceride-lowering effect of marine polyunsaturates in patients with hypertriglyceridemia. Arteriosclerosis 1985;5:459-65.

49. Griffin MD, Sanders TA, Davies IG, et al. Effects of altering the ratio of dietary n-6 to n3 fatty acids on insulin sensitivity, lipoprotein size, and postprandial lipemia in men and postmenopausal women aged 45-70 y: the OPTILIP Study. Am J Clin Nutr 2006;84:1290-8.

50. Park Y, Harris WS. Omega-3 fatty acid supplementation accelerates chylomicron triglyceride clearance. J Lipid Res 2003;44:455-63.

51. Levy E, Roy CC, Goldstein R, Bar-On H, Ziv E. Metabolic fate of chylomicrons obtained from rats maintained on diets varying in fatty acid composition. J Am Coll Nutr 1991;10:69-78.

52. Martins IJ, Mortimer BC, Miller J, Redgrave TG. Effects of particle size and number on the plasma clearance of chylomicrons and remnants. J Lipid Res 1996;37:2696-705.

53. Yang LY, Kuksis A. Apparent convergence (at 2-monoacylglycerol level) of phosphatidic acid and 2-monoacylglycerol pathways of synthesis of chylomicron triacylglycerols. J Lipid Res 1991;32:1173-86.

54. Berry SE. Triacylglycerol structure and interesterification of palmitic and stearic acidrich fats: an overview and implications for cardiovascular disease. Nutr Res Rev 2009;22:3-17.

55. Dagorn JC, Lahaie RG. Dietary regulation of pancreatic protein synthesis. I. Rapid and specific modulation of enzyme synthesis by changes in dietary composition. Biochim Biophys Acta 1981;654:111-8.

56. Brannon PM. Adaptation of the exocrine pancreas to diet. Annu Rev Nutr 1990;10:85105.

57. Cohen JC, Berger GM. Effects of glucose ingestion on postprandial lipemia and triglyceride clearance in humans. J Lipid Res 1990;31:597-602.

58. Westphal S, Leodolter A, Kahl S, Dierkes J, Malfertheiner P, Luley C. Addition of glucose to a fatty meal delays chylomicrons and suppresses VLDL in healthy subjects. Eur J Clin Invest 2002;32:322-7.

59. Cohen JC, Schall R. Reassessing the effects of simple carbohydrates on the serum triglyceride responses to fat meals. Am J Clin Nutr 1988;48:1031-4.

60. Jeppesen J, Chen YD, Zhou MY, Wang T, Reaven GM. Effect of variations in oral fat and carbohydrate load on postprandial lipemia. Am J Clin Nutr 1995;62:1201-5.

61. Jeppesen J, Chen YI, Zhou MY, Schaaf P, Coulston A, Reaven GM. Postprandial triglyceride and retinyl ester responses to oral fat: effects of fructose. Am J Clin Nutr 1995;61:787-91.

62. Tovar AR, Murguia F, Cruz C, et al. A soy protein diet alters hepatic lipid metabolism gene expression and reduces serum lipids and renal fibrogenic cytokines in rats with chronic nephrotic syndrome. J Nutr 2002;132:2562-9.

63. Shukla A, Brandsch C, Bettzieche A, Hirche F, Stangl GI, Eder K. Isoflavone-poor soy protein alters the lipid metabolism of rats by SREBP-mediated down-regulation of hepatic genes. J Nutr Biochem 2007;18:313-21.

64. Bettzieche A, Brandsch C, Weisse K, Hirche F, Eder K, Stangl GI. Lupin protein influences the expression of hepatic genes involved in fatty acid synthesis and triacylglycerol hydrolysis of adult rats. Br J Nutr 2008;99:952-62.

65. Spielmann J, Shukla A, Brandsch C, Hirche F, Stangl GI, Eder K. Dietary lupin protein lowers triglyceride concentrations in liver and plasma in rats by reducing hepatic gene expression of sterol regulatory element-binding protein-1c. Ann Nutr Metab 2007;51:387-92.

66. Boualga A, Prost J, Taleb-Senouci D, et al. Purified chickpea or lentil proteins impair VLDL metabolism and lipoprotein lipase activity in epididymal fat, but not in muscle, compared to casein, in growing rats. Eur J Nutr 2009;48:162-9. 
67. Shimano $\mathrm{H}$, Yahagi $\mathrm{N}$, Amemiya-Kudo $\mathrm{M}$, et al. Sterol regulatory element-binding protein-1 as a key transcription factor for nutritional induction of lipogenic enzyme genes. J Biol Chem 1999;274:35832-9.

68. Shimomura I, Bashmakov Y, Ikemoto S, Horton JD, Brown MS, Goldstein JL. Insulin selectively increases SREBP-1c mRNA in the livers of rats with streptozotocin-induced diabetes. Proc Natl Acad Sci U S A 1999;96:13656-61.

69. Westphal S, Kastner S, Taneva E, Leodolter A, Dierkes J, Luley C. Postprandial lipid and carbohydrate responses after the ingestion of a casein-enriched mixed meal. Am J Clin Nutr 2004;80:284-90.

70. Floyd JC, Jr., Fajans SS, Conn JW, Knopf RF, Rull J. Insulin secretion in response to protein ingestion. J Clin Invest 1966;45:1479-86.

71. Floyd JC, Jr., Fajans SS, Conn JW, Knopf RF, Rull J. Stimulation of insulin secretion by amino acids. J Clin Invest 1966;45:1487-502.

72. Sharman MJ, Kraemer WJ, Love DM, et al. A ketogenic diet favorably affects serum biomarkers for cardiovascular disease in normal-weight men. J Nutr 2002;132:187985.

73. Volek JS, Gomez AL, Kraemer WJ. Fasting lipoprotein and postprandial triacylglycerol responses to a low-carbohydrate diet supplemented with n-3 fatty acids. J Am Coll Nutr 2000;19:383-91.

74. Parks EJ. Effect of dietary carbohydrate on triglyceride metabolism in humans. J Nutr 2001;131:2772S-2774S.

75. Nestel PJ, Carroll KF, Havenstein N. Plasma triglyceride response to carbohydrates, fats and caloric intake. Metabolism 1970;19:1-18.

76. Boberg J, Carlson LA, Freyschuss U. Determination of splanchnic secretion rate of plasma triglycerides and of total and splanchnic turnover of plasma free fatty acids in man. Eur J Clin Invest 1972;2:123-32.

77. Boberg J, Carlson LA, Freyschuss U, Lassers BW, Wahlqvist ML. Splanchnic secretion rates of plasma triglycerides and total and splanchnic turnover of plasma free fatty acids in men with normo- and hypertriglyceridaemia. Eur J Clin Invest 1972;2:454-66.

78. Parks EJ, Krauss RM, Christiansen MP, Neese RA, Hellerstein MK. Effects of a lowfat, high-carbohydrate diet on VLDL-triglyceride assembly, production, and clearance. J Clin Invest 1999;104:1087-96.

79. Mohrschladt MF, Weverling-Rijnsburger AW, de Man FH, et al. Hyperlipoproteinemia affects cytokine production in whole blood samples ex vivo. The influence of lipidlowering therapy. Atherosclerosis 2000;148:413-9.

80. Sampedro MC, Motran C, Gruppi A, Kivatinitz SC. VLDL modulates the cytokine secretion profile to a proinflammatory pattern. Biochem Biophys Res Commun 2001;285:393-9.

81. Cabezas MC, de Bruin TW, Westerveld HE, Meijer E, Erkelens DW. Delayed chylomicron remnant clearance in subjects with heterozygous familial hypercholesterolaemia. J Intern Med 1998;244:299-307.

82. Bentley C, Hathaway N, Widdows J, et al. Influence of chylomicron remnants on human monocyte activation in vitro. Nutr Metab Cardiovasc Dis 2010.

83. van Oostrom AJ, Rabelink TJ, Verseyden C, et al. Activation of leukocytes by postprandial lipemia in healthy volunteers. Atherosclerosis 2004;177:175-82.

84. Nappo F, Esposito K, Cioffi M, et al. Postprandial endothelial activation in healthy subjects and in type 2 diabetic patients: role of fat and carbohydrate meals. J Am Coll Cardiol 2002;39:1145-50.

85. Ceriello A, Quagliaro L, Piconi L, et al. Effect of postprandial hypertriglyceridemia and hyperglycemia on circulating adhesion molecules and oxidative stress generation and the possible role of simvastatin treatment. Diabetes 2004;53:701-10.

86. Van Oostrom AJ, Sijmonsma TP, Rabelink TJ, Van Asbeck BS, Cabezas MC. Postprandial leukocyte increase in healthy subjects. Metabolism 2003;52:199-202.

87. Ridker PM, Cushman M, Stampfer MJ, Tracy RP, Hennekens CH. Inflammation, aspirin, and the risk of cardiovascular disease in apparently healthy men. $\mathrm{N}$ Engl $\mathrm{J}$ Med 1997;336:973-9.

88. Ridker PM, Hennekens $\mathrm{CH}$, Buring JE, Rifai N. C-reactive protein and other markers of inflammation in the prediction of cardiovascular disease in women. $\mathrm{N}$ Engl $\mathrm{J}$ Med 2000;342:836-43. 
89. Ridker PM, Rifai N, Stampfer MJ, Hennekens CH. Plasma concentration of interleukin6 and the risk of future myocardial infarction among apparently healthy men. Circulation 2000;101:1767-72.

90. Ridker PM, Hennekens CH, Roitman-Johnson B, Stampfer MJ, Allen J. Plasma concentration of soluble intercellular adhesion molecule 1 and risks of future myocardial infarction in apparently healthy men. Lancet 1998;351:88-92.

91. Manning PJ, Sutherland WH, McGrath MM, de Jong SA, Walker RJ, Williams MJ. Postprandial cytokine concentrations and meal composition in obese and lean women. Obesity (Silver Spring) 2008;16:2046-52.

92. Cook DG, Mendall MA, Whincup PH, et al. C-reactive protein concentration in children: relationship to adiposity and other cardiovascular risk factors. Atherosclerosis 2000;149:139-50.

93. Visser M, Bouter LM, McQuillan GM, Wener MH, Harris TB. Low-grade systemic inflammation in overweight children. Pediatrics 2001;107:E13.

94. Moon YS, Kim DH, Song DK. Serum tumor necrosis factor-alpha levels and components of the metabolic syndrome in obese adolescents. Metabolism 2004;53:863-7.

95. Yudkin JS, Stehouwer CD, Emeis JJ, Coppack SW. C-reactive protein in healthy subjects: associations with obesity, insulin resistance, and endothelial dysfunction: a potential role for cytokines originating from adipose tissue? Arterioscler Thromb Vasc Biol 1999;19:972-8.

96. Blackburn P, Despres JP, Lamarche B, et al. Postprandial variations of plasma inflammatory markers in abdominally obese men. Obesity (Silver Spring) 2006;14:1747-54.

97. Shoelson SE, Herrero L, Naaz A. Obesity, inflammation, and insulin resistance. Gastroenterology 2007;132:2169-80.

98. Pepys MB, Rowe IF, Baltz ML. C-reactive protein: binding to lipids and lipoproteins. Int Rev Exp Pathol 1985;27:83-111.

99. Morley JJ, Kushner I. Serum C-reactive protein levels in disease. Ann N Y Acad Sci 1982;389:406-18.

100. Herity NA. Interleukin 6: a message from the heart. Heart 2000;84:9-10.

101. Ross R. Atherosclerosis--an inflammatory disease. N Engl J Med 1999;340:115-26.

102. Castell JV, Gomez-Lechon MJ, David M, Fabra R, Trullenque R, Heinrich PC. Acutephase response of human hepatocytes: regulation of acute-phase protein synthesis by interleukin-6. Hepatology 1990;12:1179-86.

103. Heinrich PC, Castell JV, Andus T. Interleukin-6 and the acute phase response. Biochem J 1990;265:621-36.

104. Zahedi RG, Summers LK, Lumb P, Chik G, Crook MA. The response of serum sialic acid and other acute phase reactants to an oral fat load in healthy humans. Eur $\mathrm{J}$ Intern Med 2001;12:510-514.

105. Tulk HM, Robinson LE. Modifying the $n-6 / n-3$ polyunsaturated fatty acid ratio of a highsaturated fat challenge does not acutely attenuate postprandial changes in inflammatory markers in men with metabolic syndrome. Metabolism 2009.

106. Gill JM, Caslake MJ, McAllister C, et al. Effects of short-term detraining on postprandial metabolism, endothelial function, and inflammation in endurance-trained men: dissociation between changes in triglyceride metabolism and endothelial function. $J$ Clin Endocrinol Metab 2003;88:4328-35.

107. Shimabukuro M, Chinen I, Higa N, Takasu N, Yamakawa K, Ueda S. Effects of dietary composition on postprandial endothelial function and adiponectin concentrations in healthy humans: a crossover controlled study. Am J Clin Nutr 2007;86:923-8.

108. Chen W, Jump DB, Grant MB, Esselman WJ, Busik JV. Dyslipidemia, but not hyperglycemia, induces inflammatory adhesion molecules in human retinal vascular endothelial cells. Invest Ophthalmol Vis Sci 2003;44:5016-22.

109. Bellido C, Lopez-Miranda J, Blanco-Colio LM, et al. Butter and walnuts, but not olive oil, elicit postprandial activation of nuclear transcription factor kappaB in peripheral blood mononuclear cells from healthy men. Am J Clin Nutr 2004;80:1487-91.

110. Collins T, Cybulsky MI. NF-kappaB: pivotal mediator or innocent bystander in atherogenesis? J Clin Invest 2001;107:255-64. 
111. Erridge C, Attina T, Spickett CM, Webb DJ. A high-fat meal induces low-grade endotoxemia: evidence of a novel mechanism of postprandial inflammation. Am J Clin Nutr 2007;86:1286-92.

112. Harris HW, Grunfeld C, Feingold KR, et al. Chylomicrons alter the fate of endotoxin, decreasing tumor necrosis factor release and preventing death. J Clin Invest 1993;91:1028-34.

113. Vreugdenhil AC, Rousseau CH, Hartung T, Greve JW, van 't Veer C, Buurman WA. Lipopolysaccharide (LPS)-binding protein mediates LPS detoxification by chylomicrons. J Immunol 2003;170:1399-405.

114. Ghoshal S, Witta J, Zhong J, de Villiers W, Eckhardt E. Chylomicrons promote intestinal absorption of lipopolysaccharides. J Lipid Res 2009;50:90-7.

115. Dickinson S, Hancock DP, Petocz P, Ceriello A, Brand-Miller J. High-glycemic index carbohydrate increases nuclear factor-kappaB activation in mononuclear cells of young, lean healthy subjects. Am J Clin Nutr 2008;87:1188-93.

116. Motton DD, Keim NL, Tenorio FA, Horn WF, Rutledge JC. Postprandial monocyte activation in response to meals with high and low glycemic loads in overweight women. Am J Clin Nutr 2007;85:60-5.

117. Shikany JM, Phadke RP, Redden DT, Gower BA. Effects of low- and high-glycemic index/glycemic load diets on coronary heart disease risk factors in overweight/obese men. Metabolism 2009;58:1793-801.

118. Bray GA, Nielsen SJ, Popkin BM. Consumption of high-fructose corn syrup in beverages may play a role in the epidemic of obesity. Am J Clin Nutr 2004;79:537-43.

119. Havel PJ. Dietary fructose: implications for dysregulation of energy homeostasis and lipid/carbohydrate metabolism. Nutr Rev 2005;63:133-57.

120. Lefer AM, Ma XL. Decreased basal nitric oxide release in hypercholesterolemia increases neutrophil adherence to rabbit coronary artery endothelium. Arterioscler Thromb 1993;13:771-6.

121. Cohen RA, Zitnay KM, Haudenschild CC, Cunningham LD. Loss of selective endothelial cell vasoactive functions caused by hypercholesterolemia in pig coronary arteries. Circ Res 1988;63:903-10.

122. Cooke JP, Tsao PS. Is NO an endogenous antiatherogenic molecule? Arterioscler Thromb 1994;14:653-5.

123. Clarkson P, Adams MR, Powe AJ, et al. Oral L-arginine improves endotheliumdependent dilation in hypercholesterolemic young adults. J Clin Invest 1996;97:198994.

124. Adams MR, McCredie R, Jessup W, Robinson J, Sullivan D, Celermajer DS. Oral Larginine improves endothelium-dependent dilatation and reduces monocyte adhesion to endothelial cells in young men with coronary artery disease. Atherosclerosis 1997;129:261-9.

125. Lekakis JP, Papathanassiou S, Papaioannou TG, et al. Oral L-arginine improves endothelial dysfunction in patients with essential hypertension. Int $\mathrm{J}$ Cardiol 2002;86:317-23.

126. Yin WH, Chen JW, Tsai C, Chiang MC, Young MS, Lin SJ. L-arginine improves endothelial function and reduces LDL oxidation in patients with stable coronary artery disease. Clin Nutr 2005;24:988-97.

127. Borucki K, Aronica S, Starke I, Luley C, Westphal S. Addition of $2.5 \mathrm{~g}$ L-arginine in a fatty meal prevents the lipemia-induced endothelial dysfunction in healthy volunteers. Atherosclerosis 2009;205:251-4.

128. Westphal S, Taneva E, Kastner S, et al. Endothelial dysfunction induced by postprandial lipemia is neutralized by addition of proteins to the fatty meal. Atherosclerosis 2006;185:313-9.

129. Ceriello A, Taboga C, Tonutti L, et al. Evidence for an independent and cumulative effect of postprandial hypertriglyceridemia and hyperglycemia on endothelial dysfunction and oxidative stress generation: effects of short- and long-term simvastatin treatment. Circulation 2002;106:1211-8.

130. Kawano H, Motoyama T, Hirashima O, et al. Hyperglycemia rapidly suppresses flowmediated endothelium-dependent vasodilation of brachial artery. J Am Coll Cardiol 1999;34:146-54. 



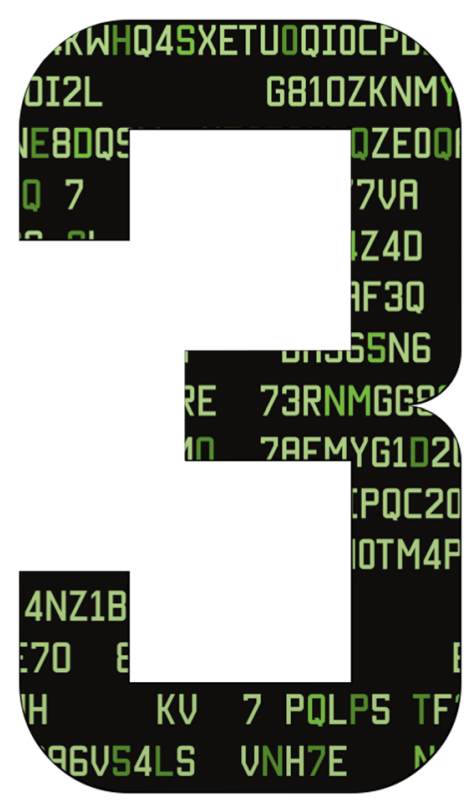

\section{FATTY ACID- PND CHOLESTERDL TRANSPORTER PROTEIN EXPRESSION RLONG THE HUMAN INTESTINAL TRACT}

[J MASSON, J PLAT, RP MENSINK, A NAMIOT, W KISIELEWSKI, Z NAMIOT, J FULLEKRUG, R EHEHALT, JFC GLATZ, MMAL PELSERS PLOS DNE [2010], 5[4]: E10380. 


\section{ABSTRACT}

Protein distribution profiles along the human intestinal tract of transporters involved in the absorption of cholesterol and long-chain fatty acids (LCFA) have been scarcely evaluated. In post-mortem samples from 11 subjects, intestinal transporter protein distribution profiles were determined by Western Blot. Differences in transporter levels were statistically tested using ANOVA and Tukey's Post Hoc comparisons. Levels in all segments were expressed relative to those in duodenum. Except for ABCG5 and FATP4, levels (mean \pm SEM) were the highest in the ileum. For ABCA1, ileal levels $(1.80 \pm 0.26)$ differed significantly from those in duodenum $(P=0.049)$ and proximal colon $(0.92 \pm 0.14 ; P=0.029)$. ABCG8 levels in ileum (1.91 \pm 0.30$)$ differed from those in duodenum $(P=0.041)$ and distal colon $(0.84 \pm 0.22 ; P=0.010)$ and jejunum $(1.64 \pm 0.26)$ tended to be higher than distal colon $(0.84 \pm 0.22$; $\mathrm{P}=0.087)$. Ileal NPC1L1 levels $(2.56 \pm 0.51)$ differed from duodenum levels $(P=0.019)$ and from distal colon $(1.09 \pm 0.22 ; P=0.030)$. There was also a trend $(P=0.098)$ for higher jejunal $(2.23 \pm 0.37)$ than duodenal NPC1L1 levels. The levels of ABCG5 did not correlate with those of ABCG8. FAT/CD36 levels in ileum $(2.03 \pm 0.42)$ differed from those in duodenum $(P=0.017)$, and proximal and distal colon $(0.89 \pm 0.13$ and $0.97 \pm 0.15$ respectively; $P=0.011$ and $P=0.014)$. FABPpm levels in ileum (1.04 \pm 0.13$)$ differed from proximal $(0.64$ $\pm 0.07 ; \mathrm{P}=0.026)$ and distal colon $(0.66 \pm 0.09 ; \mathrm{P}=0.037)$. The distribution profiles showed a bell-shape pattern along the Gl-tract with the highest levels in ileum for ABCA1, ABCG8, NPC1L1, FATCD36 and FABPm, suggesting a role for ileum in transporter-mediated uptake of cholesterol and LCFAs. 


\section{INTRODUCTION}

The incidence of the metabolic syndrome (MS) has rapidly increased over the last few decades $(1,2)$. MS is a clustering of metabolic risk markers, including abdominal obesity, elevated plasma glucose levels, and an atherogenic lipid profile, which altogether contribute to the development of cardiovascular disease (CVD) $(3,4)$. Patients suffering from the MS often show disturbances in fatty acid (FA) metabolism (5) leading to elevated plasma free fatty acid levels which negatively influence insulin-mediated glucose uptake $(6,7)$. The disturbances in lipoprotein profiles most likely originate from an elevated hepatic production of large triacylglycerol-rich VLDL1 particles, which in combination with increased cholesterylester transfer protein (CETP) mediated lipid fluxes and decreased lipoprotein lipase (LPL) mediated lipolysis results in hypertriglyceridemia and low serum HDL cholesterol concentration (8-10). However, it becomes more and more evident that lipoprotein metabolism is also regulated by absorption characteristics of cholesterol and FA in the intestine. For example, it was recently shown that the level of cholesterol absorption from the intestine was inversely related to reverse cholesterol transport from peripheral tissue macrophages into the feces (11).

Concerning the MS, there is an ongoing discussion whether these patients are characterized by elevated and/or accelerated intestinal cholesterol absorption or not. In this respect, Miettinen et al. (12) have proposed, that subjects can be characterized as cholesterol absorbers (with a low cholesterol synthesis) or as cholesterol synthesizers (with a low cholesterol absorption). Based on circulating levels of plant sterols which can be used as markers for fractional cholesterol absorption, it has been suggested that subjects with the MS are rather cholesterol synthesizers than absorbers (13). Indeed, obese subjects displayed increased cholesterol synthesis and a decreased fractional cholesterol absorption (14).

Intestinal cholesterol absorption is tightly regulated by a number of transporter proteins and whether an individual is a cholesterol absorber or cholesterol synthesizer might be influenced by variations in the intestinal protein levels or activities of these cholesterol transporters. Four important proteins involved in transporting sterols across the intestinal lining are (1) adenosinetriphosphate (ATP) binding cassette A1 (ABCA1), a $226 \mathrm{kDa}$ basolateral membrane protein which is involved in the synthesis of HDL by basolateral donation of cholesterol to its acceptor apolipoprotein A1; (2) ATP binding cassette G5 (ABCG5) and (3) G8 (ABCG8), also called sterolin-1 and sterolin2 respectively, both with a molecular weight of $\sim 65 \mathrm{kDa}$. ABCG5 and ABCG8 are expressed apically at the brush border membrane (15) and collaborate in transporting excess sterols out of the enterocyte back into the lumen (16). The fourth protein is Niemann-Pick C1 like 1 (NPC1L1), a $150 \mathrm{kDa}$ protein which 
may cooperate with the scavenger receptor class B type 1 (SR-BI) (17) and regulates the intestinal uptake of sterols (Figure 3.1).

In addition, some recent studies suggest that several FA transporters, i.e. membrane fatty acid translocase (FAT/CD36) and cytoplasmic fatty acidbinding protein (I-FABP and L-FABP), are also involved in the uptake of cholesterol, making cholesterol and long-chain fatty acid (LCFA) uptake potentially interrelated (18-20).

Important intestinal FA transporters are (1) FABPpm, a $40 \mathrm{kDa}$ protein located peripherally on the plasma membrane and identical to the mitochondrial enzyme aspartate aminotransferase (21); (2) FAT/CD36, an 88 kDa integral membrane glycoprotein with two predicted transmembrane domains, also known as the Class B scavenger receptor CD36 (22) and (3) fatty acid transport protein subtype 4 (FATP4), a $63 \mathrm{kDa}$ integral membrane protein which possibly can drive fatty acid uptake or activate FA by trapping them inside the cell as their CoA thioesters (23-27). Once LCFA are taken up, they can be transported to the mitochondria via cytoplasmic fatty acid-binding proteins $\left(F A B P_{c}\right)$ for $ß$-oxidation (Figure 3.2) $(28,29)$. These proteins also facilitate the cellular uptake of FA and protect against the cytotoxic effects of free cellular FA (30).

Data concerning differences in the intestinal levels of these transporter proteins between MS patients and healthy controls is not available. However, new strategies to improve serum lipoprotein profiles could focus on the role of the intestine in dyslipidemia $(31,32)$. Therefore, it is important to know the intestinal protein distribution profiles of these transporter proteins, which are chosen based upon recent up-to-date reviews, in order to develop possible site-specific modulators of intestinal fatty acid and sterol metabolism. For these reasons, we decided to investigate the protein levels of these transporters in different segments of the intestinal tract to visualize their distribution profiles along the human duodenal-colonal axis. 


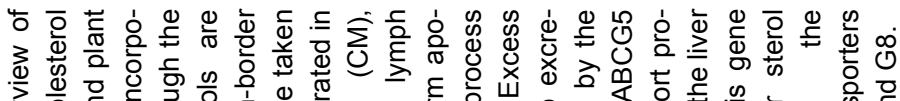

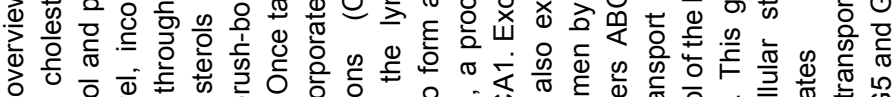
ठ ठ

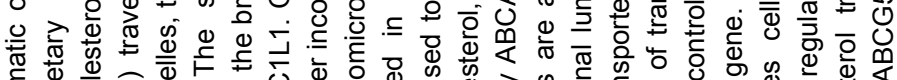



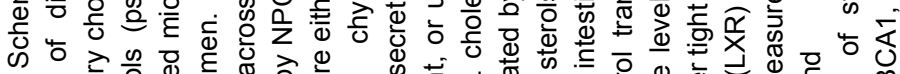

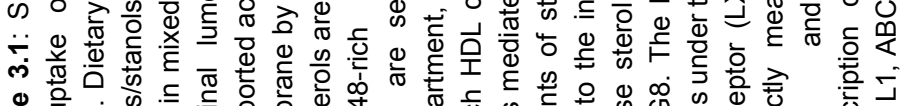

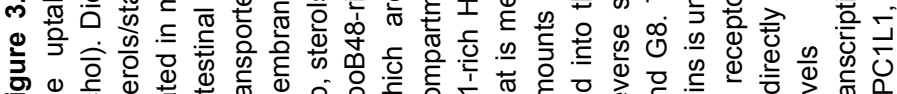

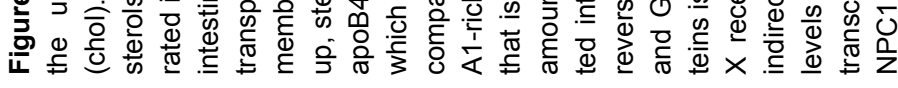

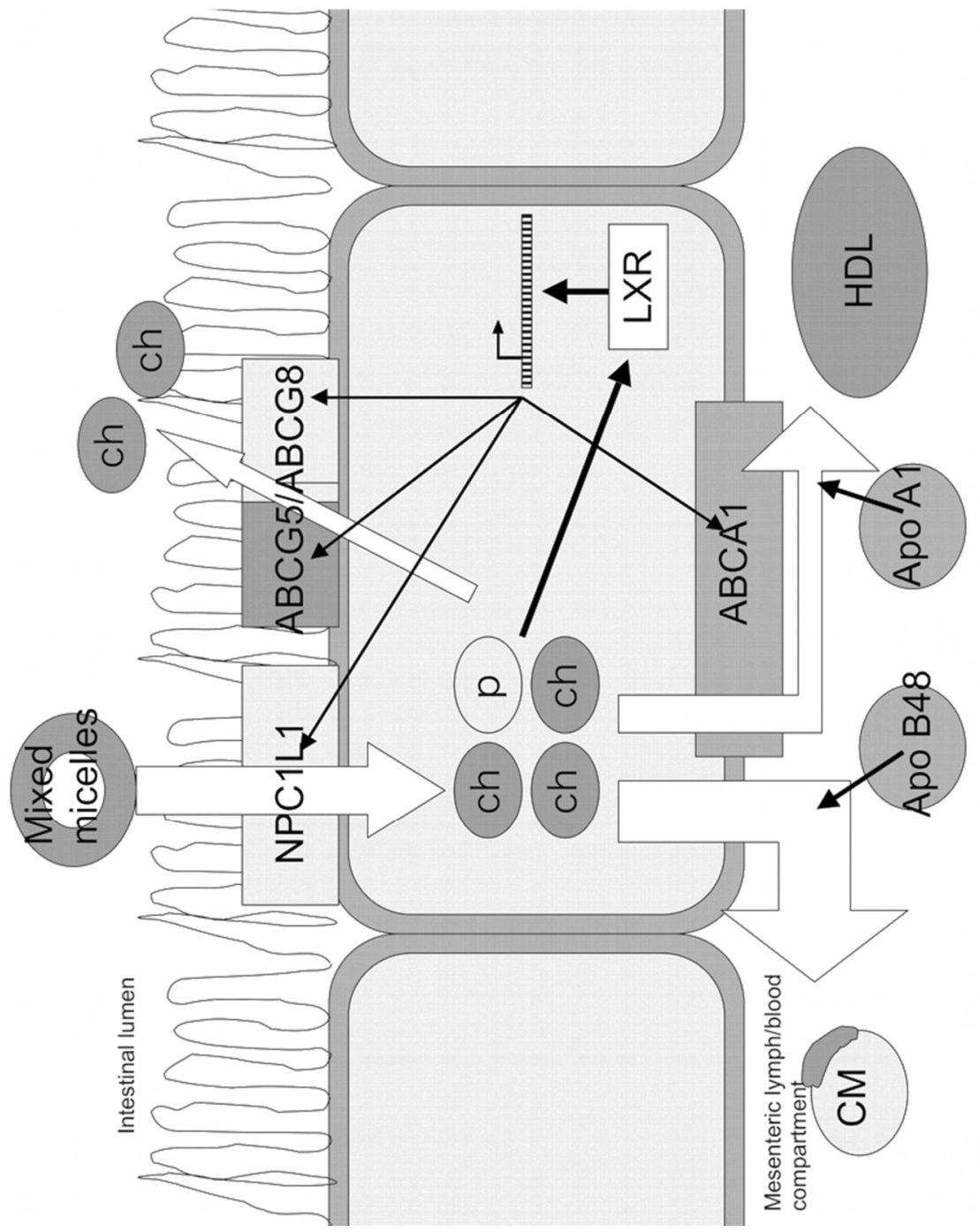




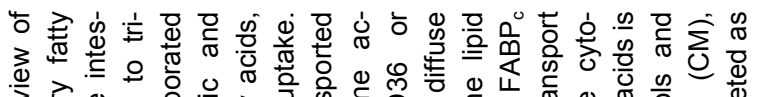

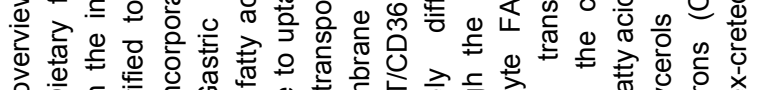

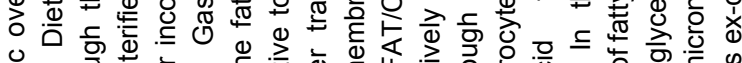

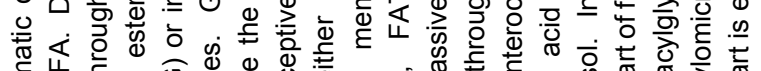

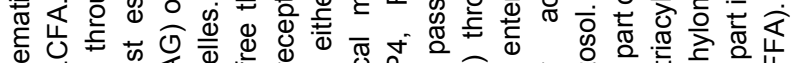

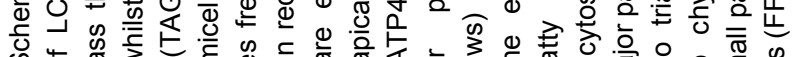

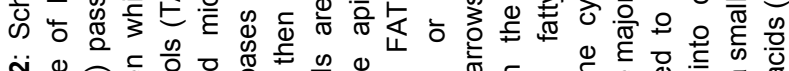
ஸ்

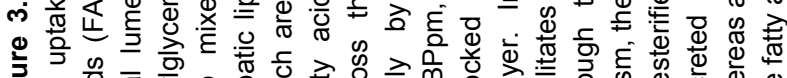

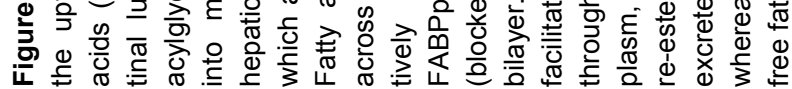

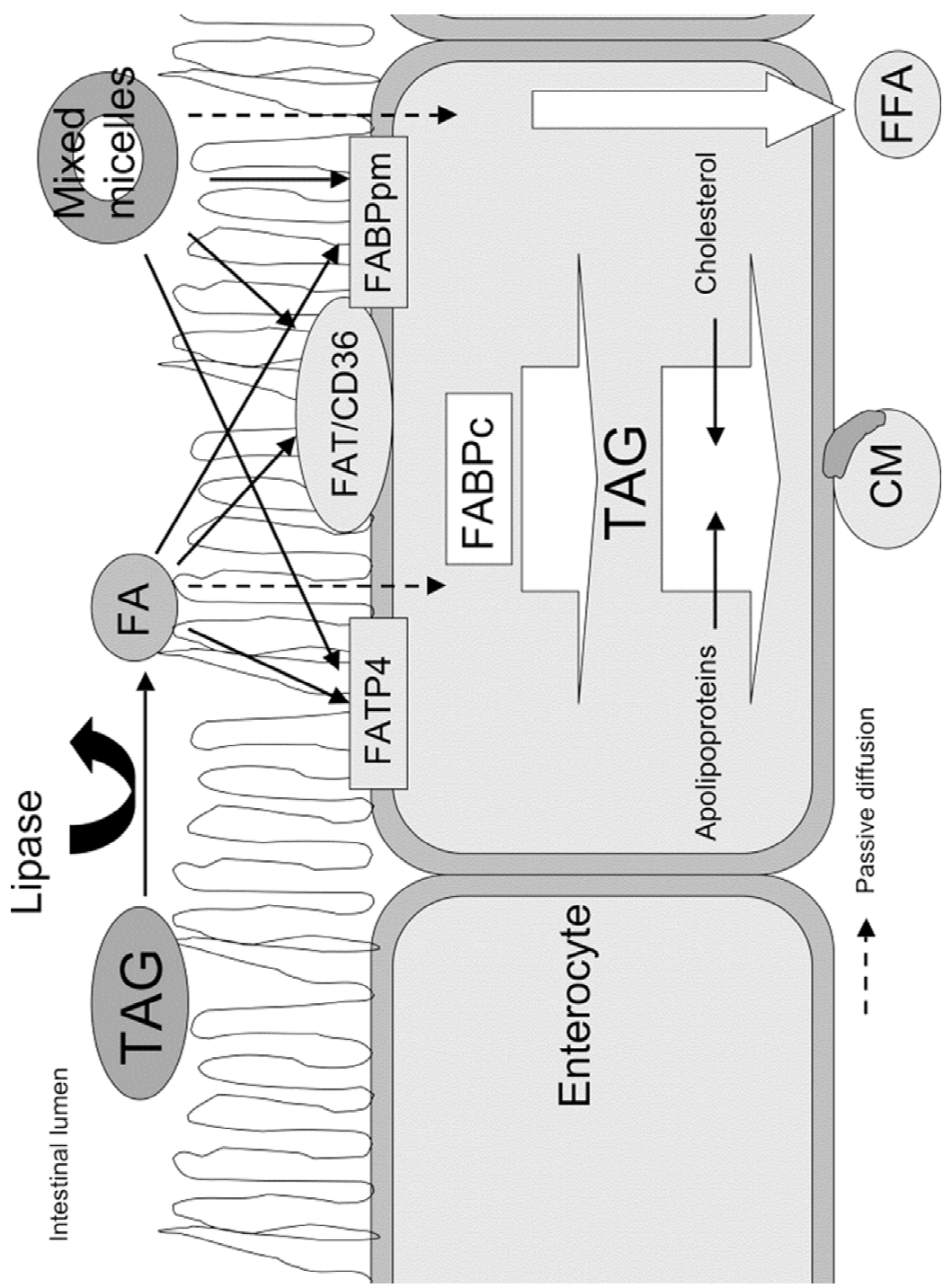




\section{MATERIALS AND METHODS}

\section{Human tissue preparation}

Human intestinal tissue samples were obtained from autopsies of 7 female and 4 male subjects, aged 37 to 83 years ( $62.8 \pm 5.0$ (mean \pm SEM); Medical University of Bialystok, Bialystok, Poland and Mental Hospital, Choroszcz, Poland), $18.1 \pm 1.5 \mathrm{~h}$ after death (Table 3.1). The subjects died of nonintestine related diseases, such as cardiac, cerebral, renal or pulmonary events. Samples, which were directly frozen in liquid nitrogen, were taken from the duodenum, jejunum, ileum, proximal colon and distal colon. Subsequent sample preparations were performed at $4^{\circ} \mathrm{C}$.

Before analyses, tissues were homogenized (3-16\% w/v) in SET-buffer $(0.25$ $M$ sucrose, $10 \mathrm{mM}$ EDTA, $10 \mathrm{mM}$ Tris, $\mathrm{pH}$ 7.4) using an Ultra-Turrax homogenizer (IKA Werke, Breisgau, Germany) and sonificated on ice $(4 \times 15 \mathrm{~s}$, MSE ultrasonic disintegrator). Total crude homogenate samples were stored at $-80^{\circ} \mathrm{C}$ until analyses. Protein concentrations in the tissue homogenates were quantified with the Pierce micro-BCA assay (Pierce, Rockford, USA).

Table 3.1: Subject information on age at death and biopsy time (mean \pm SEM).

\begin{tabular}{lcccc}
\hline & men & women & all & P \\
\hline $\mathrm{n}$ & 4 & 7 & 11 & - \\
age at death & $57.8 \pm 9.4$ & $65.7 \pm 5.9$ & $62.8 \pm 5.0$ & 0.469 \\
time of biopsy & $20.0 \pm 2.8$ & $17.0 \pm 1.7$ & $18.1 \pm 1.5$ & 0.360 \\
\hline
\end{tabular}

Western blot analyses of human FABPpm, FATP4, ABCG5/G8, ABCA1 and NPC1L1

For detection of $F A B P p m$, tissue samples containing $30 \mu \mathrm{g}$ protein were loaded on SDS-PAGE precast gels (4-15\% gradient gel, Tris- $\mathrm{HCl}, 1.0 \mathrm{~mm}$, Biorad, Hercules, USA) applying the Criterion ${ }^{\mathrm{TM}}$ system (Biorad, Hercules, USA). For detection of ABCG5, ABCG8 and FATP4, self-cast gels were prepared with a $7.5 \%$ gradient. For ABCA1 and NPC1L1 detection, a gel with a gradient of $5 \%$ was prepared. Samples were electrophorezed (90 min, 200 $\mathrm{V})$ and blotted on nitrocellulose $(0.45 \mu \mathrm{m})$ at $4^{\circ} \mathrm{C}$. After blotting, membranes were blocked overnight at $4^{\circ} \mathrm{C}$ with either $5 \%$ non-fat dry-milk (NFDM) in TBSTween 20 0.1\% (TBS-T) for FABPpm, ABCG5, ABCG8 and FATP4, and 3\% NFDM in TBS-T for ABCA1 and NPC1L1. After blocking, all blots were washed 
5 times with TBS-T and incubated for $1 \mathrm{~h}$ with the primary antibodies polyclonal goat anti-FATP4 (prepared, purified and characterized by dr. J. Füllekrug, Department of Gastroenterology, University Hospital Heidelberg, Germany), polyclonal anti-ABCG5 and anti-ABCG8 (Santa Cruz Biotechnology, CA, USA), polyclonal rabbit anti-FABPpm (kind gift from dr. Calles-Escandon, Department of Medicine, University of Vermont, Burlington, Vermont), monoclonal mouse anti-ABCA1 (kind gift from dr. A.K. Groen, Department of Pediatrics / Laboratory Medicine, University Hospital Groningen, Groningen, The Netherlands), polyclonal rabbit anti-NPC1L1 (Cayman Chemical, MI, USA) in either $5 \%$ non-fat dry-milk (NFDM) in TBSTween 20 0.1\% (TBS-T) for FABPpm, ABCG5 and G8 and FATP4, and 3\% NFDM in TBS-T for ABCA1 and NPC1L1. Following overnight blocking, secondary antibodies were added and incubated for $60 \mathrm{~min}$. Detection of ABCG5/G8, FABPpm, FATP4, ABCA1 and NPC1L1 was performed by enhanced chemi-luminescence $(E C L)$. Blots were subsequently analyzed by Quantity One software (Biorad, Hercules, USA).

\section{FAT/CD36 ELISA}

FAT/CD36 protein level in the different segments was measured via a sandwich ELISA as described previously (33). In short, a polyvinylchloride microtitre plate (Falcon type 3912, Beckton Dickinson, Oxnard, CA) was coated overnight and washed five times. Thereafter, wells were blocked for 30 min with PBS $/ 2 \%$ Marvel. Following 5 washing steps with PBT, standard containing $0-1 \mu \mathrm{g} / \mathrm{ml}$ recombinant 6 -His FAT in PBS/0.4 \%Triton X-100 was added per well. The samples were diluted $1: 1$ and added to the plate after centrifugation. After incubation for $90 \mathrm{~min}$, wells were washed. Then, phage ( $2 \times 10^{11}$ colony forming units (cfu)/well in PBS/2\% Marvel) were added and incubated for $90 \mathrm{~min}$. After 5 washes, 1/5000 diluted sheep anti-fd labeled with horseradish peroxidase in $\mathrm{PBS} / 2 \%$ Marvel was added. After one-hour incubation and 5 washes, plates were developed with $100 \mu \mathrm{l} \mathrm{TMB} /$ well. The reaction was stopped after $10 \mathrm{~min}$ and the absorbance was read at $450 \mathrm{~nm}$ using a Titertek Multiscan Mkll microplate reader. The CD36 ELISA showed a detection limit of $50 \mu \mathrm{g} / \mathrm{L}$. Using standards of 2000 and $1000 \mu \mathrm{g} / \mathrm{L}$, the intraassay and inter-assay coefficients of variation (CV) were $<10 \%$ and $15 \%$, respectively. 


\section{Standardization}

Protein level of each lane was standardized by loading $30 \mu \mathrm{g}$ of protein for every sample. A duodenal biopsy sample was included in every blot as an internal standard and levels of intestinal protein level of all biopsy samples loaded on the blots were corrected for the variations in the internal standards. Furthermore, duodenal transporter level was set at 1 and levels in the other segments were compared to that in duodenum.

Since intestinal samples contained both enterocytes and myocytes, we also measured H-FABP as a marker of muscle content with a direct noncompetitive sandwich-type ELISA using monoclonal antibodies obtained from Hycult biotechnology (HK 403; Uden, the Netherlands) as described previously (34). These data showed significantly higher H-FABP in jejunum $(1.73 \pm 0.30)$ as compared to duodenum, ileum $(1.09 \pm 0.19)$, proximal colon $(0.97 \pm 0.16)$ and distal colon $(0.90 \pm 0.17)$, whereas the levels between the other segments were not different. Because of this, we concluded that the biopsy muscle content was for an unknown reason higher in our jejunum biopsies and this might have resulted in an underestimation of cholesterol transport protein levels. Therefore we corrected the cholesterol transport protein levels for muscle content. Because FA transport proteins are also present in myocytes, differences in distribution patterns of the fatty acid transporters could have been influenced by the higher levels of myocytes in our jejunal biopsies. However, it is not possible to correct FA transporter levels for this possible confounding effect, because of their presence in myocytes and we do not know whether this correction might lead to overestimation or underestimation of the transport protein levels.

\section{Statistical analysis}

Data are presented as mean \pm SEM. All protein levels were related to the duodenal protein level. All data were normally distributed as tested with Shapiro-Wilk's test for normality. Analysis of variance (ANOVA) was used to compare mean transporter levels between the various segments of the intestine. Alpha inflation due to multiple comparisons was corrected with Tukey's HSD Post Hoc tests and $\mathrm{P}<0.05$ was considered to be statistically significant. Independent sample t-tests were used to compare transporter levels between men and women within each segment. Pearson's correlations were determined to evaluate the possible relationship between ageing and intestinal transport protein level within each segment. Moreover, linear regression analysis was performed regarding time of biopsy after death versus expression levels of ABCA1, ABCG5, ABCG8, NPC1L1 and FAT/CD36 to evaluate whether protein degradation was an issue. All tests were performed with SPSS 16.0 (SPSS Inc. Chicago, Illinois). 


\section{RESULTS}

\section{(Chole)sterol transport proteins}

As explained in the method section, the level of each individual protein in duodenum was arbitrarily set at 1 . ABCA1 protein level was significantly higher in ileum $(1.80 \pm 0.26)$ than in duodenum $(P=0.049)$ and proximal colon $(0.92 \pm 0.14 ; P=0.029)$ (Figure 3.3A). For $A B C G 5$, no significant differences between duodenum, jejunum (1.41 \pm 0.19 ), ileum ( $1.13 \pm 0.20)$, proximal colon $(0.98 \pm 0.24)$ and distal colon $(0.98 \pm 0.19)$ were found (Figure 3.3B). Ileal level of $A B C G 8$ was significantly higher $(1.91 \pm 0.30)$ than that in duodenum $(P=0.041)$ and distal colon $(0.84 \pm 0.22 ; P=0.010)$ and also tended to be higher in jejunum $(1.64 \pm 0.26)$ than in distal colon $(P=0.087)$ (Figure 3.3C). The protein level of the cholesterol transporter Niemann-Pick C1 Like 1 was significantly higher in ileum $(2.56 \pm 0.51)$ as compared to that in duodenum $(P=0.019)$ and in distal colon $(1.09 \pm 0.22 ; P=0.030)$, whereas jejunum NPC1L1 level $(2.23 \pm 0.37)$ tended to be higher than distal colon $(P=0.098)$ (Figure 3.3D). Blots of individual subjects representative for the group are presented in figure $3 \mathrm{E}$. Protein levels of the various sterol transporters did not differ between men and women, and did not correlate with age. There was no significant correlation between ABCG5 and ABCG8.

Concerning the linear regression analysis, no relation was found between time of biopsy after death and expression levels of ABCA1, ABCG8, NPC1L1 and FAT/CD36, whereas even a positive relation was found for $A B C G 5\left(R^{2}=0.25\right.$; $P=0.0001$ ). Additionally, this analysis was performed per intestinal segment, but the results were comparable (data not shown). 


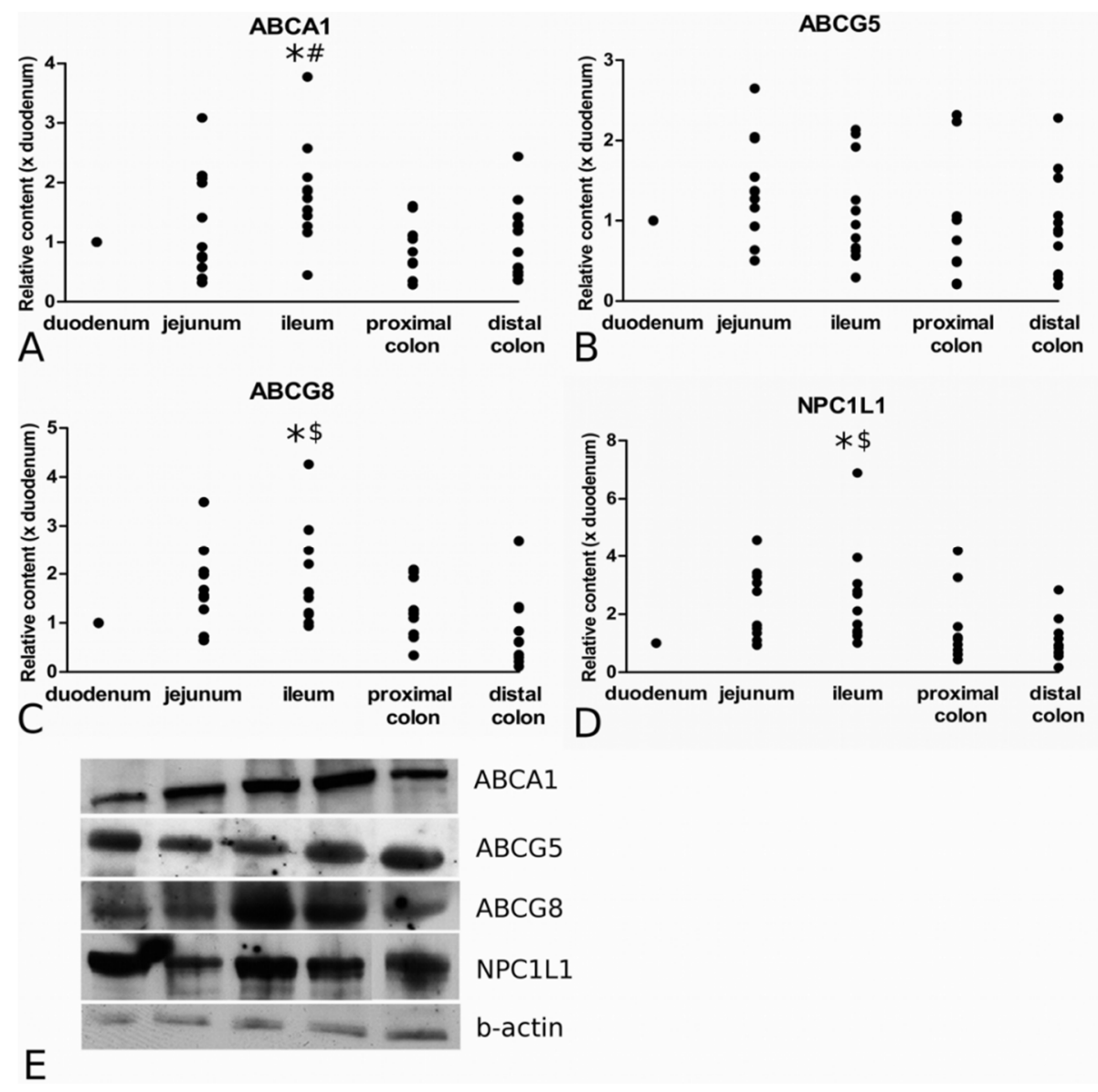

Figure 3.3: Distribution of the cholesterol transport proteins ABCA1 (panel A), ABCG5 (panel $B$ ), ABCG8 (panel C) and NPC1L1 (panel D) along the longitudinal axis of the human intestine. Panel $E$ displays Western Blots of single subjects, which are representative for the average distribution pattern of $A B C A 1, A B C G 5$ and $A B C G 8$ and NPC1L1. ${ }^{*}=P<0.05$ compared to duodenum; $\#=$ $\mathrm{P}<0.05$ compared to proximal colon; $\$=\mathrm{P}<0.05$ compared to distal colon. $\mathrm{D}=$ duodenum, $\mathrm{J}=$ jejunum, I = ileum, $P C=$ proximal colon and $\mathrm{DC}=$ distal colon .

\section{Long-chain fatty acid transport proteins}

FABPpm protein level was significantly higher in ileum $(1.04 \pm 0.13)$ than in proximal colon $(0.64 \pm 0.07 ; P=0.026)$ and distal colon $(0.66 \pm 0.09 ; P=0.037)$, and tended to be higher in duodenum than in proximal and distal colon ( $P=0.059$ and $P=0.082$ respectively) (Figure 3.4A). For FATP4, no significant differences were found between any of the segments (Figure 3.4B). FAT/CD36 protein level was significantly higher in ileum (2.03 \pm 0.42$)$, 
FABPpm

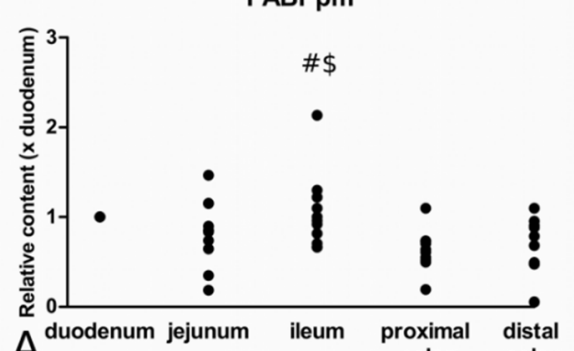

A
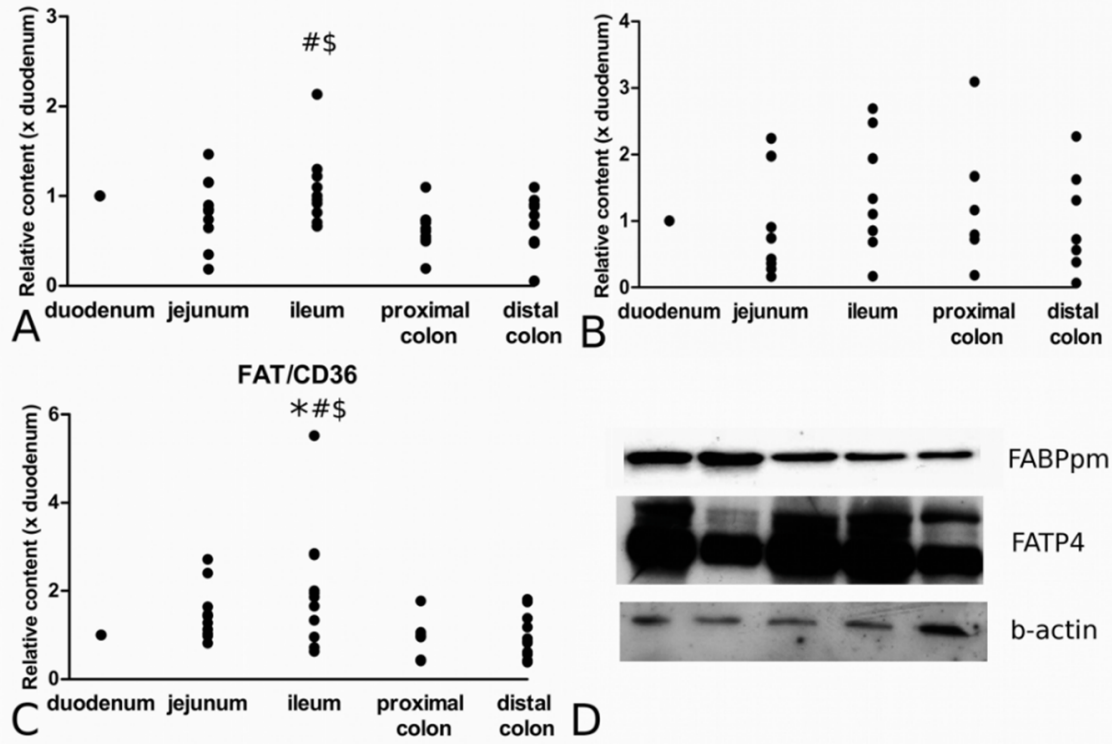

Figure 3.4: Distribution of fatty acid transporters FABPpm (panel A), FATP4 (panel B) and FAT/CD36 (panel C) along the proximal-distal axis of human intestine. Panel D displays Western Blots of the different segments of a single subject, which is representative for the average distribution pattern of FABPpm and FATP4. ${ }^{*}=\mathrm{P}<0.05$ compared to duodenum; $\#=\mathrm{P}<0.05$ compared to proximal colon; $\$=P<0.05$ compared to distal colon. $\mathrm{D}=$ duodenum, $\mathrm{J}=$ jejunum, $\mathrm{I}$ = ileum, $\mathrm{PC}=$ proximal colon and $\mathrm{DC}=$ distal colon .

when compared to that in duodenum $(P=0.017)$, proximal colon $(0.89 \pm 0.13$; $\mathrm{P}=0.011)$ and distal colon $(0.97 \pm 0.15 ; \mathrm{P}=0.014)$ (Figure 3.4C). Comparable to the sterol transporters, no significant differences were found in intestinal LCFA transporter levels between men and women and no correlations with age could be shown. Blots of individual subjects representative for the group are presented in Figure 3.4D. 


\section{DISCUSSION}

\section{Sterol transporters}

Since intestinal cholesterol absorption is tightly regulated by a number of transporter proteins (ABCA1, ABCG5, ABCG8, and NPC1L1) we decided to describe for the first time distribution profiles of these transporter proteins along the duodenal-colonic axis in humans, as a first step to further understand in vivo human intestinal cholesterol metabolism. In contrast to humans, some animal data on the importance of different segments for intestinal cholesterol metabolism is available. For example, Sylven et al. (35) have reported that in rats the major part of cholesterol was taken up in the proximal half of the small intestine, when cholesterol was administered in crystallized form. When administered in an oil phase, the gross uptake occurred more distally. In humans, cholesterol is in the duodenum first incorporated into micelles. Thus, if these animal data can be extrapolated to the human situation, it suggests that cholesterol absorption in humans mainly occurs in the distal part of the small intestine. However, from in vivo studies with porcine intestine, it was concluded that the predominant site for cholesterol uptake was the jejunum (36-38). Thus, results from animal studies are not uniform and it was therefore a priori unclear where the protein level of cholesterol-transporter proteins like NPC1L1, ABCG5 and ABCG8 would be highest. We now found that the levels of NPC1L1 and ABCG8 were bellshaped along the proximal-distal axis, with the highest levels in ileum, suggesting that transporter-dependent sterol fluxes in humans are located more distally than in pigs.

For mRNA, Davies et al. (39), showed that NPC1L1 expression was very similar in jejunum, ileum and duodenum, but higher in these segments than in segments of the large intestine. This may suggest that protein levels do not parallel mRNA expression. Another study in rats found the highest NPC1L1 mRNA and protein levels in jejunum (40). Similarly, Sané and coworkers (17) found the highest levels of NPC1L1 in jejunum in human subjects. The differences between this study and our results might be explained by the difference in subject population, since the samples in the study by Sané et al. were partially derived from patients with Crohn's Disease, which are often known to display abnormalities in lipid metabolism $(41,42)$, which presumably might also lead to alterations in protein expression levels and distribution patterns. Finally, it should also be realized that a lot of the data available in the literature is derived from animal studies. However, it was shown for example that there are differences in organ-specific transport protein mRNA levels between mouse, rat and human tissue (40), which may also indicate different distribution patterns between species within the intestine. 
Because of the co-localization of ABCG5 and ABCG8 towards the apical membrane (43-45), a similar distribution pattern of these two transporters was expected. However, ABCG5 levels were very similar between the intestinal segments and did not correlate with ABCG8 levels, for which we do not have an explanation.

ABCA1 plays a role in the biogenesis of anti-atherogenic high-density lipoproteins (HDL) in the intestinal lining (46-48). Using enterocyte specific ABCA1 knock-out mice, Brunham et al. (49) showed that in mice approximately $30 \%$ of the steady state plasma HDL pool was due to intestinal $A B C A 1$ activity. According to our data, ABCA1 protein levels were the highest in ileum. A similar distribution has been described for ABCA1 mRNA in hamsters (50). This may suggest that the ABCA1-mediated assembly of HDL in the human intestine mainly occurs in ileum.

Except for levels (expressed per mg of total protein) of the active transporters, the actual absorption also depends on the surface areas of the different segments. Estimates for the duodenum are $0.1 \mathrm{~m}^{2}$, for jejunum $60 \mathrm{~m}^{2}$, for ileum $60 \mathrm{~m}^{2}$, and for colon $0.2 \mathrm{~m}^{2}(51,52)$. Combining these areas with the segmental transporter levels, it can now be hypothesized that the ileum is the most important site for transporter-dependent sterol fluxes.

\section{Sterol and LCFA transporters}

Recent studies have suggested that the LCFA transporter FAT/CD36, like the cholesterol transporter NPC1L1 a member of the CD36 superfamily, plays a crucial role in cholesterol uptake in the proximal intestine of mice (18). In FAT/CD36 deficient mice, in vitro cholesterol uptake in the first of three equal intestinal segments was approximately $75 \%$ lower as compared to that in wildtype littermates. For the second and third segment no differences were found. The distribution pattern of FAT/CD36 was comparable to the pattern found for NPC1L1, but the highest protein expressions were found more distally than would be expected based upon the hypothesis of their role in proximal cholesterol uptake.

In a different study on the role of FA transporters in cholesterol transport (19), overexpression of cytoplasmic I-FABP in a human intestinal epithelial cell line not only resulted in a decrease in free cholesterol absorption from micelles, but also in a downregulation of NPC1L1, and upregulation of ABCA1, ABCG5 and G8. These findings suggest that overexpression of cytosolic I-FABP favors cholesterol efflux.

Expression of transporter molecules may be changed by the composition of the diet, as in mice the FABP protein level in the distal small intestine was increased after high-fat intakes (53). Similar findings were shown for FAT/CD36 after consumption of LCFAs, but not after consumption of MCFAs 
(54). These studies clearly indicate a role for nutrition in regulating mRNA and possibly also protein levels. Unfortunately, we have no data records on dietary habits of the subjects. De Vogel-van den Bosch et al. (20) studied the possible interrelations between FA and cholesterol uptake in vivo. A cholesterol-free, high-fat diet suppressed gene expression of the cholesterol transporters NPC1L1, ABCA1, ABCG5 and ABCG8 in the middle segment of the mouse small intestine after 2, 4 and 8 weeks. Thus, these studies suggest that an interrelation exists between FA and cholesterol uptake, potentially mediated by changes in intestinal transporter activity. Although these interrelations are not completely understood, it does suggest that knowledge on distribution profiles of LCFA transporters in combination with those of sterol transporters is needed to optimize potential intervention strategies to lower sterol absorption.

Besides playing a potential role in intestinal cholesterol uptake, FAT/CD36 is also involved in a wide range of physiological processes and disorders (55). FAT/CD36 in particular is important for very long-chain (VLC) FA (more than 18 carbon atoms) metabolism, since intestinal VLCFA uptake was completely abolished in CD36-- mice (56).

Lobo et al. (57) described that in humans, FAT/CD36 protein was restricted to duodenal and jejunal epithelium. On the other hand, Poirier et al. (54) also found FAT/CD36 protein in rat ileal epithelium, although in lower amounts, with the highest FAT/CD36 protein expression in jejunum, followed by duodenum. In both of the studies, membrane proteins were separated from the lysates and then analyzed. In contrast, Chen et al. (58) used total cell protein, and found a distribution pattern comparable with that of Poirier et al. (54), but also found FAT/CD36 protein in the stomach and colon. Another study by Nassir et al.(18) found the highest levels of FAT/CD36 in rats in duodenum, with a steep decrease in expression when proceeding more distally.

Since discrepancies were found between species, Wang et al. (59) looked at tissues of both rats and humans. These authors also used total lysates and showed ubiquitous CD36 mRNA and protein in all intestinal segments of the rat. In the human samples the mRNA distribution was different from FAT/CD36 protein, since FAT/CD36 protein was highest in ileum, while mRNA was lower in ileum than in duodenum, jejunum and colon. Our data closely resemble the protein data from Wang et al., in which the same technique for tissue preparation was used. The above data indicates that there are differences in the distribution patterns of CD36 between different species and that, at least in humans, protein levels do not resemble mRNA levels, a finding of which there are numerous other examples as reviewed by Glatz et al.(60). Our results suggest a more distally situated (ileum) FAT/CD36-mediated 
uptake of LCFA in humans than in rats. Additionally, we found a small amount of FAT/CD36 in colon, but levels were relatively low.

Wang et al. (59) even suggested that FABPpm is co-expressed with FAT/CD36. Indeed, there are several indications for an interaction between both transporters at the protein level $(61,62)$. As levels were the highest in the ileum, our results suggest that the small intestine is more important than the large intestine in FABPpm mediated LCFA uptake. Co-expression of FABPpm and FAT/CD36 is not suggested by our data, since we did not find significant correlations for any of the segments.

Also FATP4 is important in LCFA transport $(23,63)$. In mice, Stahl et al. (23) showed the highest expression of FATP4 in jejunum and ileum, but there were also detectable amounts present in duodenum. These findings are partly confirmed by our study, since we found FATP4 in all segments. The presence of FATP4 in human colon is not in agreement with the findings of Stahl et al. (23). We suggest that the presence of fatty acid transporters in the distal intestine is a last resort for the absorption of LCFA. In fact, fatty acid uptake is very efficient and approximately $90-95 \%$ of dietary fatty acids are absorbed. Most of the FA uptake is probably complete in the proximall small intestine $(64,65)$, but also ileum is capable of absorbing FA $(66,67)$, which is in line with the locations of the LCFA transport proteins in combination with estimations of segmental surface area. Additionally, based upon the findings mentioned above and the finding that bowel resection of the proximal $75 \%$ of the pig small intestine led to adaptive absorption of cholesterol in ileum (36), it may be speculated that the dietary availability of fatty acids and cholesterol is important in understanding these inconsistencies. Relatively, intraluminal availability of (dietary) cholesterol and LCFA is highest in duodenum, where a lot of fatty acids and cholesterol can easily be absorbed by the relevant transport proteins and also passive diffusion of $F A$ is more eligible to occur. More distally, relative cholesterol and fatty acid bioavailability is lower, and therefore more transport proteins are required for the same absolute uptake of cholesterol and fatty acids. Finally, it should be noted that we were not able to correct the fatty acid transport protein levels for the amount of myotubes in the intestinal samples, since variations in fatty acid transporter levels in myocytes along the duodenal-colonic axis cannot be ruled out, which could have influenced the results. 


\section{Gender and age differences}

Duan et al. (68) showed that estrogens may influence cholesterol uptake through up-regulation of NPC1L1 and possibly by down-regulation of the sterol efflux transporters ABCG5 and ABCG8. It was suggested that estrogen acts as transcription modulator for the target genes through effects on estrogen receptor (ER) $\alpha$ or ER $\beta$, two subtypes of the steroid hormone receptor superfamily. Furthermore, a significant positive effect of aging on cholesterol uptake through inhibition of the sterol efflux transporters ABCG5 and ABCG8 has been reported (68). In contrast, fat uptake was suggested to decline with ageing (69-71) and also more recently decreased ileal uptake of palmitic, stearic, oleic and linoleic acid was found with ageing in rats (72). These effects were abolished when mucosal surface area was considered. Other studies however have suggested that age is not related to lipid absorption (73) or to morphological changes of the intestine (74), whilst others have even reported an increased lipid uptake with ageing (75). We did not find a decrease in any of the lipid transport proteins with ageing, nor genderrelated differences. However, since the women were probably postmenopausal, no estrogen-related gender difference was expected. Concerning the influence of gender and age, the power of the study may not have been sufficient or the range of age may not have been large enough.

\section{Conclusion}

In conclusion, this is the first study that has analyzed the distribution of cholesterol and LCFA transport proteins along the human duodenal-colonal axis. Protein distribution patterns are different from the sites suggested for predominant uptake of cholesterol and LCFA in pigs, mice and rats $(18,35-$ 37 ), which may arguably indicate that the higher proximal concentrations of cholesterol and LCFA are more easily absorbed and that more distally a higher transporter protein expression is needed. Also, the discrepancy between the distribution patterns of ABCG5 and ABCG8 was not expected. Most of the data available in the literature is derived from animal studies. When considering the human data in this manuscript, it should be realized that human profiles might indeed differ from profiles in animals. Unfortunately, we were not able to determine the subcellular distribution of cholesterol and LCFA transporters or protein activities. Therefore, further research in this field is warranted. 


\section{REFERENCES}

1. Wild S, Roglic G, Green A, Sicree R, King H. Global prevalence of diabetes: estimates for the year 2000 and projections for 2030. Diabetes Care 2004;27:1047-53.

2. Lorenzo C, Williams K, Hunt KJ, Haffner SM. Trend in the prevalence of the metabolic syndrome and its impact on cardiovascular disease incidence: the San Antonio Heart Study. Diabetes Care 2006;29:625-30.

3. Gogia A, Agarwal PK. Metabolic syndrome. Indian J Med Sci 2006;60:72-81.

4. Grundy SM. Cardiovascular and metabolic risk factors: how can we improve outcomes in the high-risk patient? Am J Med 2007;120:S3-8; discussion S9.

5. Executive Summary of The Third Report of The National Cholesterol Education Program (NCEP) Expert Panel on Detection, Evaluation, And Treatment of High Blood Cholesterol In Adults (Adult Treatment Panel III). Jama 2001;285:2486-97.

6. McGarry JD. Banting lecture 2001: dysregulation of fatty acid metabolism in the etiology of type 2 diabetes. Diabetes 2002;51:7-18.

7. Boden G. Free fatty acids, insulin resistance, and type 2 diabetes mellitus. Proc Assoc Am Physicians 1999;111:241-8.

8. Nordestgaard BG, Abildgaard S, Wittrup HH, Steffensen R, Jensen G, TybjaergHansen A. Heterozygous lipoprotein lipase deficiency: frequency in the general population, effect on plasma lipid levels, and risk of ischemic heart disease. Circulation 1997;96:1737-44.

9. Agerholm-Larsen B, Tybjaerg-Hansen A, Schnohr P, Steffensen R, Nordestgaard BG. Common cholesteryl ester transfer protein mutations, decreased HDL cholesterol, and possible decreased risk of ischemic heart disease: The Copenhagen City Heart Study. Circulation 2000;102:2197-203.

10. Pollex RL, Hegele RA. Genetic determinants of the metabolic syndrome. Nat Clin Pract Cardiovasc Med 2006;3:482-9.

11. Sehayek E, Hazen SL. Cholesterol absorption from the intestine is a major determinant of reverse cholesterol transport from peripheral tissue macrophages. Arterioscler Thromb Vasc Biol 2008;28:1296-7.

12. Miettinen TA, Strandberg TE, Gylling H. Noncholesterol sterols and cholesterol lowering by long-term simvastatin treatment in coronary patients: relation to basal serum cholestanol. Arterioscler Thromb Vasc Biol 2000;20:1340-6.

13. Gylling $\mathrm{H}$, Hallikainen $\mathrm{M}$, Kolehmainen $\mathrm{M}$, et al. Cholesterol synthesis prevails over absorption in metabolic syndrome. Transl Res 2007;149:310-6.

14. Miettinen TA, Gylling $\mathrm{H}$. Cholesterol absorption efficiency and sterol metabolism in obesity. Atherosclerosis 2000;153:241-8.

15. Klett EL, Lee MH, Adams DB, Chavin KD, Patel SB. Localization of ABCG5 and ABCG8 proteins in human liver, gall bladder and intestine. BMC Gastroenterol 2004;4:21.

16. Kruit JK, Groen AK, van Berkel TJ, Kuipers F. Emerging roles of the intestine in control of cholesterol metabolism. World J Gastroenterol 2006;12:6429-39.

17. Sane AT, Sinnett D, Delvin E, et al. Localization and role of NPC1L1 in cholesterol absorption in human intestine. J Lipid Res 2006;47:2112-20.

18. Nassir F, Wilson B, Han X, Gross RW, Abumrad NA. CD36 is important for fatty acid and cholesterol uptake by the proximal but not distal intestine. J Biol Chem 2007;282:19493-501.

19. Montoudis A, Seidman E, Boudreau F, et al. Intestinal fatty acid binding protein regulates mitochondrion beta-oxidation and cholesterol uptake. J Lipid Res 2008;49:961-72.

20. de Vogel-van den Bosch HM, de Wit NJ, Hooiveld GJ, et al. A cholesterol-free, high-fat diet suppresses gene expression of cholesterol transporters in murine small intestine. Am J Physiol Gastrointest Liver Physiol 2008;294:G1171-80.

21. Stump DD, Zhou SL, Berk PD. Comparison of plasma membrane FABP and mitochondrial isoform of aspartate aminotransferase from rat liver. Am $\mathrm{J}$ Physiol 1993;265:G894-902.

22. Abumrad NA, el-Maghrabi MR, Amri EZ, Lopez E, Grimaldi PA. Cloning of a rat adipocyte membrane protein implicated in binding or transport of long-chain fatty acids that is induced during preadipocyte differentiation. Homology with human CD36. J Biol Chem 1993;268:17665-8. 
23. Stahl A, Hirsch DJ, Gimeno RE, et al. Identification of the major intestinal fatty acid transport protein. Mol Cell 1999;4:299-308.

24. Pelsers MM, Stellingwerff T, van Loon LJ. The role of membrane fatty-acid transporters in regulating skeletal muscle substrate use during exercise. Sports Med 2008;38:38799.

25. DiRusso CC, Li H, Darwis D, Watkins PA, Berger J, Black PN. Comparative biochemical studies of the murine fatty acid transport proteins (FATP) expressed in yeast. J Biol Chem 2005;280:16829-37.

26. Pei Z, FraisI P, Berger J, Jia Z, Forss-Petter S, Watkins PA. Mouse very long-chain Acyl-CoA synthetase 3/fatty acid transport protein 3 catalyzes fatty acid activation but not fatty acid transport in MA-10 cells. J Biol Chem 2004;279:54454-62.

27. Watkins PA. Very-long-chain acyl-CoA synthetases. J Biol Chem 2008;283:1773-7.

28. Glatz JF, Van Breda E, Van der Vusse GJ. Intracellular transport of fatty acids in muscle. Role of cytoplasmic fatty acid-binding protein. Adv Exp Med Biol 1998;441:20718.

29. Glatz JF, van der Vusse GJ. Cellular fatty acid-binding proteins: their function and physiological significance. Prog Lipid Res 1996;35:243-82.

30. Besnard P, Niot I, Bernard A, Carlier H. Cellular and molecular aspects of fat metabolism in the small intestine. Proc Nutr Soc 1996;55:19-37.

31. Lally S, Tan CY, Owens D, Tomkin GH. Messenger RNA levels of genes involved in dysregulation of postprandial lipoproteins in type 2 diabetes: the role of Niemann-Pick C1-like 1, ATP-binding cassette, transporters G5 and G8, and of microsomal triglyceride transfer protein. Diabetologia 2006;49:1008-16.

32. Tomkin GH. Targets for intervention in dyslipidemia in diabetes. Diabetes Care 2008;31 Suppl 2:S241-8.

33. Pelsers MM, Lutgerink JT, Nieuwenhoven FA, et al. A sensitive immunoassay for rat fatty acid translocase (CD36) using phage antibodies selected on cell transfectants: abundant presence of fatty acid translocase/CD36 in cardiac and red skeletal muscle and up-regulation in diabetes. Biochem J 1999;337 ( Pt 3):407-14.

34. Wodzig KW, Pelsers MM, van der Vusse GJ, Roos W, Glatz JF. One-step enzymelinked immunosorbent assay (ELISA) for plasma fatty acid-binding protein. Ann Clin Biochem 1997;34 ( Pt 3):263-8.

35. Sylven $\mathrm{C}$, Nordstrom $\mathrm{C}$. The site of absorption of cholesterol and sitosterol in the rat small intestine. Scand J Gastroenterol 1970;5:57-63.

36. Pakarinen MP, Halttunen J, Kuusanmaki P, Lauronen J, Miettinen TA. Absorption, excretion, and distribution of plant sterols after proximal gut resection and autotransplantation of porcine ileum. Lipids 1998;33:267-76.

37. Pakarinen M, Miettinen TA, Kuusanmaki P, Vento P, Kivisto T, Halttunen J. Effect of ileal autotransplantation on cholesterol, bile acids, and biliary lipids in pigs with proximal small bowel resection. Hepatology 1997;25:1315-22.

38. Pakarinen MP, Miettinen TA, Kuusanmaki P, et al. Adaptive lipid metabolism after ileal autotransplantation in pigs with proximal gut resection. Surgery 1997;122:950-61.

39. Davies JP, Scott C, Oishi K, Liapis A, Ioannou YA. Inactivation of NPC1L1 causes multiple lipid transport defects and protects against diet-induced hypercholesterolemia. J Biol Chem 2005;280:12710-20.

40. Altmann SW, Davis HR, Jr., Zhu LJ, et al. Niemann-Pick C1 Like 1 protein is critical for intestinal cholesterol absorption. Science 2004;303:1201-4.

41. Hrabovsky V, Zadak Z, Blaha V, et al. Cholesterol metabolism in active Crohn's disease. Wien Klin Wochenschr 2009;121:270-5.

42. Hakala K, Vuoristo M, Miettinen TA. Serum cholesterol, cholesterol precursors and plant sterols in different inflammatory bowel diseases. Digestion 1996;57:83-9.

43. Graf GA, Yu L, Li WP, et al. ABCG5 and ABCG8 are obligate heterodimers for protein trafficking and biliary cholesterol excretion. J Biol Chem 2003;278:48275-82.

44. Graf GA, Cohen JC, Hobbs HH. Missense mutations in ABCG5 and ABCG8 disrupt heterodimerization and trafficking. J Biol Chem 2004;279:24881-8.

45. Graf GA, Li WP, Gerard RD, et al. Coexpression of ATP-binding cassette proteins ABCG5 and ABCG8 permits their transport to the apical surface. J Clin Invest 2002;110:659-69.

46. Yokoyama S. ABCA1 and biogenesis of HDL. J Atheroscler Thromb 2006;13:1-15. 
47. Oram JF. HDL apolipoproteins and ABCA1: partners in the removal of excess cellular cholesterol. Arterioscler Thromb Vasc Biol 2003;23:720-7.

48. Oram JF, Heinecke JW. ATP-binding cassette transporter A1: a cell cholesterol exporter that protects against cardiovascular disease. Physiol Rev 2005;85:1343-72.

49. Brunham LR, Kruit JK, Iqbal J, et al. Intestinal ABCA1 directly contributes to HDL biogenesis in vivo. J Clin Invest 2006;116:1052-62.

50. Field FJ, Born E, Mathur SN. Stanol esters decrease plasma cholesterol independently of intestinal $A B C$ sterol transporters and Niemann-Pick C1-like 1 protein gene expression. J Lipid Res 2004;45:2252-9.

51. Kararli TT. Comparison of the gastrointestinal anatomy, physiology, and biochemistry of humans and commonly used laboratory animals. Biopharm Drug Dispos 1995; 16:351-80.

52. Edmonds CJ. Absorption of sodium and water by human rectum measured by a dialysis method. Gut 1971;12:356-62.

53. Ockner RK, Manning JA. Fatty acid-binding protein in small intestine. Identification, isolation, and evidence for its role in cellular fatty acid transport. $\mathrm{J}$ Clin Invest 1974;54:326-38.

54. Poirier H, Degrace P, Niot I, Bernard A, Besnard P. Localization and regulation of the putative membrane fatty-acid transporter (FAT) in the small intestine. Comparison with fatty acid-binding proteins (FABP). Eur J Biochem 1996;238:368-73.

55. Febbraio M, Hajjar DP, Silverstein RL. CD36: a class B scavenger receptor involved in angiogenesis, atherosclerosis, inflammation, and lipid metabolism. J Clin Invest 2001;108:785-91.

56. Drover VA, Nguyen DV, Bastie CC, et al. CD36 mediates both cellular uptake of very long chain fatty acids and their intestinal absorption in mice. $\mathrm{J}$ Biol Chem 2008;283:13108-15.

57. Lobo MV, Huerta L, Ruiz-Velasco N, et al. Localization of the lipid receptors CD36 and CLA-1/SR-BI in the human gastrointestinal tract: towards the identification of receptors mediating the intestinal absorption of dietary lipids. $J$ Histochem Cytochem 2001;49:1253-60.

58. Chen M, Yang Y, Braunstein E, Georgeson KE, Harmon CM. Gut expression and regulation of FAT/CD36: possible role in fatty acid transport in rat enterocytes. Am J Physiol Endocrinol Metab 2001;281:E916-23.

59. Wang Q, Herrera-Ruiz D, Mathis AS, Cook TJ, Bhardwaj RK, Knipp GT. Expression of PPAR, RXR isoforms and fatty acid transporting proteins in the rat and human gastrointestinal tracts. J Pharm Sci 2005;94:363-72.

60. Glatz JF, Luiken JJ, Bonen A. Membrane fatty acid transporters as regulators of lipid metabolism: implications for metabolic disease. Physiol Rev;90:367-417.

61. Glatz JF, Storch J. Unravelling the significance of cellular fatty acid-binding proteins. Curr Opin Lipidol 2001;12:267-74.

62. Glatz JF, van Nieuwenhoven FA, Luiken JJ, Schaap FG, van der Vusse GJ. Role of membrane-associated and cytoplasmic fatty acid-binding proteins in cellular fatty acid metabolism. Prostaglandins Leukot Essent Fatty Acids 1997;57:373-8.

63. Gimeno RE, Hirsch DJ, Punreddy S, et al. Targeted deletion of fatty acid transport protein-4 results in early embryonic lethality. J Biol Chem 2003;278:49512-6.

64. Turner DA. The absorption, transport, and deposition of fat; application of a new method for the determination of I 131-lipid activity in dogs and man. II. Am J Dig Dis 1958;3:682708.

65. Booth CC, Read AE, Jones E. Studies on the site of fat absorption: 1. The sites of absorption of increasing doses of I-labelled triolein in the rat. Gut 1961;2:23-31.

66. Singleton AO, Jr., Redmond DC, 2nd, McMurray JE. lleocecal Resection and Small Bowel Transit and Absorption. Ann Surg 1964;159:690-4.

67. Brand SJ, Morgan RG. Fatty acid uptake and esterification by proximal and distal intestine in bile fistula rats. Biochim Biophys Acta 1974;369:1-7.

68. Duan LP, Wang HH, Ohashi A, Wang DQ. Role of intestinal sterol transporters Abcg5, Abcg8, and Npc1l1 in cholesterol absorption in mice: gender and age effects. Am $J$ Physiol Gastrointest Liver Physiol 2006;290:G269-76.

69. Becker $\mathrm{GH}$, Meyer J, Necheles $\mathrm{H}$. Fat absorption in young and old age. Gastroenterology 1950;14:80-92. 
70. Thomson AB. Effect of age on uptake of homologous series of saturated fatty acids into rabbit jejunum. Am J Physiol 1980;239:G363-71.

71. Flores CA, Hing SA, Wells MA, Koldovsky O. Rates of triolein absorption in suckling and adult rats. Am J Physiol 1989;257:G823-9.

72. Woudstra TD, Drozdowski LA, Wild GE, Clandinin MT, Agellon LB, Thomson AB. An isocaloric PUFA diet enhances lipid uptake and weight gain in aging rats. Lipids 2004;39:343-54.

73. Holt PR. Diarrhea and malabsorption in the elderly. Gastroenterol Clin North Am 2001;30:427-44.

74. Webster SG, Leeming JT. The appearance of the small bowel mucosa in old age. Age Ageing 1975;4:168-74.

75. Hollander D, Dadufalza VD. Increased intestinal absorption of oleic acid with aging in the rat. Exp Gerontol 1983;18:287-92. 



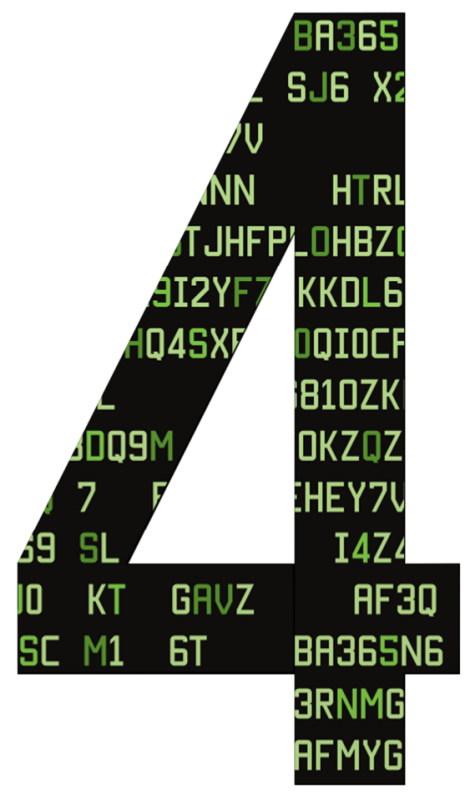

\section{EXCHANGING SATURATED FATTY ACIDS FOR [N-6] POLYUNSATURATED FATTY ACIDS IN A MIXED MEAL MAY DECREASE POSTPRANDIRL LIPEMIA AND MARKERS OF INFLAMMATION AND ENDOTHELIRL ACTIUITY IN OUERWEIGHT MEN}

[J MASSDN RND RP MENSINK J NUTR. [2011] MAY;141[5]:816-21 


\section{ABSTRACT}

Postprandial lipemia, low-grade systemic inflammation and endothelial activity are related to metabolic disorders. It is well known that dietary fatty acid composition modulates postprandial lipemia, but information on the other metabolic risk markers is limited. We therefore studied the acute effects of a meal rich in SFA versus those of a meal rich in (n-6) PUFA on postprandial responses in overweight men, who are at an increased risk to develop the metabolic syndrome and its comorbidities. In a crossover design, the effects of $50 \mathrm{~g}$ butter (rich in SFA) on lipemia and markers for inflammation and endothelial activity were compared to those of $50 \mathrm{~g}$ sunflower oil (rich in (n-6) PUFA) during an 8-h postprandial mixed meal tolerance test in 13 overweight men. Postprandial changes in serum TG were comparable between the meals $(P=0.38)$, except for a reduction in the incremental area under the curve $(P=0.046)$ in the late postprandial phase after $(n-6)$ PUFA $(125 \pm 96$ $\left.\mathrm{mmol} \cdot \mathrm{min} \cdot \mathrm{L}^{-1}\right)$ as compared to SFA $\left(148 \pm 98 \mathrm{mmol} \cdot \mathrm{min} \cdot \mathrm{L}^{-1}\right)$. Compared with the SFA meal, the (n-6) PUFA meal significantly decreased plasma IL-6 $(P=0.003)$, TNF $\alpha(P=0.005)$, soluble TNF receptors I and II (sTNFr ${ }^{5} ; P=0.024$ and $P<0.001$ respectively) and soluble vascular cell adhesion molecule-1 concentrations (sVCAM-1; $P=0.030$ ). These results indicate that exchanging SFA from butterfat for (n-6) PUFA in a mixed meal may decrease postprandial lipemia and concentrations of IL-6, TNF $\alpha$, STNFr-I and II, and SVCAM-1 in overweight men. 


\section{INTRODUCTION}

Postprandial lipemia, which is positively related to cardiovascular risk (1), is influenced by the composition of the diet. In this respect, linoleic acid from vegetable oils may be more beneficial than SFA (2). Results, however, are controversial. Especially, conflicting results have been found for butterfat, as both decreased and increased TG responses have been reported compared to those of linoleic acid $(3,4)$. Results between studies however are difficult to compare due to differences in experimental designs. In the latter studies (3, 4), for example, the test fats were added to an energy-free soup or to tomato sauce, or consumed as a spread. In the soup and tomato sauce, the solid fat content of the meal was probably lowered due to its high temperature, which may aggravate postprandial lipemia (5). Also, genetic background may be important. Recently, it was shown that single nucleotide polymorphisms of the TCFL2 gene may affect postprandial responses to (n-6) PUFA (6), indicating the complexity of postprandial metabolic responses.

Less is known on effects of dietary composition on markers of low-grade systemic inflammation and endothelial activation, which are both involved in the process of atherosclerosis (7). Several in vitro studies have suggested that SFA are pro-inflammatory, whereas PUFA are anti-inflammatory $(8,9)$. On the other hand, in another in vitro study (10), incubation with (n-6) PUFA (linoleic or arachidonic acid) resulted in higher expression of the cellular adhesion molecules (CAM) ICAM-1 and VCAM-1 than incubations with SFA (palmitic acid) and (n-3) PUFA (DHA) did. In vivo, it was recently shown that acute ingestion of carbohydrate meals with or without $0.6 \mathrm{~g}$ fat $/ \mathrm{kg}$ body wt resulted in higher late-postprandial IL-6 concentrations in obese than in lean women, but no differences between cream (SFA), olive oil (MUFA+SFA) and canola oil (MUFA+ (n-6) PUFA) meals were found (11). However, other relevant markers of inflammation and endothelial activation were not measured. Another study showed no differences in inflammatory markers in normal weight men, after altering the ratio of saturated to unsaturated fatty acids of a high-fat (3.1 MJ; 70.8 percent of energy (En\%) from fat) test meal (12). In addition, the acute effects of different types of fat on markers of inflammation and endothelial activation have not been studied in overweight men, who are at increased risk for developing the metabolic syndrome (13).

We therefore decided to examine in overweight men changes in concentrations of plasma markers related to inflammation and endothelial activation after the consumption of a mixed meal providing $50 \mathrm{~g}$ of fat from butter or margarine, which are rich in respectively SFA and (n-6) PUFA (linoleic acid). 


\section{MATERIALS AND METHODS}

\section{Participants}

Volunteers were recruited through announcements in local newspapers or among participants who had participated in earlier studies at the department. Female participants were excluded to avoid any possible variations in postprandial responses due to hormonal effects. Participants were invited for 2 screening visits if they met the following inclusion criteria: aged between 18 and $70 \mathrm{y}, \mathrm{BMI}$ between 25 and $30 \mathrm{~kg} / \mathrm{m}^{2}$, stable body weight (weight gain or loss $<5 \%$ in the previous $3 \mathrm{mo}$ ), no intention to change the physical activity pattern during the study, no use of lipid-lowering medication or a prescribed diet, and no participation in another biochemical trial for the past $30 \mathrm{~d}$. Fifteen participants were included (Table 4.1). They had mean fasting serum concentrations $<8.0 \mathrm{mmol} / \mathrm{L}$ for total cholesterol and $<1.7 \mathrm{mmol} / \mathrm{L}$ for TG; no indications for treatment for hyperlipidemia according to the Dutch Cholesterol Consensus (14); no inflammatory disease; no clinical condition known to affect lipid metabolism; no drug or alcohol abuse; and no history of coronary artery disease, heart failure (class III or IV), cardiomyopathy or kidney, liver, or pancreatic disease or malignancy $<5 \mathrm{y}$ ago. All participants gave written informed consent before entering the study. The study protocol was approved by the Ethics Committee of Maastricht University.

Table 4.1: Baseline characteristics of the overweight male participants

\begin{tabular}{lc}
\hline $\mathbf{n}=\mathbf{1 3}$ & mean $\mathbf{\text { SD }}$ \\
\hline age, $y$ & $51.2 \pm 16.7$ \\
$\mathrm{BMI}, \mathrm{kg} \cdot \mathrm{m}^{-2}$ & $29.1 \pm 1.28$ \\
blood pressure, $\mathrm{mmHg}$ & \\
systolic & $135 \pm 18.1$ \\
diastolic & $86.4 \pm 11.2$ \\
glucose, $\mathrm{mmol} \cdot \mathrm{L}^{-1}$ & $5.63 \pm 0.56$ \\
insulin, $\mathrm{pmol} \cdot \mathrm{L}^{-1}$ & $117 \pm 45.7$ \\
$\mathrm{TC}, \mathrm{mmol} \cdot \mathrm{L}^{-1}$ & $5.73 \pm 1.11$ \\
$\mathrm{HDL}-\mathrm{cholesterol}, \mathrm{mmol} \cdot \mathrm{L}^{-1}$ & $1.39 \pm 0.23$ \\
$\mathrm{TG}, \mathrm{mmol} \cdot \mathrm{L}^{-1}$ & $1.35 \pm 0.29$ \\
\hline
\end{tabular}




\section{Study design}

A randomized, double-blind crossover design was used, in which all participants received two different interventions. On the day before each test, participants were asked not to engage in any strenuous physical exercise or to consume alcohol. Participants were also asked to refrain from high-fat foods, including fried foods and sausages.

After a $12 \mathrm{~h}$ overnight fast (from $20 \mathrm{~h}$ ), participants visited the department by public transport or car. After resting for $20 \mathrm{~min}$ in supine position, an intravenous cannula was inserted into a vein of the non-dominant arm. At $\mathrm{T}=$ 0 min (T0), a blood sample was collected. Participants were then requested to consume within $10 \mathrm{~min}$, one of the two test meals: a meal rich in butterfat or a meal rich in sunflower oil. Both meals provided $50 \mathrm{~g}$ fat. Subsequent blood samples were collected at $\mathrm{T}=15 \mathrm{~min}$ after meal consumption (T15), and at $\mathrm{T}$ $=30 \min (\mathrm{T} 30), \mathrm{T}=45 \min (\mathrm{T} 45), \mathrm{T}=60 \mathrm{~min}$ (T60), $\mathrm{T}=90 \mathrm{~min}$ (T90), $\mathrm{T}=120$ $\min$ (T120) and $\mathrm{T}=180 \mathrm{~min}$ (T180). After T180, participants received a lowfat lunch. Further blood samples were drawn at $\mathrm{T}=240 \mathrm{~min}$ (T240), $\mathrm{T}=300$ $\min (\mathrm{T} 300), \mathrm{T}=360 \mathrm{~min}$ (T360), $\mathrm{T}=420 \mathrm{~min}$ (T420) and $\mathrm{T}=480 \mathrm{~min}$ (T480). After sampling, the cannula was rinsed with $1 \mathrm{~mL} 1 \%$ heparin (LEO Pharma BV, Breda, Netherlands).

During each 8-h test period, participants had to drink $250 \mathrm{~mL}$ of water at T0, T180, and T360. A period of at least $7 \mathrm{~d}$ separated the test days. Participants were requested not to alter their food intake pattern or physical activity level during the entire study.

\section{Test meals}

The participants received 2 muffins providing $50 \mathrm{~g}$ butterfat (butter meal) or $40 \mathrm{~g}$ margarine plus $10 \mathrm{~g}$ safflower oil (margarine meal) and a glass of water $(250 \mathrm{~mL}$ ). The meals (Table 4.2) had a comparable energy content (4095 kJ and $4253 \mathrm{~kJ}$, respectively) and macronutrient composition (fat/carbohydrate/protein: 51 En\%/43 En\%/6 En\% for the butter meal vs. 53 En\%/41 En\%/6 En\% for the margarine meal, respectively). The butter meal consisted for a large part of SFA, while in the margarine meal, most of the SFA of the butter meal was replaced by linoleic acid, an (n-6) PUFA. Egg yolk was added to the margarine muffins to standardize the amount of cholesterol between the meals.

One batch of muffins was prepared for the entire study. After baking for 20 min at $180^{\circ} \mathrm{C}$ and cooling down for $20 \mathrm{~min}$, the muffins were portion packed and frozen at $-20^{\circ} \mathrm{C}$. The low-fat lunch consisted of $200 \mathrm{~mL}$ low-fat yogurt with sweetener and an apple. 
Table 4.2: Macronutrient composition of the high-fat mixed test meals and of the low-fat lunch ${ }^{1}$

\begin{tabular}{lccc}
\hline & butter & margarine & low-fat lunch \\
\hline energy, $k J$ & $4095(1694)$ & $4253(1689)$ & $692(173)$ \\
protein, $g$ & $14.5(6.0)$ & $16.0(6.4)$ & $9(2.25)$ \\
CHO, $g$ & $103(42.7)$ & $103(40.8)$ & $50.2(12.55)$ \\
total fat, $g$ & $56.6(23.4)$ & $60.5(24.0)$ & $0.2(0.05)$ \\
SFA, $g$ & $33.9(14.0)$ & $12.9(5.1)$ & $0(0)$ \\
MCFA, $g$ & $3.7(1.5)$ & $1.2(0.5)$ & $0(0)$ \\
TFA, $g$ & $2.2(0.9)$ & $0.4(0.1)$ & $0(0)$ \\
MUFA, $g$ & $14.5(6.0)$ & $21.3(8.5)$ & $0(0)$ \\
PUFA, $g$ & $2.7(1.1)$ & $21.8(8.7)$ & $0(0)$ \\
linoleic acid, $g$ & $1.7(0.7)$ & $20.1(8.0)$ & $0(0)$ \\
cholesterol, $g$ & $349(144.3)$ & $349(138)$ & $0.4(0.1)$ \\
\hline
\end{tabular}

${ }^{1}$ Values between brackets are expressed per $100 \mathrm{~g}$

\section{Blood analyses}

EDTA-containing $10 \mathrm{~mL}$ vacutainer tubes (Becton Dickinson, Plymouth, UK) and $\mathrm{NaF}$-containing $4 \mathrm{~mL}$ vacutainer tubes (Becton Dickinson, Plymouth, UK) were placed on ice directly after blood sampling. Tubes were centrifuged at $1,300 \mathrm{xg}$ at $4^{\circ} \mathrm{C}$ for $15 \mathrm{~min}$. Blood drawn in $5 \mathrm{~mL}$ vacutainer serum tubes (Becton Dickinson, Plymouth, UK) was allowed to clot for $30 \mathrm{~min}$ at $21^{\circ} \mathrm{C}$. Subsequently, the serum tubes were centrifuged at $1,300 \mathrm{xg}$ for $15 \mathrm{~min}$ at $21^{\circ} \mathrm{C}$. Plasma and serum aliquots were directly frozen in liquid nitrogen and stored at $-80^{\circ} \mathrm{C}$ until analysis.

Fasting serum was measured enzymatically by the CHOD-PAP method (Roche Diagnostics, Mannheim, Germany) for serum total cholesterol and for serum HDL cholesterol after precipitation of apoB-containing lipoproteins (Phosphotungstate precipitant; Roche Diagnostics, Mannheim, Germany). Plasma glucose (Roche Diagnostic Systems, Hoffmann-La Roche Ltd., Basel, Switzerland) was measured in $\mathrm{NaF}$ plasma at $\mathrm{T0}, 15,30,45,60,90,120,300$ and 480 and serum insulin concentrations were determined $0,15,30,45,60$, 120,300 and 480 min after meal consumption with a human insulin-specific radioimmunoassay kit (Linco Research Inc., St. Charles, MO, USA).

Serum TG with correction for free glycerol was determined hourly (GPO Trinder; Sigma-Aldrich Corp., St. Louis, MO, USA), and serum apo B-48 concentrations were analyzed $0,120,240,360$ and $480 \mathrm{~min}$ after meal consumption (Shibayagi Co Ltd, Ishihara, Japan).

Plasma inflammatory markers (IL-6, IL-8 and TNF $\alpha$ ) were measured 0, 120, 240,360 and 480 min after consumption of the test meals with a commercially 
available Multi Spot ELISA kit (Meso Scale Discovery, Gaithersburg, MD, USA). TNF receptors 1 and 2 were measured at the same time points in plasma with a commercially available Multi Spot ELISA kit (Meso Scale Discovery, Gaithersburg, MD, USA). Serum monocyte chemoattractant protein-1 (MCP-1) was measured 0, 60, 120, 240 and 480 min after test meal consumption with a single spot ELISA kit (Meso Scale Discovery, Gaithersburg, MD, USA). Cellular adhesion molecules S-ICAM and S-VCAM were measured in plasma at T0,120, 240, 360 and 480 with a Multi Spot ELISA kit (Meso Scale Discovery, Gaithersburg, MD, USA).

\section{Statistical analysis}

All results are presented as mean \pm SD. Differences in baseline concentrations between test days were tested using a paired t-test. Changes in concentrations were analyzed by ANOVA with diet and time as fixed factors and with diet.time as interaction term. If the term was not statistically significant, it was omitted from the model. If factor time was significant, post hoc tests with Bonferroni correction were carried out to compare concentrations to baseline concentrations. For both meals, the maximum change from baseline (peak change) and the time period between meal consumption and peak change (time to peak) were calculated. Also, the incremental AUC (iAUC; the area above baseline (TO) concentrations) or the decremental AUC (dAUC; the area below baseline concentrations) was calculated using the trapezoidal rule (15). Since serum TG concentrations peaked approximately $4 \mathrm{~h}$ after meal consumption, we divided the postprandial period in an early (0-240 $\mathrm{min}$ ) and a late postprandial phase (240$480 \mathrm{~min}$ ). Comparable analyses were performed for apoB-48, glucose and insulin concentrations. The differences in peak changes, time to peak, and iAUC or dAUC between the meals were compared using paired samples ttests. Differences were considered to be statistically significant when $P<0.05$. Statistical analyses were performed using SPSS 16.0 software (SPSS Inc. Chicago, Illinois). 


\section{RESULTS}

After screening, 15 participants started the study. One subject dropped out due to other commitments and 14 participants completed both postprandial tests. One of these participants was excluded from the statistical analyses, because he was not fasting on one of the two test days, as indicated by a large difference between fasting TG concentrations on these two days (5.08 $\mathrm{mmol} / \mathrm{L}$ vs. $1.34 \mathrm{mmol} / \mathrm{L})$.

\section{Postprandial lipemia}

Fasting TG concentrations were comparable between the test days $(P=0.60)$. After meal consumption, postprandial TG concentrations rose until 3-4 $\mathrm{h}$ and returned to baseline after $8 \mathrm{~h}$ (Figure 4.1A). Changes in TG concentrations did not significantly differ between the meals ( $P=0.38$ for diet effect). The iAUC of serum TG over the 8h-postprandial period and in the early phase (T0 to T240) were comparable after consumption of the meals, but the iAUC in the late postprandial phase (T240 to T480) was significantly higher $(P=0.046)$ after the butter meal $\left(148 \pm 98 \mathrm{mmol} \cdot \mathrm{min} \cdot \mathrm{L}^{-1}\right)$ than after the margarine meal $\left(125 \pm 96 \mathrm{mmol} \cdot \mathrm{min} \cdot \mathrm{L}^{-1}\right)$. There was a significant delay in time-to-peak of 55 min after consuming the butter meal $(P=0.008)$, whereas the maximum changes from baseline were comparable (Tables 4.3 and 4.4). Serum concentrations of apolipoprotein B-48 increased over time (Figure 4.1B). The changes in apoB-48 concentrations after the meals did not differ $(P=0.95)$ and the iAUC, the iAUC for the early and late postprandial phases (data not shown), maximum changes, or the time to peak did not differ (Tables 4.3, 4.4 and 4.5).
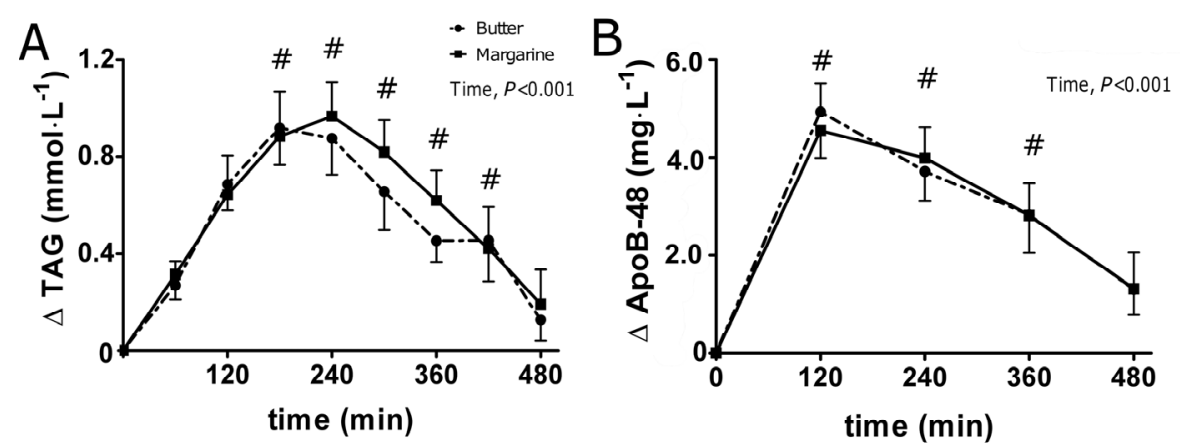

Figure 4.1: Serum concentrations of $(A)$ TAG and $(B)$ apoB-48 before and after a high-fat mixed meal rich in either ( $n-6)$ PUFA (margarine) or SFA (butter) in a randomized crossover study with overweight men. Data are presented as mean \pm SEM; $n=13$. \#Different from baseline, $P<0.05$ 


\section{Postprandial glycemia}

Glucose $(P=0.58)$ and insulin concentrations $(P=0.24)$ at baseline did not differ between the test days. Following each meal, there was a rapid increase in both glucose and insulin, which was significant for the factor time $(P<0.001$; Figure 4.2). Plasma glucose concentrations were significantly increased during the first $60 \mathrm{~min}(P<0.05$ at all time points) and serum insulin during the first $2 \mathrm{~h}(P<0.001$ at all time points) after both interventions. The glucose $(P=0.83)$ and insulin $(P=0.65)$ responses did not differ between the meals. The postprandial responses, also between the early (T0-T120) and late postprandial phase (T120-T480), between the test meals were comparable for all other variables (Tables 4.3, 4.4 and 4.5).
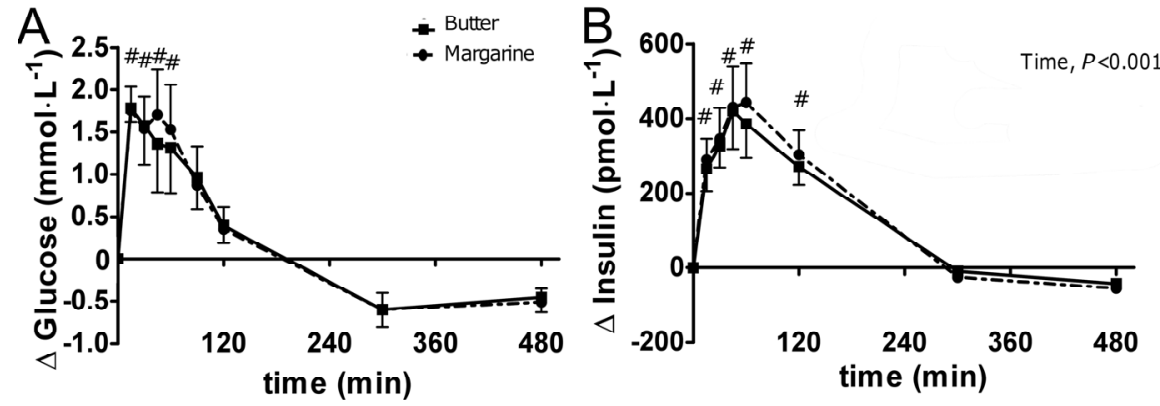

Figure 4.2: Concentrations of $(A)$ plasma glucose and $(B)$ serum insulin before and after a highfat mixed meal rich in either ( $n-6)$ PUFA (margarine) or SFA (butter) in a postprandial, randomized crossover study with overweight men. Data are presented as mean $\pm S E M ; n=13$. \#Different from baseline, $P<0.05$

Table 4.3: Time between consumption of two single challenge meals rich in either (n-6) PUFA or SFA and maximum change from baseline in glucose, insulin, TG and apoB-48 concentrations in overweight male participants ${ }^{1}$

\begin{tabular}{lccc}
\hline & (n-6) PUFA & SFA & difference \\
\hline glucose, $\min$ & $35.8 \pm 24.1$ & $27.7 \pm 17.2$ & $8.08 \pm 21.8$ \\
insulin, $\min$ & $43.8 \pm 18.8$ & $39.2 \pm 18.9$ & $4.62 \pm 15.5$ \\
TG, $\min$ & $208 \pm 90.4^{*}$ & $263 \pm 79.5$ & $-55.4 \pm 62.3$ \\
apoB-48, $\min$ & $157 \pm 90.1$ & $185 \pm 116$ & $-27.7 \pm 87.0$ \\
\hline
\end{tabular}

${ }^{1}$ Values are presented as mean $\pm S D ; n=13$

* Different from SFA, $P<0.01$ 
Table 4.4: Maximum changes from baseline in glucose, insulin, TG, apoB-48, IL-6, IL-8, TNF $\alpha$, TNF receptor I and II, MCP-1, sVCAM-1 and sICAM-1 after consumption of two single challenge meals rich in either ( $n-6)$ PUFA or SFA in overweight male participants ${ }^{1}$

\begin{tabular}{lccc}
\hline & (n-6) PUFA & SFA & difference \\
\hline glucose, $m m o l \cdot L^{-1}$ & $2.40 \pm 1.56$ & $2.49 \pm 1.35$ & $-0.10 \pm 0.88$ \\
Insulin, $\mathrm{pmol} \cdot \mathrm{L}^{-1}$ & $545 \pm 394$ & $523 \pm 312$ & $22.0 \pm 182$ \\
TG, $\mathrm{mmol} \cdot \mathrm{L}^{-1}$ & $1.04 \pm 0.57$ & $1.13 \pm 0.47$ & $-0.09 \pm 0.36$ \\
apoB-48, $\mathrm{mg} \cdot \mathrm{L}^{-1}$ & $5.34 \pm 2.35$ & $4.99 \pm 2.20$ & $0.35 \pm 1.90$ \\
$\mathrm{IL}-6, \mathrm{ng} \cdot \mathrm{L}^{-1}$ & $0.15 \pm 2.93$ & $1.59 \pm 2.71$ & $-1.44 \pm 3.68$ \\
$\mathrm{IL}-8, \mathrm{ng} \cdot \mathrm{L}^{-1}$ & $0.04 \pm 1.37$ & $0.03 \pm 2.92$ & $0.00 \pm 2.92$ \\
TNFa, $\mathrm{ng} \cdot \mathrm{L}^{-1}$ & $-0.85 \pm 1.56$ & $0.13 \pm 1.45$ & $-0.98 \pm 1.96$ \\
TNFr-I, $\mu \mathrm{g} \cdot \mathrm{L}^{-1}$ & $-0.39 \pm 0.15^{*}$ & $-0.25 \pm 0.26$ & $-0.15 \pm 0.24$ \\
TNFr-II, $\mu \mathrm{g} \cdot \mathrm{L}^{-1}$ & $-1.18 \pm 1.15$ & $-0.13 \pm 1.05$ & $-1.05 \pm 1.80$ \\
MCP-1, $\mu \mathrm{g} \cdot \mathrm{L}^{-1}$ & $-0.20 \pm 0.08$ & $-0.20 \pm 0.08$ & $-0.01 \pm 0.07$ \\
sICAM-1, $\mu \mathrm{g} \cdot \mathrm{L}^{-1}$ & $-14.6 \pm 46.7$ & $6.05 \pm 40.28$ & $-20.7 \pm 74.4$ \\
$\mathrm{sVCAM}-1, \mu \mathrm{g} \cdot \mathrm{L}^{-1}$ & $-38.5 \pm 84.3$ & $-9.49 \pm 86.2$ & $-29.0 \pm 142$ \\
\hline
\end{tabular}

${ }^{1}$ Values are presented as mean $\pm S D ; n=13$

Table 4.5: iAUC and dAUC for glucose, insulin, TG, apoB-48, IL-6, IL-8, TNF $\alpha$, sTNFr-I and II, MCP-1, sICAM-1, and SVCAM-1 after consumption of two single challenge meals rich in either (n-6) PUFA or SFA in overweight male participants ${ }^{1}$

\begin{tabular}{|c|c|c|c|c|}
\hline & & (n-6) PUFA & SFA & difference \\
\hline glucose, $\mathrm{mmol} \cdot \min \cdot \mathrm{L}^{-1}$ & iAUC & $202 \pm 184$ & $188 \pm 155$ & $14.5 \pm 100$ \\
\hline insuline, $n \mathrm{~mol} \cdot \min \cdot \mathrm{L}^{-1}$ & ¡AUC & $67.8 \pm 53.2$ & $63.0 \pm 38.9$ & $4.74 \pm 26.6$ \\
\hline $\mathrm{TG}, \mathrm{mmol} \cdot \min \cdot \mathrm{L}^{-1}$ & iAUC & $264 \pm 155$ & $287 \pm 132$ & $-23.8 \pm 53.8$ \\
\hline apoB-48, $g \cdot \min \cdot L^{-1}$ & iAUC & $1.47 \pm 0.747$ & $1.46 \pm 0.802$ & $0.017 \pm 0.592$ \\
\hline \multirow[t]{2}{*}{$\mathrm{IL}-6, n g \cdot \min \cdot \mathrm{L}^{-1}$} & ¡AUC & $222 \pm 324$ & $425 \pm 663$ & $-203 \pm 613$ \\
\hline & $\mathrm{dAUC}$ & $334 \pm 535$ & $44.5 \pm 59.0$ & $290 \pm 559$ \\
\hline \multirow[t]{2}{*}{$\mathrm{IL}-8, n g \cdot \min \cdot \mathrm{L}^{-1}$} & iAUC & $175 \pm 244$ & $101 \pm 200$ & $73.9 \pm 320$ \\
\hline & dAUC & $145 \pm 177$ & $271 \pm 253$ & $-126 \pm 311$ \\
\hline \multirow[t]{2}{*}{ TNFa, $n g \cdot \min \cdot \mathrm{L}^{-1}$} & iAUC & $56.6 \pm 125$ & $135 \pm 275$ & $-78.7 \pm 272$ \\
\hline & dAUC & $292 \pm 456$ & $102 \pm 112$ & $190 \pm 411$ \\
\hline TNFr-I, $\mu g \cdot \min \cdot L^{-1}$ & dAUC & $109 \pm 58.5$ & $86.6 \pm 65.8$ & $22.9 \pm 75.3$ \\
\hline TNFr-II, $\mu g \cdot \min \cdot L^{-1}$ & $\mathrm{dAUC}$ & $397 \pm 417$ & $135 \pm 158$ & $262 \pm 458$ \\
\hline $\mathrm{MCP}-1, \mu g \cdot \min \cdot L^{-1}$ & $\mathrm{dAUC}$ & $53.3 \pm 29.5$ & $64.6 \pm 35.9$ & $-11.3 \pm 24.6$ \\
\hline sICAM-1, $m g \cdot \min \cdot L^{-1}$ & dAUC & $7.40 \pm 10.7$ & $3.95 \pm 4.70$ & $3.45 \pm 12.6$ \\
\hline $\mathrm{sVCAM}-1, \mathrm{mg} \cdot \mathrm{min} \cdot \mathrm{L}^{-1}$ & $\mathrm{dAUC}$ & $160 \pm 22.0$ & $8.06 \pm 8.71$ & $7.91 \pm 26.0$ \\
\hline
\end{tabular}

${ }^{1}$ Values are presented as mean $\pm S D ; n=13$ 

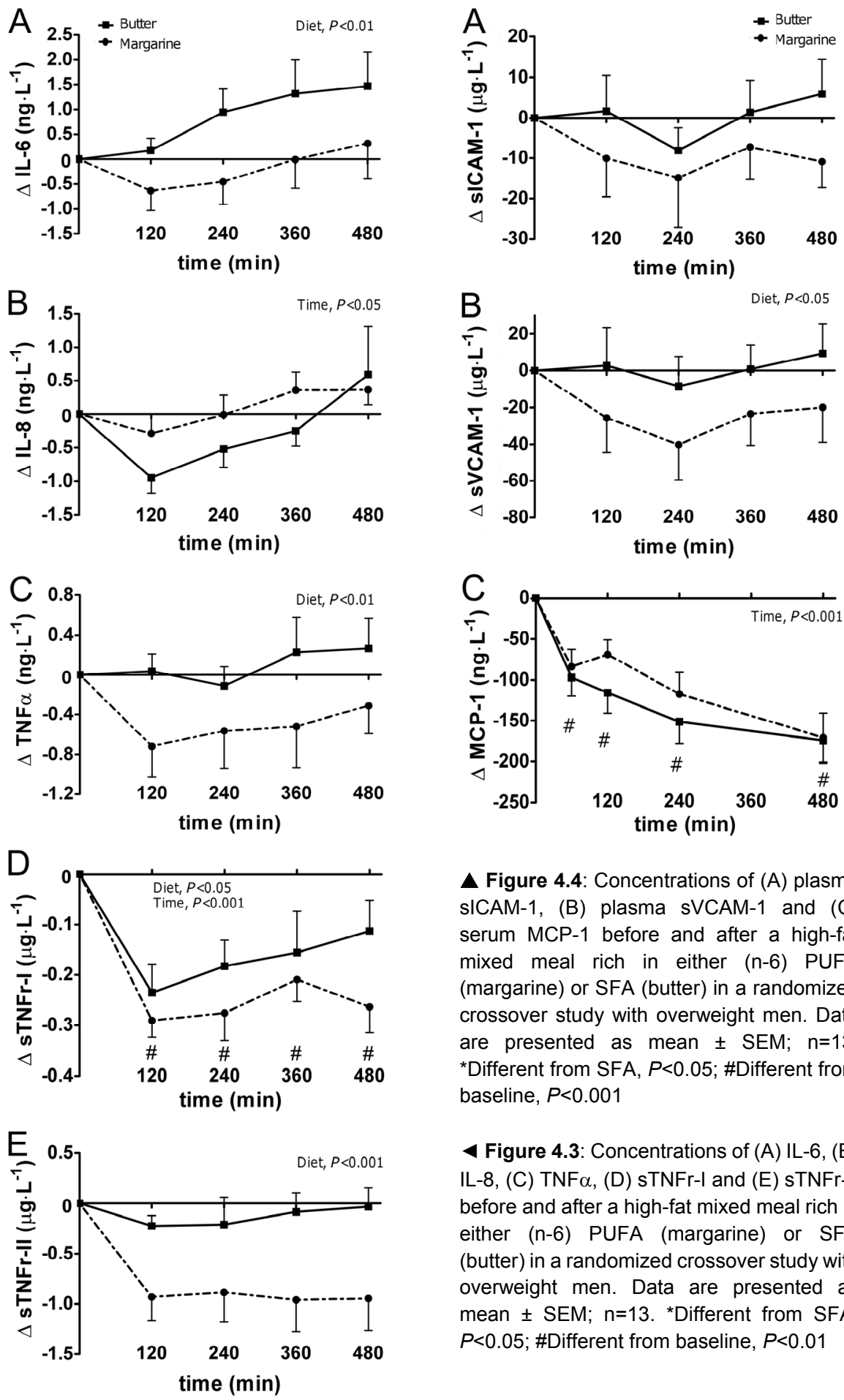

$\Delta$ Figure 4.4: Concentrations of (A) plasma sICAM-1, (B) plasma sVCAM-1 and (C) serum MCP-1 before and after a high-fat mixed meal rich in either (n-6) PUFA (margarine) or SFA (butter) in a randomized crossover study with overweight men. Data are presented as mean \pm SEM; $n=13$. ${ }^{*}$ Different from SFA, $P<0.05$; \#Different from baseline, $P<0.001$

4 Figure 4.3: Concentrations of (A) IL-6, (B) IL-8, (C) TNF $\alpha$, (D) sTNFr-I and (E) sTNFr-II before and after a high-fat mixed meal rich in either (n-6) PUFA (margarine) or SFA (butter) in a randomized crossover study with overweight men. Data are presented as mean \pm SEM; $n=13$. *Different from SFA, $P<0.05$; \#Different from baseline, $P<0.01$ 


\section{Postprandial markers of inflammation and endothelial activation}

Baseline concentrations of all the markers related to inflammation and endothelial activation were comparable between the test days, except for sTNFr-II, which was significantly lower $(P=0.049)$ at the butter test day than at the margarine test day.

Changes in plasma IL-6 concentrations were not significant for time $(P=0.14)$, but increased more after butter than after margarine ( $P=0.003$; Figure 4.3A). The dAUC tended to be higher after margarine than butter $(P=0.09$; data not shown), whereas other variables were comparable (Tables 4.4 and 4.5 ).

Changes in IL-8 concentrations after the meals showed a significant time effect ( $P=0.011$; Figure 4.3B). After adjustment for multiple comparisons, however, none of the time points was statistically different from baseline. Moreover, there was no significant meal effect $(P=0.12)$. Other variables were also comparable between the meals (Tables 4.4 and 4.5).

For TNF $\alpha$, postprandial concentrations were significantly lower after margarine than after butter ( $P=0.005$ for diet effect; Figure 4.3C), and there was a trend for a higher maximum decrease in plasma TNF $\alpha$ concentrations after the margarine than after the butter meal $(P=0.10$; Table 4.4).

sTNFr-I concentrations decreased $(P<0.001)$ and sTNFr-II tended to decrease after meal consumption ( $P=0.06$ for time effect; Figure 4.3D). Plasma sTNFrI concentrations $(P=0.024)$ and sTNFr-II concentrations $(P<0.001)$ were lower after margarine consumption than after butter. The maximum decrease in sTNFr-I was significantly higher after margarine than after butter $(P=0.049)$. For sTNFr-II, there was a trend for a larger dAUC ( $P=0.06$; data not shown), and a higher maximum decrement $(P=0.06)$ after margarine consumption (Tables 4.4 and 4.5).

Postprandial sICAM-1 and SVCAM-1 concentrations did not change over time $(P=0.63$ and $P=0.62$ respectively; Figure $4.4 \mathrm{~A}$ and $\mathrm{B})$. For sVCAM-1 there was a significant diet effect $(P=0.030)$ with higher concentrations after butter than after margarine. For sICAM-1, concentrations tended to be lower after consumption of the margarine meal as compared to the butter meal $(P=0.07)$. Other variables were comparable (Tables 4.4 and 4.5).

Postprandial MCP-1 concentrations decreased after meal consumption over time $(P<0.001)$ and were significantly lower than baseline at all time points $(P<0.001$; Figure 4.4C), whereas the other variables did not differ between the meals (Tables 4.4 and 4.5 ). 


\section{DISCUSSION}

\section{Postprandial lipemic response}

Serum TG concentrations peaked after approximately $3 \mathrm{~h}$ after consumption of the margarine meal, but $4 \mathrm{~h}$ after consumption of the butter meal. It should however be realized that postprandial concentrations are the resultant of two main coinciding processes, e.g. absorption and clearance. It has been suggested that absorption is delayed if the melting point of a fat is high, resulting in a higher solid fat content at body temperature $(5,16)$. The solid fat content of butter fat is close to $0 \%$ at body temperature (17). We do not know whether this has affected absorption. For both meals, differences in absorption and clearance were comparable during the early postprandial phase, resulting in similar TG responses. However, it is still possible that ( $n$ 6) PUFA (linoleic acid) are absorbed faster and that the clearance rate is higher, as increased postprandial LPL activity was found after consumption of linoleic acid as compared to stearic and palmitic acids (18), which may explain the increased postprandial lipemia in the late postprandial phase after SFA. Additionally, it has been suggested that large chylomicrons are cleared faster from the circulation than smaller chylomicrons when equal fat loads are given (19). In rats safflower oil resulted in larger chylomicrons as compared to coconut oil, rich in SFA (20). In our study however, the equal apoB-48 responses after the meals indicated that the number of intestinally derived lipoproteins was equal, but whether particle size was different is not known. Dworatzek et al. (21) have reported similar responses for total serum TG when butter was compared with safflower oil. Chylomicron TG responses however were decreased after the butter meal. The authors speculated that this may have been due to the fact that a part of the TG after the butter meal was packed into smaller, denser lipoproteins, which were lost during isolation. Alternatively, it was mentioned that the lower TG concentrations may have resulted from the absorption of medium-chain fatty acids (MCFA) into the portal circulation, which does not result in the formation of chylomicrons. However, Nielsen et al. (22) found no differences in postprandial lipemia when either palm oil or butter was added to a low-fat meal, which suggests that MCFA are not an important determinant for total serum TG responses during the postprandial phase.

\section{Postprandial markers of inflammation and endothelial activation}

After the consumption of the butter muffins, IL-6 concentrations increased in our study, whereas IL- 6 concentrations decreased after consumption of the margarine muffins. In studies with lean and overweight children (23), men with metabolic syndrome (24), abdominally obese men (25), CHD patients (26) and 
healthy participants (27), an increase in IL-6 concentrations was observed after a high-fat meal, whereas a carbohydrate-rich meal did not influence IL-6 concentrations (28). In contrast, no differences in IL-6 responses were found in obese men when the $(n-6) /(n-3)$ fatty acid ratio was decreased from $20: 1$ to 2:1 (24), or in lean and obese women when SFA was exchanged for MUFA or (n-6) PUFA (11). Reasons for inconsistencies may be found in differences between study populations, i.e. men vs. women. Additionally, we have compared mixed meals with a low (3\% of total fatty acids) or a high $33 \%$ of total fatty acids) linoleic acid content, whereas in the study by Manning et al. (11) differences in linoleic acid content between the cream meal and canola oil meal were less pronounced ( $4 \%$ vs. $19 \%$ ).

For IL-8 we did not find significant changes from baseline. In contrast, van Oostrom et al. (27) found increased concentrations of IL-8 (50\% increase) $1 \mathrm{~h}$ after ingestion of a glucose bolus, but no statistically significant effects after intake of a fat bolus. The latter effect, however, was much more pronounced (130\% increase) and the lack of statistical significance was therefore related to high inter-subject variations. The discrepancy between our study and the findings by van Oostrom et al. (27) might be explained by the timing of sampling. In the latter study, IL-8 concentrations were only measured at 0, 1 and $2 \mathrm{~h}$ after the glucose bolus and after the fat bolus. We measured IL-8 concentrations at 2-h intervals during $8 \mathrm{~h}$ after the intake of a mixed meal. Therefore, it is possible that we have missed an early increment in IL-8 concentrations. Our findings in overweight men, however, are in agreement with the aforementioned study of Manning et al. (11), who found no early peak in IL-8 concentrations nor time or meal dependent variations in IL-8 concentrations after 1,4 and $6 \mathrm{~h}$. These findings suggest that the type of fatty acid consumed does not acutely affect IL-8 concentrations during an 8-h postprandial period.

In our study, we found a potentially favorable reduction in TNF $\alpha$ concentrations after the muffins rich in linoleic acid, whereas TNF $\alpha$ concentrations remained stable after the butter muffins and slightly increased 6-8 $\mathrm{h}$ postprandially after both meals. In studies with abdominally obese men (25) and with both men and women covering a broad range of adiposity (29), $\mathrm{TNF} \alpha$ concentrations were significantly reduced. Unfortunately, the compositions of the test meals used in these two studies $(25,29)$ were not reported, which makes a comparison with our study difficult. On the other hand, Nappo et al. (28) found a time-dependent increase in TNF $\alpha$ concentrations in both healthy participants and type 2 diabetic patients after consumption of a test meal rich in SFA and MUFA.

With respect to variations in TNF $\alpha$ concentrations, the responses in STNFr-I and -II should also be considered, although their exact roles are under debate 
(30-34). In our study, the response in plasma sTNFr-II after consumption of both meals followed that of plasma TNF $\alpha$. sTNFr-I concentrations, however, were significantly reduced after consumption of both types of muffins. To the best of our knowledge, no other intervention studies have compared postprandial responses in STNFr-I and STNFr-II between meals with a different fatty acid composition.

Postprandial serum MCP-1 concentrations decreased significantly after both meals, irrespective of the type of fat consumed. In contrast, endothelial MCP1 mRNA expression was previously shown to increase after incubation with fasting or postprandially derived TG-rich lipoproteins from hypertriglyceridemic participants (35) or chylomicron remnants (36). In vivo, high intake of mainly saturated fat increased MCP-1 concentrations in hypertriglyceridemic patients with metabolic syndrome (37). In contrast, in HIV-patients (38), postprandial MCP-1 was not significantly affected after an oral fat load. The reason for these inconsistencies is unknown.

In our study, we did not find time-dependent differences in sICAM-1 and sVCAM-1. However there was a significant meal-dependent reduction in sVCAM-1 concentrations and a trend for lower SICAM-1 concentrations after the margarine muffins. In contrast, most other studies found postprandial increases in SICAM-1 and SVCAM-1 after fat loads mainly providing SFA in healthy participants, type 2 diabetic patients and hyperlipidemic participants $(28,39,40)$. In contrast, Rubin et al. (41) did not find postprandial variations in SICAM-1 and SVCAM-1 after a mixed meal with mainly SFA and MUFA. The authors, however, noted that this could have been the result of the high retinol content of the test meal, as increases in SICAM-1 and SVCAM-1 were found when retinol was excluded from the test meal. On the other hand, no increases or rather decreased SICAM-1 and SVCAM-1 concentrations were found in premature CHD patients and healthy controls (26) or mildly obese men (42) after a high-fat meal with MUFA or (n-6) PUFA. Thus, large differences exist between studies for which we do not have an explanation. In summary, our data indicate that exchanging SFA from butterfat for ( $n-6)$ PUFA in a mixed meal may decrease postprandial lipemia and affects several postprandial markers of inflammation and endothelial activation in overweight men. Postprandial glucose and insulin concentrations were not affected differently. The impact of these findings on long-term health remains to be elucidated. 


\section{REFERENCES}

1. Nordestgaard BG, Benn M, Schnohr P, Tybjaerg-Hansen A. Nonfasting triglycerides and risk of myocardial infarction, ischemic heart disease, and death in men and women. JAMA. 2007;298:299-308.

2. Kris-Etherton PM, Hecker KD, Binkoski AE. Polyunsaturated fatty acids and cardiovascular health. Nutr Rev. 2004;62:414-26.

3. Mekki N, Charbonnier M, Borel P, Leonardi J, Juhel C, Portugal H, Lairon D. Butter differs from olive oil and sunflower oil in its effects on postprandial lipemia and triacylglycerolrich lipoproteins after single mixed meals in healthy young men. J Nutr. 2002;132:36429.

4. Thomsen C, Rasmussen O, Lousen T, Holst JJ, Fenselau S, Schrezenmeir J, Hermansen K. Differential effects of saturated and monounsaturated fatty acids on postprandial lipemia and incretin responses in healthy subjects. Am J Clin Nutr. 1999;69:1135-43.

5. Berry SE, Miller GJ, Sanders TA. The solid fat content of stearic acid-rich fats determines their postprandial effects. Am J Clin Nutr. 2007;85:1486-94.

6. Warodomwichit D, Arnett DK, Kabagambe EK, Tsai MY, Hixson JE, Straka RJ, Province $\mathrm{M}$, An P, Lai CQ, et al. Polyunsaturated fatty acids modulate the effect of TCF7L2 gene variants on postprandial lipemia. J Nutr. 2009;139:439-46.

7. Ross R. Atherosclerosis--an inflammatory disease. N Engl J Med. 1999;340:115-26.

8. Weigert C, Brodbeck K, Staiger H, Kausch C, Machicao F, Haring HU, Schleicher ED. Palmitate, but not unsaturated fatty acids, induces the expression of interleukin- 6 in human myotubes through proteasome-dependent activation of nuclear factor-kappaB. J Biol Chem. 2004;279:23942-52.

9. Ajuwon KM, Spurlock ME. Palmitate activates the NF-kappaB transcription factor and induces IL-6 and TNFalpha expression in 3T3-L1 adipocytes. J Nutr. 2005;135:1841-6.

10. Chen W, Jump DB, Grant MB, Esselman WJ, Busik JV. Dyslipidemia, but not hyperglycemia, induces inflammatory adhesion molecules in human retinal vascular endothelial cells. Invest Ophthalmol Vis Sci. 2003;44:5016-22.

11. Manning PJ, Sutherland WH, McGrath MM, de Jong SA, Walker RJ, Williams MJ. Postprandial cytokine concentrations and meal composition in obese and lean women. Obesity (Silver Spring). 2008.

12. Poppitt SD, Keogh GF, Lithander FE, Wang Y, Mulvey TB, Chan YK, McArdle BH, Cooper GJ. Postprandial response of adiponectin, interleukin-6, tumor necrosis factor-alpha, and C-reactive protein to a high-fat dietary load. Nutrition. 2008;24:322-9.

13. Guh DP, Zhang W, Bansback N, Amarsi Z, Birmingham CL, Anis AH. The incidence of co-morbidities related to obesity and overweight: a systematic review and meta-analysis. BMC Public Health. 2009;9:88.

14. Behandeling en preventie van coronaire hartziekten door verlaging van de plasma cholesterolconcentratie. (Treatment and prevention of coronary heart disease by lowering plasma cholesterol concentrations.). Utrecht, Netherlands Centraal begeleidingsorgaan voor de intercollegiale toetsing. 1998 (in Dutch).

15. Matthews JN, Altman DG, Campbell MJ, Royston P. Analysis of serial measurements in medical research. Bmj. 1990;300:230-5.

16. Berry SE, Sanders TA. Influence of triacylglycerol structure of stearic acid-rich fats on postprandial lipaemia. Proc Nutr Soc. 2005;64:205-12.

17. Kim BH, Akoh CC. Chemical and physical properties of butterfat-vegetable oil blend spread prepared with enzymatically transesterified canola oil and caprylic acid. J Agric Food Chem. 2005;53:4954-61.

18. Tholstrup T, Sandstrom B, Bysted A, Holmer G. Effect of 6 dietary fatty acids on the postprandial lipid profile, plasma fatty acids, lipoprotein lipase, and cholesterol ester transfer activities in healthy young men. Am J Clin Nutr. 2001;73:198-208.

19. Quarfordt SH, Goodman DS. Heterogeneity in the rate of plasma clearance of chylomicrons of different size. Biochim Biophys Acta. 1966;116:382-5.

20. Levy E, Roy CC, Goldstein R, Bar-On H, Ziv E. Metabolic fate of chylomicrons obtained from rats maintained on diets varying in fatty acid composition. J Am Coll Nutr. 1991;10:69-78.

21. Dworatzek PD, Hegele RA, Wolever TM. Postprandial lipemia in subjects with the threonine 54 variant of the fatty acid-binding protein 2 gene is dependent on the type of fat ingested. Am J Clin Nutr. 2004;79:1110-7. 
22. Nielsen NS, Marckmann P, Hoy C. Effect of meal fat quality on oxidation resistance of postprandial VLDL and $\mathrm{LDL}$ particles and plasma triacylglycerol level. $\mathrm{Br} \mathrm{J}$ Nutr. 2000;84:855-63.

23. Alvarez JA, Higgins PB, Oster RA, Fernandez JR, Darnell BE, Gower BA. Fasting and postprandial markers of inflammation in lean and overweight children. Am $\mathrm{J}$ Clin Nutr. 2009;89:1138-44.

24. Tulk HM, Robinson LE. Modifying the $n-6 / n-3$ polyunsaturated fatty acid ratio of a highsaturated fat challenge does not acutely attenuate postprandial changes in inflammatory markers in men with metabolic syndrome. Metabolism. 2009;58:1709-16.

25. Blackburn P, Despres JP, Lamarche B, Tremblay A, Bergeron J, Lemieux I, Couillard C. Postprandial variations of plasma inflammatory markers in abdominally obese men. Obesity (Silver Spring). 2006;14:1747-54.

26. Lundman P, Boquist S, Samnegard A, Bennermo M, Held C, Ericsson CG, Silveira A, Hamsten A, Tornvall P. A high-fat meal is accompanied by increased plasma interleukin6 concentrations. Nutr Metab Cardiovasc Dis. 2007;17:195-202.

27. van Oostrom AJ, Sijmonsma TP, Verseyden C, Jansen EH, de Koning EJ, Rabelink TJ, Castro Cabezas M. Postprandial recruitment of neutrophils may contribute to endothelial dysfunction. J Lipid Res. 2003;44:576-83.

28. Nappo F, Esposito K, Cioffi M, Giugliano G, Molinari AM, Paolisso G, Marfella R, Giugliano D. Postprandial endothelial activation in healthy subjects and in type 2 diabetic patients: role of fat and carbohydrate meals. J Am Coll Cardiol. 2002;39:1145-50.

29. Payette C, Blackburn P, Lamarche B, Tremblay A, Bergeron J, Lemieux I, Despres JP, Couillard C. Sex differences in postprandial plasma tumor necrosis factor-alpha, interleukin-6, and C-reactive protein concentrations. Metabolism. 2009;58:1593-601.

30. Van Zee KJ, Kohno T, Fischer E, Rock CS, Moldawer LL, Lowry SF. Tumor necrosis factor soluble receptors circulate during experimental and clinical inflammation and can protect against excessive tumor necrosis factor alpha in vitro and in vivo. Proc Natl Acad Sci U S A. 1992;89:4845-9.

31. Olsson I, Lantz M, Nilsson E, Peetre C, Thysell H, Grubb A, Adolf G. Isolation and characterization of a tumor necrosis factor binding protein from urine. Eur $\mathrm{J}$ Haematol. 1989;42:270-5.

32. Aderka D, Engelmann H, Maor $\mathrm{Y}$, Brakebusch $\mathrm{C}$, Wallach D. Stabilization of the bioactivity of tumor necrosis factor by its soluble receptors. J Exp Med. 1992;175:323-9.

33. De Groote D, Grau GE, Dehart I, Franchimont P. Stabilisation of functional tumor necrosis factor-alpha by its soluble TNF receptors. Eur Cytokine Netw. 1993;4:359-62.

34. van Greevenbroek MM, van der Kallen CJ, Geurts JM, Janssen RG, Buurman WA, de Bruin TW. Soluble receptors for tumor necrosis factor-alpha (TNF-R p55 and TNF-R p75) in familial combined hyperlipidemia. Atherosclerosis. 2000;153:1-8.

35. Norata GD, Grigore L, Raselli S, Redaelli L, Hamsten A, Maggi F, Eriksson P, Catapano AL. Post-prandial endothelial dysfunction in hypertriglyceridemic subjects: molecular mechanisms and gene expression studies. Atherosclerosis. 2007;193:321-7.

36. Domoto K, Taniguchi T, Takaishi H, Takahashi T, Fujioka Y, Takahashi A, Ishikawa Y, Yokoyama M. Chylomicron remnants induce monocyte chemoattractant protein-1 expression via p38 MAPK activation in vascular smooth muscle cells. Atherosclerosis. 2003;171:193-200.

37. Rosenson RS, Huskin AL, Wolff DA, Helenowski IB, Rademaker AW. Fenofibrate reduces fasting and postprandial inflammatory responses among hypertriglyceridemia patients with the metabolic syndrome. Atherosclerosis. 2008;198:381-8.

38. Coll B, van Wijk JP, Parra S, Castro Cabezas M, Hoepelman IM, Alonso-Villaverde C, de Koning EJ, Camps J, Ferre N, et al. Effects of rosiglitazone and metformin on postprandial paraoxonase-1 and monocyte chemoattractant protein-1 in human immunodeficiency virus-infected patients with lipodystrophy. Eur J Pharmacol. 2006;544:104-10.

39. Ceriello A, Quagliaro L, Piconi L, Assaloni R, Da Ros R, Maier A, Esposito K, Giugliano D. Effect of postprandial hypertriglyceridemia and hyperglycemia on circulating adhesion molecules and oxidative stress generation and the possible role of simvastatin treatment. Diabetes. 2004;53:701-10.

40. Marchesi S, Lupattelli G, Lombardini R, Roscini AR, Siepi D, Vaudo G, Pirro M, Sinzinger $H$, Schillaci G, Mannarino E. Effects of fenofibrate on endothelial function and cell adhesion molecules during post-prandial lipemia in hypertriglyceridemia. J Clin Pharm Ther. 2003;28:419-24. 
41. Rubin D, Claas S, Pfeuffer M, Nothnagel M, Foelsch UR, Schrezenmeir J. S-ICAM-1 and s-VCAM-1 in healthy men are strongly associated with traits of the metabolic syndrome, becoming evident in the postprandial response to a lipid-rich meal. Lipids Health Dis. 2008;7:32.

42. Plat J, Jellema A, Ramakers J, Mensink RP. Weight loss, but not fish oil consumption, improves fasting and postprandial serum lipids, markers of endothelial function, and inflammatory signatures in moderately obese men. J Nutr. 2007;137:2635-40. 


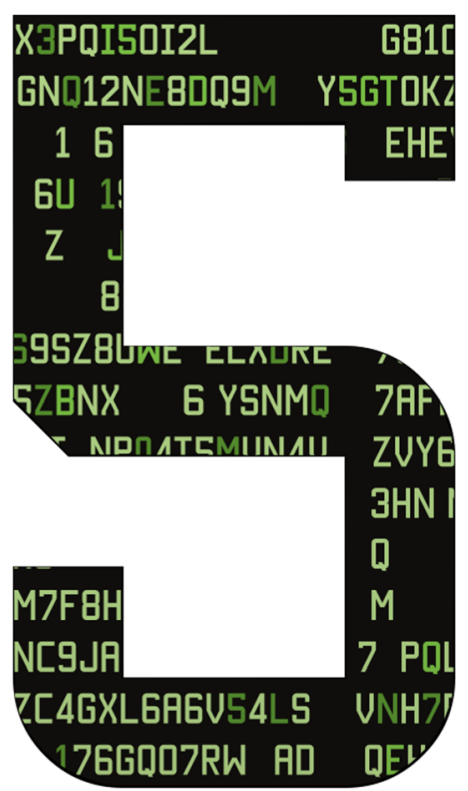

\section{THE EFFECTS DF MILK AND MILK CONSTITUENTS PROUIDED WITH A HIGH-FAT MERL ON POSTPRANDIAL MARKERS FOR INFLAMMATION IN OUERWEIGHT MEN}

[J MASSON, LE[ UAN MEIJL, RP MENSINK 


\section{ABSTRACT}

Some epidemiological studies have suggested that an increased intake of dairy products may decrease cardiovascular risk. It is not very likely that this is due to effects on conventional cardiovascular risk markers. We therefore studied the effects of milk and two major milk constituents (protein and calcium) on postprandial markers for inflammation and endothelial activation, which are more and more acknowledged as emerging cardiovascular risk markers.

In a randomized crossover study, 16 overweight men $\left(\mathrm{BMI}>27 \mathrm{~kg} / \mathrm{m}^{2}\right.$, age 18$70 \mathrm{y}$ ) were given a high-fat meal (44 g fat) with $500 \mathrm{~mL}$ skimmed milk, a milk protein drink with similar protein $(20.4 \mathrm{~g})$ and calcium contents $(700 \mathrm{mg})$, a calcium drink $(700 \mathrm{mg}$ ) or water (control). After $60 \mathrm{~min}$, sICAM-1 concentrations were lower after milk than after calcium $(14 \% ; \mathrm{P}=0.008)$ or control $(16 \% ; P=0.004)$, and lower after protein than calcium (11\%; $P=0.030)$ or control (13\%; $\mathrm{P}=0.016)$. A comparable pattern was observed for sVCAM-1. After $60 \mathrm{~min}$, TNF $\alpha$ was lower after control than after calcium (10\%; $P=0.018)$, and after 120 min lower after milk and control than after protein $(19 \%$ and $23 \%$, respectively; $\mathrm{P}<0.001$ for both) and calcium ( $17 \%$ and $21 \% ; \mathrm{P}=0.027$ and $\mathrm{P}<0.001)$. After $240 \mathrm{~min}$ TNF $\alpha$ was lower after control than all other meals $(14-19 \% ; P<0.01)$. This was also reflected by a larger decremental AUC $(\mathrm{P}<0.050)$. IL-6 and IL-8 were not different between diets.

Our results indicate that adding skimmed milk to a high-fat meal may beneficially affect postprandial SICAM-1 and sVCAM-1 concentrations, but negatively those of TNF $\alpha$. The protein fraction may be the most important determinant for the effects on SICAM-1 and SVCAM-1. 


\section{INTRODUCTION}

Several epidemiological studies have suggested that an increased intake of dairy products reduces the risk to develop cardiovascular disease (CVD) (13 ). In some studies $(4,5)$, however, only positive associations were found for low-fat dairy products, while it should be noted that in other studies no relationships were observed at all (6). These findings however do suggest that dairy products may contain constituents that negate the potential deleterious effects of saturated fatty acids and cholesterol.

Since CVD is thought to be an inflammatory disease leading to both structural and functional changes of the endothelium, fasting serum concentrations of inflammatory and endothelial markers may be important in cardiovascular risk assessment (7-9). A recent cross-sectional survey in more than 3000 subjects found a significant negative dose-dependent relationship for fasting levels of proinflammatory cytokines C-reactive protein (CRP), interleukin-6 (IL-6) and tumor necrosis factor $\alpha(T N F \alpha)$, when low-fat dairy intake increased from less than 8 servings per week to between 11 and 14 servings, or more than 14 servings per week (10). Relations were less significant when full-fat dairy was included in the model. In an intervention study with overweight and obese subjects, Zemel et al. (11) recently found that the consumption of a dairybased smoothie 3 times per day for 28 days significantly reduced fasting serum CRP, IL-6, TNF $\alpha$ and monocyte chemoattractant protein-1 (MCP-1) concentrations and oxidative stress as compared to consumption of an isocaloric soy-based smoothie. The macronutrient content of the diets was comparable and body weight did not change in that study. However, it remains unknown which dairy constituents may have been responsible for the effects observed, as the experimental products differed not only in the source of protein, but also in calcium content. In vitro studies with murine adipose tissue, for example, have shown that leucine, which is more abundant in milk protein than in soy protein, may decrease energy storage and increase fat oxidation, but increase oxidative and inflammatory stress (12). However, since no decrease in body weight was found, it is unlikely that the difference in leucine content can explain the difference in inflammatory markers in that study (11). Secondly, the addition of casein to a high-fat meal decreased the postprandial triacylglycerol (TAG) response (13), which may also affect plasma biomarkers of inflammation, since triglyceride-rich lipoproteins (TRL) have been shown to augment cytokine production by endothelial cells and macrophages $(14,15)$. Calcium on the other hand may decrease the formation of reactive oxygen species by altering mitochondrial uncoupling status by suppression of calcitriol (16). Additionally, calcium may decrease the absorption of fatty acids by the formation of insoluble calcium soaps in the intestine, resulting in a decreased TAG response (17). Also, these studies $(10,11)$ did not provide information 
on postprandial inflammatory and endothelial responses, which may be modulated by TRL and oxidative stress $(18,19)$. Since reductions of postprandial excursions of pro-inflammatory cytokines and endothelial markers may be beneficial (20), this can provide a mechanism for the proposed relations between dairy consumption and CVD risk. Therefore, we decided to investigate the effects of adding milk or its two major constituents - milk protein and calcium - to a high-fat meal on these postprandial markers in overweight men.

\section{SUBJECTS AND METHODS}

\section{Subjects}

Subjects were recruited through announcements in local newspapers or among subjects who had participated in earlier studies at the department. Subjects who were interested in participation were informed about the purposes and requirements of the study and all gave their written informed consent before entering the screening procedure. Subjects were invited for 2 screening visits, if they met the following inclusion criteria: male; age 18-70 y; body mass index $(\mathrm{BMI})>27 \mathrm{~kg} / \mathrm{m}^{2}$; stable body weight (weight gain or loss $<5 \%$ in the previous 3 months); no intention to change the physical activity pattern during the study; no indications for treatment for hyperlipidemia; no inflammatory disease; no clinical condition known to affect lipid metabolism; no drug or alcohol abuse; and no history of or active cardiovascular disease or other medical conditions that might interfere with the study outcomes. During the screening visits, body weight, height and blood pressure were measured and a fasting blood sample was drawn to determine serum lipid and lipoprotein concentrations. Sixteen subjects were enrolled and were asked not to change their dietary habits, use of alcohol, and physical activity level during the study period. All subjects completed the study (Table 5.1). The study protocol was approved by the Medical Ethical Committee of Maastricht University Medical Center+ and was registered at www.ClinicalTrials.gov as NCT00917878. 
Table 5.1: Baseline characteristics of the overweight male participants

\begin{tabular}{|c|c|c|c|}
\hline \multirow{2}{*}{$\begin{array}{l}\mathbf{n}=16 \\
\text { age, } y\end{array}$} & \multicolumn{3}{|c|}{ mean \pm SEM } \\
\hline & 49.8 & \pm & 3.88 \\
\hline $\mathrm{BMI}, \mathrm{kg} \cdot \mathrm{m}^{-2}$ & 31.2 & \pm & 0.90 \\
\hline weight, $k g$ & 102 & \pm & 2.65 \\
\hline height, $m$ & 1.81 & \pm & 0.01 \\
\hline systolic, $\mathrm{mm} \mathrm{Hg}$ & 129 & \pm & 3.08 \\
\hline diastolic, $\mathrm{mm} \mathrm{Hg}$ & 86.0 & \pm & 2.03 \\
\hline glucose, $m m o l \cdot L^{-1}$ & 5.66 & \pm & 0.09 \\
\hline insulin, $m U \cdot L^{-1}$ & 23.0 & \pm & 2.55 \\
\hline total cholesterol, $\mathrm{mmol} \cdot \mathrm{L}^{-1}$ & 5.58 & \pm & 0.22 \\
\hline $\mathrm{HDL}$ cholesterol, $\mathrm{mmol} \cdot \mathrm{L}^{-1}$ & 1.23 & \pm & 0.07 \\
\hline LDL cholesterol, $\mathrm{mmol} \cdot \mathrm{L}^{-1}$ & 3.57 & \pm & 0.18 \\
\hline triacylglycerol, $\mathrm{mmol} \cdot \mathrm{L}^{-1}$ & 1.71 & \pm & 0.16 \\
\hline IL-6, ng $\cdot^{-1}$ & 1.94 & \pm & 0.30 \\
\hline $\mathrm{IL}-8, n g \cdot \mathrm{L}^{-1}$ & 3.48 & \pm & 0.20 \\
\hline $\mathrm{TNF} \alpha, n g \cdot \mathrm{L}^{-1}$ & 7.05 & \pm & 0.55 \\
\hline sICAM-1, $\mu g \cdot L^{-1}$ & 252 & \pm & 13.8 \\
\hline sVCAM-1, $\mu g \cdot L^{-1}$ & 420 & \pm & 27.5 \\
\hline
\end{tabular}

\section{Study design}

In a randomized crossover design, subjects received the different interventions on four separate occasions, which were separated by washout periods of at least 3 days. On each test day, subjects participated in a postprandial test. On the day before each test, subjects were asked not to engage in any strenuous physical exercise or to consume alcohol, and to refrain from high-fat foods.

After an overnight fast, subjects visited the department by public transport or car. After resting for 20 minutes in supine position, an intravenous cannula (Venflon ${ }^{\circledR}$, Becton Dickinson, Plymouth, UK) was inserted into an antecubital vein of the non-dominant arm. At T = 0 min (T0), a blood sample was collected for analysis of fasting concentrations of metabolic risk markers. Subjects were then requested to consume within 10 minutes one of the test meals. Subsequent blood samples were collected at $T=15 \mathrm{~min}$ after meal consumption (T15), and at $\mathrm{T}=30 \mathrm{~min}$ (T30), $\mathrm{T}=45 \mathrm{~min}$ (T45), $\mathrm{T}=60 \mathrm{~min}$ (T60), $T=90 \min (T 90), T=120 \mathrm{~min}(\mathrm{~T} 120), T=180 \mathrm{~min}(\mathrm{~T} 180), \mathrm{T}=240 \mathrm{~min}$ (T240), $T=300 \mathrm{~min}$ (T300), and $\mathrm{T}=360 \mathrm{~min}$ (T360). After sampling, the cannula was rinsed with $1 \mathrm{~mL} 1 \%$ heparin (LEO Pharma BV, Breda, Netherlands) in $0.9 \% \mathrm{NaCl}$. During each 6-hour test period, subjects had to drink $250 \mathrm{~mL}$ of water directly after the blood collections of T120 and T240. 


\section{Test meals}

The subjects received, on each occasion, $168 \mathrm{~g}$ butter cake and $500 \mathrm{~mL}$ of one of four drinks: water, water with calcium, water with calcium and total milk protein, or milk as reported earlier (21) (Table 5.2). In order to standardize lactose content, $29 \mathrm{~g}$ lactose (DMV International, Veghel, the Netherlands) was added to the water-based drinks. The milk from the milk intervention was skimmed milk ( $0 \%$ fat; Campina, Woerden, the Netherlands). Compared with the milk drink, the calcium drink was formulated to contain an equal amount of calcium (700 mg; Lactoval $($; DMV International, Veghel, the Netherlands), and the protein drink an equal amount of milk protein (20.4 g protein; REFIT®; DMV International, Veghel, the Netherlands) and calcium. The drinks were prepared on the morning of the test day.

Table 5.2: Composition of the control, calcium, milk protein and milk meals

\begin{tabular}{lcccc}
\hline & control & calcium & milk protein & milk \\
\hline Energy, $k$ cal & 864 & 864 & 948 & 948 \\
Protein, $g$ & 8 & 8 & 29 & 29 \\
Carbohydrates, $g$ & 109 & 109 & 109 & 109 \\
Mono/disaccharides, $g$ & 74 & 74 & 74 & 74 \\
Lactose, $g$ & 30 & 30 & 30 & 30 \\
Fat, $g$ & 44 & 44 & 44 & 44 \\
Calcium, $m g$ & 49 & 699 & 703 & 697 \\
Phosphorus, $m g$ & 100 & 353 & 407 & 600 \\
\hline
\end{tabular}

\section{Blood analyses}

EDTA-containing vacutainer tubes (Becton Dickinson, Plymouth, UK) were placed on ice directly after blood sampling. Tubes were centrifuged at $1300 \mathrm{~g}$ at $4^{\circ} \mathrm{C}$ for 15 minutes. Blood drawn in vacutainer serum tubes (Becton Dickinson, Plymouth, UK) was allowed to clot for at least 30 minutes at $21^{\circ} \mathrm{C}$. Subsequently, the serum tubes were centrifuged at $1300 \mathrm{~g}$ for 15 minutes at $21^{\circ} \mathrm{C}$. Plasma and serum aliquots were directly frozen in liquid nitrogen and stored at $-80^{\circ} \mathrm{C}$ until analysis. Fasting serum samples were analyzed for triacylglycerol concentrations with correction for free glycerol (GPO Trinder; Sigma-Aldrich Corp., St. Louis, MO, USA), total cholesterol (CHOD-PAP method; Roche Diagnostics, Mannheim, Germany) and HDL cholesterol concentrations (phosphotungstate precipitant; Roche Diagnostics, Mannheim, Germany), and insulin concentrations (Linco Research Inc., St. Charles, MO, USA). Fasting plasma samples were analyzed for glucose concentrations (Horiba ABX, Montpellier, France).

Plasma inflammatory markers (IL-6, interleukin-8 (IL-8) and TNF $\alpha$ ) were measured $0,60,120,240$, and 360 min after consumption of the test meals 
with a commercially available Multi Spot ELISA kit (Meso Scale Discovery, Gaithersburg, MD, USA).

Plasma soluble intercellular adhesion molecule (sICAM)-1 and soluble vascular cell adhesion molecule (sVCAM)-1 were measured 0, 60, 120, 240, and 360 min after meal consumption using a Multi Spot ELISA kit (Meso Scale Discovery, Gaithersburg, MD, USA).

\section{Statistical analysis}

All data are presented as mean \pm SEM. Baseline concentrations were compared using univariate ANOVA with diet as fixed factor and subject number as random factor. Changes from baseline were compared using linear mixed models with diet and time as within-subject fixed factors, and with diet-time interaction. If the interaction term was not statistically significant, it was omitted from the model. Based upon the information criteria output, the most suitable covariance model was selected. In case of significant diet effects, the diets were compared pairwise using a Bonferroni correction. If time was significant, time points were compared to baseline values. If the diet time interaction term reached statistical significance, differences between the diets were tested at each individual time point. For all parameters the incremental or decremental area under the curve (iAUC/dAUC) was calculated using the trapezoidal rule (22). Moreover, the maximum positive and negative change from baseline (peak change), and the time period between meal consumption and peak changes (time to peak) were calculated and compared using ANOVA. In addition, correlations between various parameters were analyzed using partial correlations with correction for subject number.

All statistical analyses were performed using SPSS 16.0 (SPSS Inc., Chicago, IL, USA) and differences were considered to be statistically significant when $\mathrm{P}<0.05$.

\section{RESULTS}

\section{Markers for inflammation}

Baseline plasma IL- 6 concentrations were comparable between the meals $(P=0.720)$. The diet-time interaction term did not reach statistical significance $(P=0.105)$. Concentrations of IL-6 changed significantly over time after consumption of the meals $(P<0.001$ for time effect), but time courses were not different between the meals ( $P=0.341$ for diet effect) (Figure 5.1A). At T60 and T120, IL-6 concentrations were significantly decreased $(P=0.003$ and $P=0.015$, respectively) and at $T 360$ increased $(P=0.026)$ as compared to those at baseline (T0). The dAUC, the maximum positive and negative 
changes, and the peak times were not significantly different between diets (data not shown).

Baseline plasma concentrations of IL-8 were comparable between the meals $(P=0.312)$, while the diet time interaction term did not reach statistical significance $(P=0.253)$. Changes in IL-8 differed significantly between the time points $(P<0.001)$, but not between the meals $(P=0.158)$ (Figure 5.1B). At T60, concentrations were significantly decreased as compared to baseline $(P=0.032)$. Other parameters did not differ between meals (data not shown). Despite comparable postprandial patterns the peak changes and dAUC of IL8 did not correlate with those of IL-6 $(R=0.168, P=0.189$; and $R=-0.056$, $\mathrm{P}=0.662$, respectively).

Baseline TNF $\alpha$ concentrations were significantly higher before the control meal as compared to milk protein $\left(0.95 \pm 0.31 \mathrm{ng} \cdot \mathrm{L}^{-1}, \mathrm{P}=0.021\right)$ and calcium $\left(0.77 \pm 0.22 \mathrm{ng} \cdot \mathrm{L}^{-1}, \mathrm{P}=0.008\right)$. Plasma TNF $\alpha$ time courses (Figure 5.1C) differed significantly between diets ( $P<0.001$ for diet time interaction). At T60, TNF $\alpha$ concentrations were $10 \%$ lower $(P=0.018)$ after the control meal than after the calcium meal. As compared to control at T120, TNF $\alpha$ was $23 \%$ higher after the milk protein and $21 \%$ after the calcium meal ( $P<0.001$ for both). As compared to milk consumption, TNF $\alpha$ concentrations were $19 \%$ higher $(P<0.001)$ after the milk protein and $17 \%$ higher $(P=0.027)$ after the calcium meal. Compared with control, TNF $\alpha$ concentrations were at T240 significantly higher after the milk meal $(19 \% ; \mathrm{P}<0.001)$, milk protein $(17 \% ; \mathrm{P}=0.002)$ and calcium meal ( $14 \% ; P=0.005)$. Differences between the meals were also found for the dAUC $(P<0.001)$ and in the maximum decrease in $T N F \alpha$ concentrations $(P<0.001)$. The dAUC was significantly larger after the control meal than after the other meals $(P<0.050$ for all) and the dAUC tended to be larger after milk than after milk protein $(P=0.062)$. Moreover, the maximum decrease in TNF $\alpha$ concentrations was more pronounced after control than after milk protein $(P=0.005)$ or calcium $(P<0.001)$ and after milk than after calcium ( $P=0.043)$. Other parameters did not differ between the meals (data not shown). 
A

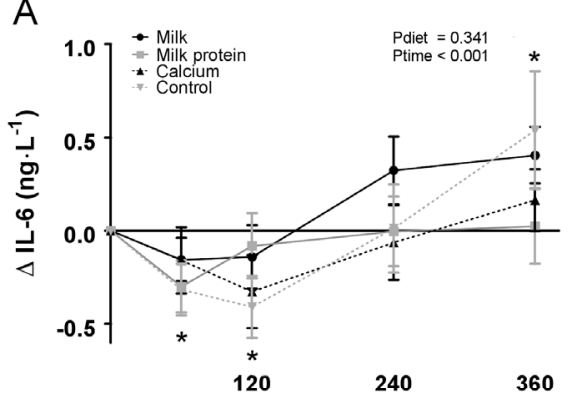

B

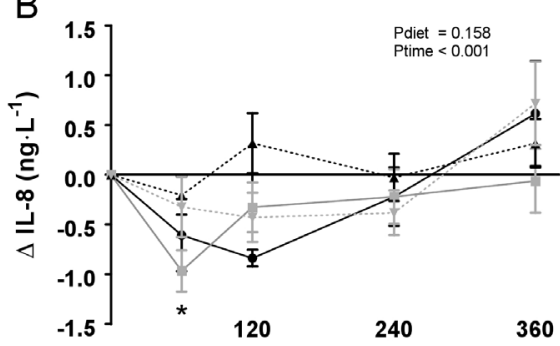

C

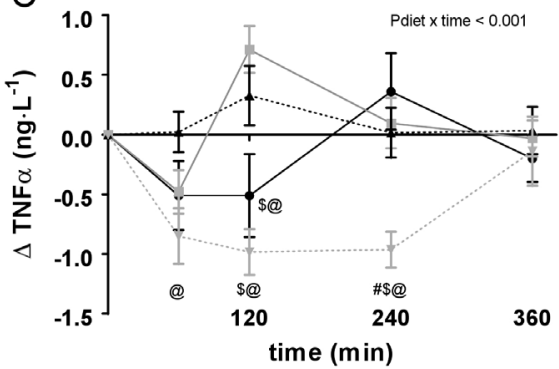

A


$\Delta$ Figure 5.2: Concentrations of $(A)$ plasma sICAM-1 and (B) plasma sVCAM-1 before and after a high-fat breakfast with either milk, milk protein, calcium, or a control drink in a randomized crossover study with overweight men. Data are presented as mean \pm SEM; $n=16$. \$Different from milk protein, $P<0.05$. \#Different from milk, $P<0.05$.

$\Delta$ Figure 5.1: Plasma concentrations of (A) IL-6, (B) IL-8, and (C) TNF $\alpha$ before and after a high-fat breakfast with either milk, milk protein, calcium, or a control drink in a randomized crossover study with overweight men. Data are presented as mean \pm SEM; $n=16$. *Different from $\mathrm{T}=0, P<0.05$. @Different from calcium, $\mathrm{P}<0.05$. \$Different from milk protein, $\mathrm{P}<0.05$. \#Different from milk. $P<0.05$.

\section{Markers for endothelial activation}

Baseline plasma concentrations of SICAM-1 were comparable between meals $(P=0.382)$. For changes in sICAM-1 (Figure 5.2A), a significant diet time interaction was found $(P<0.001)$. At T60, sICAM-1 concentrations were lower after milk consumption as compared to the calcium (14\%; $P=0.008)$ or control meals $(16 \% ; P=0.004)$, and lower after milk protein as compared to the calcium (11\%; $\mathrm{P}=0.030)$ or control meals $(13 \% ; \mathrm{P}=0.016)$. At $\mathrm{T} 120$, the sICAM-1 concentration tended to be lower after milk than after milk protein 
(10\%; $\mathrm{P}=0.082$ ). Additionally, at T360, sICAM-1 concentrations were $14 \%$ lower after milk protein as compared to the control meal $(P=0.027)$. No differences between the meals were found for the other parameters (data not shown).

Baseline plasma concentrations of sVCAM-1 were comparable between meals $(P=0.687)$. Changes in sVCAM-1 concentrations (Figure 5.2B) were comparable to changes in plasma sICAM-1 concentrations. A significant diet time interaction was found $(P<0.001)$. sVCAM-1 decreased $15 \%$ more after the milk than after the calcium meal $(P=0.011)$ and $24 \%$ more than after the control meal $(P<0.001)$. Additionally, sVCAM-1 concentrations decreased $17 \%$ more after milk protein than after the control meal $(P=0.021)$. None of the other parameters differed between meals (data not shown), except for a significantly higher maximum increase in sVCAM-1 after the control meal as compared to the milk meal $(P=0.019)$.

Significant correlations were found between sICAM-1 and SVCAM-1 for positive peaks $(R=0.853, P<0.001)$, negative peaks $(R=0.693, P<0.001)$ and dAUCs $(R=0.910, P<0.001)$.

\section{DISCUSSION}

The addition of milk or its constituents to a high-fat meal did not alter the responses in IL-6 or IL-8 concentrations in our study population. Several other studies have investigated differences in postprandial IL-6 and IL-8 concentrations, but mainly examined the effects of various fatty acids as part of a high-fat meal (23-26). These studies found no differences between diets, whereas we found in a previous study differences between saturated fat from butter and (n-6) PUFA from sunflower oil (27). To the best of our knowledge, only two studies have compared postprandial IL-6 responses between dairy products (28) or dairy proteins (29), but no studies have determined postprandial calcium effects. In these studies, Nestel et al. (28) found no differences in 3h-postprandial IL-6 responses when overweight subjects consumed single meals consisting of $50 \mathrm{~g}$ butter, $115 \mathrm{~mL}$ cream, $110 \mathrm{~g}$ cheese, $600 \mathrm{~mL}$ yogurt or $400 \mathrm{~mL}$ reduced fat milk. The meals were standardized for fat content (except for the reduced fat meal), but varied in carbohydrate and protein content. In accordance, Pal et al. (29) found that postprandial IL-6 concentrations were not differently affected when overweight postmenopausal women consumed a standardized breakfast supplemented with either $45 \mathrm{~g}$ sodium casein isolate, $45 \mathrm{~g}$ whey protein isolate, or $45 \mathrm{~g}$ glucose.

After consumption of the meals, postprandial plasma concentrations of IL-6 decreased during the first $60 \mathrm{~min}$ and then increased gradually for the next 5 
hours. At the end of the study, concentrations were higher as compared to baseline. Other studies in lean healthy subjects $(24,30)$, obese men (31), and subjects with metabolic syndrome (25) or coronary heart disease (32) have observed progressively postprandial increases in plasma IL-6 concentrations after a high-fat meal, with peaks mainly after $8 \mathrm{~h}$, whereas we found this progressive increase after $1 \mathrm{~h}$. In our study, time courses of IL-8 concentrations were very similar to those of IL-6. Comparable responses between IL-6 en IL-8 were found in one of our previous studies (27), and also when healthy subjects $(24,26)$ and obese and lean women $(33)$ consumed a high-fat meal. In the latter study (33), IL-6 concentrations were also decreased after $1 \mathrm{~h}$. Unfortunately, we did not measure IL-6 concentrations after $1 \mathrm{~h}$ in our previous study (27). Since both cytokines can be produced by macrophages (34), it is possible that their responses reflect the stimulation of these cells after meal consumption. Based on the results of these studies, however, it seems that the composition of the diet has only small effects on postprandial changes in IL-6 and IL-8.

TNFa decreased after consumption of the high-fat meal in our study. In agreement, TNF $\alpha$ has been shown to decrease after consumption of high-fat meals in various study populations $(24,31,35)$, but also increased TNFa concentrations have been reported (18). We found a reduction in TNFa $2 \mathrm{~h}$ after the consumption of the control and the milk meals, whereas TNFa was increased after the other two meals. There is no good explanation why TNFa decreased after consuming the high-fat breakfast, but we clearly showed that adding calcium or milk protein affects postprandial TNF $\alpha$ responses. Milk on the other hand did not change the TNFa response.

In the aforementioned study by Pal et al. (29) TNFa responses between the diets were not different and concentrations did not change as compared to baseline, indicating that the source of protein is not important for postprandial TNF $\alpha$ responses. Nestel et al. (28) also reported no differences in TNFa responses between the diets. The results of these studies $(28,29)$ are difficult to compare with our study due to differences in study design. Pal et al. (29) compared the effects of exchanging glucose for two different protein sources to a standardized breakfast with an equal fat content, while in our study we used a water control. Moreover, Nestel et al. (28) compared different dairy products with each other and to a low-fat control meal, whereas we compared it to a breakfast with equal fat content. In the latter study (28), the authors found that increments in insulin did not correlate with changes in inflammatory markers. We also could not find such correlations (data not shown). The large amount of leucine in milk may increase oxidative stress and endothelial activation (12). This may explain the increase in TNFa after the milk protein meal, but in that case it cannot be explained why milk did not increase TNFa. 
We have earlier shown in overweight and obese subjects (36) that 8 weeks of daily low-fat dairy consumption (500 ml low-fat milk and $150 \mathrm{~g}$ low-fat yogurt) resulted in decreased fasting concentrations of $\mathrm{TNF} \alpha$ as compared to carbohydrate-rich control products (600 $\mathrm{ml}$ fruit juice and three fruit biscuits). In contrast, in a 6-month dairy intervention study in overweight subjects who were either instructed to increase dairy intake up to 3-5 portions or to maintain habitual intake (37), no effects of dairy consumption on inflammatory markers were found. However, as the authors stated, the subjects already had a relatively high baseline dairy intake and the difference between the dairy intervention and habitual intake may not have been sufficient. The aforementioned beneficial effects $(11,36)$ were not found in the postprandial responses of IL- 6 and TNFa in our study, suggesting that these effects cannot be translated to the postprandial situation or may require longer-term dairy consumption. However, we did find that the consumption of the control and calcium meals caused a small increase in plasma sICAM-1 and SVCAM-1 over time, whereas adding milk or milk protein to the high-fat breakfast reduced concentrations of SICAM-1 and SVCAM-1 up to $2 \mathrm{~h}$ after meal consumption. Several other studies $(18,38,39)$ have found increased concentrations of SICAM-1 and SVCAM-1 after a fat load, whereas others have reported no time-dependent responses (19). Our results indicate that mainly milk protein is responsible for the reductions found in adhesion molecules, since no significant reductions were found when the calcium drink accompanied the breakfast. It must be noted however, that milk protein was ingested together with calcium, so the effects due to milk protein may be dependent on the presence of calcium. However, since milk tended to induce even larger reductions in adhesion molecules, other nutrients may be involved. Arguably, the complex dairy matrix may also have modulated the effects of the individual constituents. We can only speculate on the mechanism by which these adhesion molecules are reduced. As a strong correlation was found between insulin responses and sICAM-1 (19), protein may decrease sICAM-1 through insulin stimulation, since especially the whey fraction is insulinogenic (40). However, we did not find this correlation after consumption of the milk protein or milk meals (data not shown). From animal studies (41) and in vitro studies with endothelial cells (42), it is known that TNFa increases the expression of SICAM-1 and SVCAM-1 $5 \mathrm{~h}$ after injection (41) or $10 \mathrm{~h}$ after incubation (42). Possibly, this association is not apparent from our data, because we measured protein concentrations and not RNA expression. Moreover, it may be that the time period was too short to find effects at the protein level.

In conclusion, the results of this study provide insight into the effects of adding milk or one of its two major constituents - protein and calcium - to a high-fat 
meal on postprandial markers for inflammation and endothelial activation. Our data show that consuming $500 \mathrm{~mL}$ of skimmed milk or a milk protein drink with a high-fat meal may increase concentrations of TNFa in overweight men. On the other hand, postprandial responses of SICAM-1 and SVCAM-1 may be improved by consuming milk, which may be partially, but not solely, attributable to the protein fraction. 


\section{REFERENCES}

1. Mann Jl. Diet and risk of coronary heart disease and type 2 diabetes. Lancet 2002;360:783-9.

2. Kontogianni MD, Panagiotakos DB, Chrysohoou C, Pitsavos C, Stefanadis C. Modelling dairy intake on the development of acute coronary syndromes: the CARDIO2000 study. Eur J Cardiovasc Prev Rehabil 2006;13:791-7.

3. Soedamah-Muthu SS, Ding EL, Al-Delaimy WK, et al. Milk and dairy consumption and incidence of cardiovascular diseases and all-cause mortality: dose-response metaanalysis of prospective cohort studies. Am J Clin Nutr 2011;93:158-71.

4. Choi HK, Willett WC, Stampfer MJ, Rimm E, Hu FB. Dairy consumption and risk of type 2 diabetes mellitus in men: a prospective study. Arch Intern Med 2005;165:997-1003.

5. van Dam RM, Hu FB, Rosenberg L, Krishnan S, Palmer JR. Dietary calcium and magnesium, major food sources, and risk of type 2 diabetes in U.S. black women. Diabetes Care 2006;29:2238-43.

6. Goldbohm RA, Chorus AM, Galindo Garre F, Schouten LJ, van den Brandt PA. Dairy consumption and 10-y total and cardiovascular mortality: a prospective cohort study in the Netherlands. Am J Clin Nutr 2011;93:615-27.

7. Ridker PM, Hennekens $\mathrm{CH}$, Buring JE, Rifai N. C-reactive protein and other markers of inflammation in the prediction of cardiovascular disease in women. $\mathrm{N}$ Engl $\mathrm{J}$ Med 2000;342:836-43.

8. Ridker PM, Hennekens $\mathrm{CH}$, Roitman-Johnson B, Stampfer MJ, Allen J. Plasma concentration of soluble intercellular adhesion molecule 1 and risks of future myocardial infarction in apparently healthy men. Lancet 1998;351:88-92.

9. Ridker PM, Rifai N, Stampfer MJ, Hennekens CH. Plasma concentration of interleukin6 and the risk of future myocardial infarction among apparently healthy men. Circulation 2000;101:1767-72.

10. Panagiotakos DB, Pitsavos CH, Zampelas AD, Chrysohoou CA, Stefanadis Cl. Dairy products consumption is associated with decreased levels of inflammatory markers related to cardiovascular disease in apparently healthy adults: the ATTICA study. J Am Coll Nutr 2010;29:357-64.

11. Zemel MB, Sun X, Sobhani T, Wilson B. Effects of dairy compared with soy on oxidative and inflammatory stress in overweight and obese subjects. Am J Clin Nutr 2010;91:1622.

12. Sun X, Zemel MB. Leucine and calcium regulate fat metabolism and energy partitioning in murine adipocytes and muscle cells. Lipids 2007;42:297-305.

13. Westphal S, Kastner S, Taneva E, Leodolter A, Dierkes J, Luley C. Postprandial lipid and carbohydrate responses after the ingestion of a casein-enriched mixed meal. Am J Clin Nutr 2004;80:284-90.

14. Mohrschladt MF, Weverling-Rijnsburger AW, de Man FH, et al. Hyperlipoproteinemia affects cytokine production in whole blood samples ex vivo. The influence of lipidlowering therapy. Atherosclerosis 2000;148:413-9.

15. Sampedro MC, Motran C, Gruppi A, Kivatinitz SC. VLDL modulates the cytokine secretion profile to a proinflammatory pattern. Biochem Biophys Res Commun 2001;285:393-9.

16. Sun X, Zemel MB. 1Alpha,25-dihydroxyvitamin D3 modulation of adipocyte reactive oxygen species production. Obesity (Silver Spring) 2007;15:1944-53.

17. Lorenzen JK, Nielsen S, Holst JJ, Tetens I, Rehfeld JF, Astrup A. Effect of dairy calcium or supplementary calcium intake on postprandial fat metabolism, appetite, and subsequent energy intake. Am J Clin Nutr 2007;85:678-87.

18. Nappo F, Esposito K, Cioffi M, et al. Postprandial endothelial activation in healthy subjects and in type 2 diabetic patients: role of fat and carbohydrate meals. J Am Coll Cardiol 2002;39:1145-50.

19. Rubin D, Claas S, Pfeuffer M, Nothnagel M, Foelsch UR, Schrezenmeir J. s-ICAM-1 and S-VCAM-1 in healthy men are strongly associated with traits of the metabolic syndrome, becoming evident in the postprandial response to a lipid-rich meal. Lipids Health Dis 2008;7:32.

20. Burdge GC, Calder PC. Plasma cytokine response during the postprandial period: a potential causal process in vascular disease? Br J Nutr 2005;93:3-9. 
21. van Meijl LE. The role of dairy products and constituents in metabolic risk management. NUTRIM School for Nutrition, Toxicology \& Metabolism. Maastricht: Maastricht University, 2010:121.

22. Matthews JN, Altman DG, Campbell MJ, Royston P. Analysis of serial measurements in medical research. Bmj 1990;300:230-5.

23. Poppitt SD, Keogh GF, Lithander FE, et al. Postprandial response of adiponectin, interleukin-6, tumor necrosis factor-alpha, and C-reactive protein to a high-fat dietary load. Nutrition 2008;24:322-9.

24. Sanders TA, Filippou A, Berry SE, Baumgartner S, Mensink RP. Palmitic acid in the sn-2 position of triacylglycerols acutely influences postprandial lipid metabolism. Am J Clin Nutr 2011;94:1433-41.

25. Tulk HM, Robinson LE. Modifying the $n-6 / n-3$ polyunsaturated fatty acid ratio of a highsaturated fat challenge does not acutely attenuate postprandial changes in inflammatory markers in men with metabolic syndrome. Metabolism 2009;58:1709-16.

26. Voon PT, Ng TK, Lee VK, Nesaretnam K. Diets high in palmitic acid (16:0), lauric and myristic acids $(12: 0+14: 0)$, or oleic acid (18:1) do not alter postprandial or fasting plasma homocysteine and inflammatory markers in healthy Malaysian adults. Am J Clin Nutr 2011;94:1451-7.

27. Masson CJ, Mensink RP. Exchanging saturated fatty acids for ( $n-6)$ polyunsaturated fatty acids in a mixed meal may decrease postprandial lipemia and markers of inflammation and endothelial activity in overweight men. J Nutr 2011;141:816-21.

28. Nestel PJ, Pally S, Macintosh GL, et al. Circulating inflammatory and atherogenic biomarkers are not increased following single meals of dairy foods. Eur $\mathrm{J}$ Clin Nutr 2012;66:25-31.

29. Pal S, Ellis V. Acute effects of whey protein isolate on blood pressure, vascular function and inflammatory markers in overweight postmenopausal women. $\mathrm{Br} \mathrm{J}$ Nutr 2011;105:1512-9.

30. van Oostrom AJ, Sijmonsma TP, Verseyden C, et al. Postprandial recruitment of neutrophils may contribute to endothelial dysfunction. J Lipid Res 2003;44:576-83.

31. Blackburn P, Despres JP, Lamarche B, et al. Postprandial variations of plasma inflammatory markers in abdominally obese men. Obesity (Silver Spring) 2006;14:1747-54.

32. Lundman P, Boquist S, Samnegard A, et al. A high-fat meal is accompanied by increased plasma interleukin-6 concentrations. Nutr Metab Cardiovasc Dis 2007;17:195-202.

33. Manning PJ, Sutherland WH, McGrath MM, de Jong SA, Walker RJ, Williams MJ. Postprandial Cytokine Concentrations and Meal Composition in Obese and Lean Women. Obesity (Silver Spring) 2008.

34. Kaufman AM, Alabre $\mathrm{Cl}$, Rubash HE, Shanbhag AS. Human macrophage response to UHMWPE, TiAIV, CoCr, and alumina particles: analysis of multiple cytokines using protein arrays. J Biomed Mater Res A 2008;84:464-74.

35. Payette $C$, Blackburn $P$, Lamarche B, et al. Sex differences in postprandial plasma tumor necrosis factor-alpha, interleukin-6, and C-reactive protein concentrations. Metabolism 2009;58:1593-601.

36. van Meijl LE, Mensink RP. Effects of low-fat dairy consumption on markers of low-grade systemic inflammation and endothelial function in overweight and obese subjects: an intervention study. Br J Nutr 2010;104:1523-7.

37. Wennersberg MH, Smedman A, Turpeinen AM, et al. Dairy products and metabolic effects in overweight men and women: results from a 6-mo intervention study. Am J Clin Nutr 2009;90:960-8.

38. Ceriello A, Quagliaro L, Piconi L, et al. Effect of postprandial hypertriglyceridemia and hyperglycemia on circulating adhesion molecules and oxidative stress generation and the possible role of simvastatin treatment. Diabetes 2004;53:701-10.

39. Marchesi S, Lupattelli G, Lombardini R, et al. Effects of fenofibrate on endothelial function and cell adhesion molecules during post-prandial lipemia in hypertriglyceridemia. J Clin Pharm Ther 2003;28:419-24.

40. Nilsson M, Stenberg M, Frid AH, Holst JJ, Bjorck IM. Glycemia and insulinemia in healthy subjects after lactose-equivalent meals of milk and other food proteins: the role of plasma amino acids and incretins. Am J Clin Nutr 2004;80:1246-53. 
41. Horie $\mathrm{Y}$, Chervenak RP, Wolf R, et al. Lymphocytes mediate TNF-alpha-induced endothelial cell adhesion molecule expression: studies on SCID and RAG-1 mutant mice. J Immunol 1997; 159:5053-62.

42. lademarco MF, Barks JL, Dean DC. Regulation of vascular cell adhesion molecule-1 expression by IL-4 and TNF-alpha in cultured endothelial cells. J Clin Invest 1995;95:264-71. 


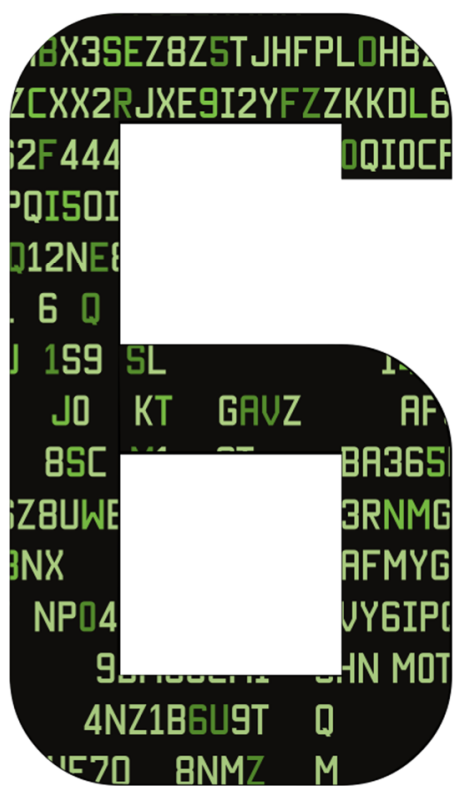

\section{MILK HOMOGENIZATION AND POSTPRANDIAL METRBOLISM IN OUERWEIGHT MEN: A RANDOMIZED STUDY}

[J MASSDN, RP MENSINK 


\section{ABSTRACT}

The physical structure of foods affects postprandial metabolism, a risk marker for $\mathrm{CVD}^{5}$. In animals, homogenization of milk changes postprandial responses, but these effects have never been studied in humans. The objective was to compare postprandial effects of homogenized milk, nonhomogenized milk, or skimmed milk plus butter on lipemic, glycemic, inflammatory and endothelial markers. Eighteen overweight men (BMI 25-30 $\mathrm{kg} / \mathrm{m}^{2}$, age 18-70 y) consumed in random order crisp bread with marmalade and $900 \mathrm{~mL}$ of homogenized whole milk (H-milk), non-homogenized whole milk (NH-milk), or skimmed milk plus $44 \mathrm{~g}$ butter. Macronutrient compositions of the meals were comparable. Compared to butter, postprandial TAG concentrations decreased significantly after $\mathrm{NH}$-milk $(\mathrm{P}=0.002)$. Furthermore, glucose concentrations on the $\mathrm{NH}$-milk meal were higher after $30 \mathrm{~min}$ $(P=0.038), 45 \mathrm{~min}(P=0.004)$ and $60 \mathrm{~min}(\mathrm{P}=0.017)$ and on the $\mathrm{H}$-milk meal after $45 \mathrm{~min}(\mathrm{P}=0.008)$. Homogenization of milk significantly increased total count $(P=0.002)$ and iAUC $(P=0.025)$ of white blood cells. IL-6 concentrations were significantly higher after the $\mathrm{H}$-milk meal as compared to the butterfat meal at $(\mathrm{P}=0.026)$ and $\mathrm{T}=480(\mathrm{P}=0.001)$ and at $\mathrm{T}=240$ as compared to $\mathrm{NH}-$ milk $(P=0.036)$. TNFa concentrations were higher after NH-milk than after butter $(P=0.007)$. Changes in concentrations of sICAM-1 and sVCAM-1 were comparable between the meals. These findings do not indicate a major role for homogenization of milk on acute postprandial responses. We did however find clear - potentially beneficial and unbeneficial - effects when fat was consumed as butter. 


\section{INTRODUCTION}

Dietary fat increases the postprandial serum triacylglycerol (TAG) response (1), which may increase cardiovascular risk (2-4). Also, postprandial increases in markers for inflammation and endothelial function are related to CVD risk (5). Whether these effects depend on the fatty-acid composition of the meal is less clear. Butterfat, for example, has been found to increase $(1,6)$ and to decrease (7-10) postprandial lipemia, as compared to a fat rich in polyunsaturated fatty acids. For carbohydrate-rich foods, the physical structure of the food product also determines postprandial responses $(11,12)$. This may be true for fat-rich foods as well. Clemente et al. (13) studied postprandial responses to a milk meal, a butter meal and a cheese (mozzarella) meal in eight type 2 diabetics. Although the incremental areas (iAUC) under the 6h TAG curve were not different between the meals, a significantly lower 0-3h iAUC and a significantly delayed peak response were found after the butter meal. However, except for the food matrix, the meals also differed in their sources of protein and fats, thereby making the comparison between milk, butter and mozzarella cheese difficult. In contrast, Tholstrup et al. (14) found no postprandial differences after consumption of lactose and total milk protein-standardized milk, butter or cheese meals, suggesting that the physical structure of the fat is not important. This study, however, was performed in healthy participants with low serum TAG concentrations. To what extent these results can be extrapolated to overweight participants with increased serum TAG concentrations, who may be more responsive $(15,16)$, is unknown. In addition, effects on other postprandial risk markers have hardly been studied. To assess the role of the food matrix of dairy on postprandial metabolism into more detail, we therefore decided to compare in overweight men side-by-side the effects of homogenized milk, non-homogenized (unprocessed) milk and butterfat. In unprocessed milk, fat is present in relatively large fat droplets, enclosed by the milk fat globule membrane (MFGM). During homogenization, milk is pressed through a filter under high pressure and under high temperature, thereby reducing milk fat globule size. It is thought that these smaller fat globules are absorbed more easily (17), which may increase postprandial lipemia. Additionally, due to a 4-10 fold increase in fat-water surface area, the MFGM composition undergoes major changes (17). It has been postulated that these changes increase vascular damage by an increased presence of several oxidation-inducing proteins, e.g. bovine xanthine oxidase, in the vasculature (18). There are, however, no human studies addressing the impact of milk homogenization on postprandial metabolism. 


\section{PARTICIPANTS AND METHODS}

\section{Participants}

Ethical approval was obtained from the Medical Ethics Committee of Maastricht University (METC 10-3-089) and the study was registered at www.clinicaltrials.gov as NCT01317524. Before inclusion, informed consent was obtained from all participants. Participants were recruited through announcements in local newspapers or among volunteers who had participated in earlier studies at the department. To exclude any possible variations in postprandial responses due to hormonal effects, female participants were excluded from participation. Fifty-three participants responded to recruitment announcements and 23 participants attended the screening visits. Participants willing to participate were invited for the two screening visits if they met the following inclusion criteria: aged between 18 and $70 \mathrm{y}, \mathrm{BMI}$ between 25 and $30 \mathrm{~kg} / \mathrm{m}^{2}$, stable body weight (weight gain or loss $<5 \%$ in the previous $3 \mathrm{mo}$ ), no intention to change their physical activity pattern during the study, no use of lipid-lowering medication or a prescribed diet, and no participation in another biochemical trial for the past $30 \mathrm{~d}$. Three participants did not meet the inclusion criteria: mean fasting serum concentrations $<8.0 \mathrm{mmol} / \mathrm{L}$ for total cholesterol and of $<1.7 \mathrm{mmol} / \mathrm{L}$ for TAG; no indications for treatment for hyperlipidemia according to the Dutch Cholesterol Consensus (19); no inflammatory disease; no clinical condition known to affect lipid metabolism; no drug or alcohol abuse; and no history of coronary artery disease, heart failure (class III or IV), cardiomyopathy or kidney, liver, or pancreatic disease or malignancy $<5 \mathrm{y}$ ago. Of the remaining 20 volunteers, two participants decided not to participate, as it was not possible to schedule their experimental days. Thus, 18 participants started the study (Table 6.1) who all completed the study. For 1 subject retinal images could not be obtained, due to cataract surgery.

\section{Study design}

A randomized, single-blind crossover design was used, in which all participants received three different interventions. On the day before each test, participants were asked not to engage in any strenuous physical exercise or to consume alcohol. Participants were also asked to refrain from high-fat foods, including fried foods and sausages. Participants arrived at approximately $7.45 \mathrm{AM}$ and rested in the supine position for $15 \mathrm{~min}$. An intravenous catheter was inserted in an antecubital vein of the non-dominant arm, after which a baseline blood sample was drawn. Participants then 
Table 6.1: Baseline characteristics of the overweight male participants

\begin{tabular}{|c|c|c|c|}
\hline \multirow{2}{*}{$\begin{array}{l}\mathbf{n}=18 \\
\text { age, } y\end{array}$} & \multicolumn{3}{|c|}{ mean \pm SEM } \\
\hline & 57.9 & \pm & 1.92 \\
\hline $\mathrm{BMI}, \mathrm{kg} \cdot \mathrm{m}^{-2}$ & 27.7 & \pm & 0.49 \\
\hline weight, $\mathrm{kg}$ & 87.4 & \pm & 1.91 \\
\hline height, $m$ & 1.78 & \pm & 0.01 \\
\hline systolic, $\mathrm{mm} \mathrm{Hg}$ & 140 & \pm & 2.73 \\
\hline diastolic, $\mathrm{mm} \mathrm{Hg}$ & 89 & \pm & 1.54 \\
\hline glucose, $\mathrm{mmol} \cdot \mathrm{L}^{-1}$ & 5.55 & \pm & 0.16 \\
\hline insulin, $m U \cdot L^{-1}$ & 15.6 & \pm & 1.13 \\
\hline HOMAir, $m m o l \cdot L^{-1} x m U \cdot L^{-1}$ & 3.87 & \pm & 0.32 \\
\hline total cholesterol, $\mathrm{mmol} \cdot \mathrm{L}^{-1}$ & 5.83 & \pm & 0.21 \\
\hline $\mathrm{HDL}$ cholesterol, $\mathrm{mmol} \cdot \mathrm{L}^{-1}$ & 1.49 & \pm & 0.05 \\
\hline triacylglycerol, $\mathrm{mmol} \cdot \mathrm{L}^{-1}$ & 1.28 & \pm & 0.08 \\
\hline
\end{tabular}

Table 6.2: Composition of the non-homogenized $(\mathrm{NH})$ milk meal, homogenized $(\mathrm{H})$ milk meal and the butterfat meal ${ }^{1}$

\begin{tabular}{lccc}
\hline & H- milk & NH- milk & Butterfat \\
\hline energy, $k J$ & 4150 & 4150 & 4228 \\
energy, $k$ cal & 992 & 992 & 1011 \\
fat, $g$ & 41.1 & 41.1 & 41.1 \\
carbohydrates, $g$ & 114.5 & 114.5 & 115.9 \\
protein, $g$ & 41.5 & 41.5 & 43.6 \\
\hline
\end{tabular}

${ }^{1}$ All meals provided $37 \%$ of energy fat, $46 \%$ carbohydrates, and $17 \%$ protein

received in random order one of the three experimental meals, which had to be consumed within 15 min. All meals provided two slices of bread with marmalade and 2 pieces of crisp bread. The non-homogenized $(\mathrm{NH})$ milk meal further consisted of $900 \mathrm{~mL}$ of whole, pasteurized milk (NIZO food research BV, Ede, the Netherlands) and the homogenized $(\mathrm{H})$ milk meal of $900 \mathrm{~mL}$ of whole, homogenized milk (NIZO food research BV, Ede, the Netherlands), made from the same batch of milk as the $\mathrm{NH}$-milk. Both types of milk provided $40 \mathrm{~g}$ of milk fat. The butterfat meal consisted of $900 \mathrm{~mL}$ of skimmed milk with $44 \mathrm{~g}$ of salted butter (to be used on the bread and crisp bread) in order to standardize the fat content between the meals. The meals provided equal amounts of energy ( $4150 \mathrm{~kJ}$ for $\mathrm{H}$-milk and $\mathrm{NH}$-milk and 4228 $\mathrm{kJ}$ for butterfat) and equal amounts of energy from fat (37 En\%), carbohydrate (46 En\%) and protein (17 En\%), as calculated with the Dutch food composition table (20) (see Table 6.2).

Blood was drawn every 15 min during the first hour after intake of the meal, every 30 min during the second hour, and hourly during the rest of the test. Blood was drawn as much as possible by the same technician, at the same 
location, and at the same time of the day between the different participants. The participants consumed an apple after $3 \mathrm{~h}$ and a glass of water $(200 \mathrm{~mL})$ after $3 \mathrm{~h}$ and $6 \mathrm{~h}$.

\section{Blood analyses}

EDTA-containing or NaF-containing vacutainer tubes (Becton Dickinson, Plymouth, UK) were placed on ice directly after blood sampling and within 60 minutes centrifuged at $1300 \mathrm{~g}$ at $4^{\circ} \mathrm{C}$ for 15 minutes. Blood drawn in vacutainer serum tubes (Becton Dickinson, Plymouth, UK) was allowed to clot for at least 30 minutes at $21^{\circ} \mathrm{C}$ and then centrifuged at $1300 \mathrm{~g}$ for 15 minutes at $21^{\circ} \mathrm{C}$. Plasma and serum aliquots were directly frozen in liquid nitrogen and stored at $-80^{\circ} \mathrm{C}$ until analysis. Serum samples of T0, T60, T120, T180, T240, T300, T360, T420 and T480 were analyzed for TAG concentrations with correction for free glycerol (GPO Trinder; Sigma-Aldrich Corp., St. Louis, MO, USA), and fasting serum samples for total cholesterol (CHOD-PAP method; Roche Diagnostics, Mannheim, Germany) and HDL cholesterol concentrations (phosphotungstate precipitant; Roche Diagnostics, Mannheim, Germany). Insulin concentrations were measured in serum samples of T0, T15, T30, T45, T60, T120, T300 and T480 (Linco Research Inc., St. Charles, MO, USA). NaF plasma samples were analyzed for glucose concentrations (Horiba ABX, Montpellier, France) at T0, T15, T30, T45, T60, T90, T120, T300 and T480 and analyzed for non-esterified fatty acids (NEFA) at T0, T60, T120, T300 and T480 (NEFA kit; WAKO, Neuss, Germany). Concentrations of apolipoprotein B-48 were measured in plasma samples at T0, T60, T120, T240, T360 and T480 (Shibayagi Co Ltd, Ishihara, Japan).

Plasma inflammatory markers (interleukin-6 (IL-6), IL-8 and tumor necrosis factor $\alpha(\mathrm{TNF} \alpha)$ ), soluble intercellular adhesion molecule (sICAM)-1 and soluble vascular cell adhesion molecule (sVCAM)- 1 were measured at T0, T60, T120, T240, T360 and T480 with a commercially available Multi Spot ELISA kit (Meso Scale Discovery, Gaithersburg, MD, USA). White blood cell counts (WBC) and differentiations were determined automatically using a Celldyn 3500 hematology analyzer (Abbott, Abbott park, IL, USA) at T0, T120 and T480. 


\section{Retinal imaging}

Retinal vascular images were obtained at T0, T240 and T480 to visualize the response of the microvasculature in the eye. During this test, participants were seated with their head resting on a chinrest, looking directly into the camera (Topcon TRC-NW-300; Topcon Co., Tokyo, Japan). The camera focused on and photographed the retina. Images were digitized and analyzed to calculate the mean artery width (MAW), mean vein width (MVW) and artery:vein ratio (AV-ratio) with the appropriate software (Generalized Dual-Bootstrap Iterative Closest Point (GDB-ICP)), as described in detail elsewhere (21). In short, the software automatically aligns the images based on detected vascular centerlines by iteratively transforming the algorithm. At least 3 arteries and 3 veins were selected, which were at all time points the same set of vessels for a subject.

\section{Sample size calculation and randomization}

Sample size calculations were based on 18 men completing the study, using the primary outcomes of the incremental area under the curve (iAUC) of postprandial TAG concentrations. This sample size has been selected to give a power of $>80 \%$ to detect a 0.75 SD unit change at $P=0.017$ (to account for multiple comparisons between groups) using a crossover design, considering an expected difference of $42 \mathrm{mmol} / \mathrm{min} / \mathrm{L}$ and an intra-subject variability of 54 $\mathrm{mmol} / \mathrm{min} / \mathrm{L}$ (13). Randomization was performed by an independent person with an online random number generator at http://www.randomization.com using performed balanced permutations.

\section{Statistical analysis}

All data are presented as mean \pm SEM. Baseline concentrations were compared using univariate ANOVA with diet as fixed factor and subject number as random factor. Changes from baseline were compared using linear mixed models with diet and time as within-subject fixed factors, and with diet-time interaction. If the interaction term was not statistically significant, it was omitted from the model. Based upon the information criteria output, the most suitable covariance model was selected. In case of significant diet effects, the diets were compared pairwise using a Bonferroni correction. If time was significant, time points were compared to baseline values. If the diet time interaction term reached statistical significance, differences between the diets were tested at each individual time point. For all parameters the incremental or decremental area under the curve (iAUC/dAUC) was calculated using the trapezoidal rule. Moreover, the maximum positive and negative change from baseline (peak change), and the time period between meal consumption and 
peak changes (time to peak) were calculated and compared using ANOVA. All statistical analyses were performed using SPSS 16.0 (SPSS Inc., Chicago, IL, USA) and differences were considered to be statistically significant when $P<0.05$.
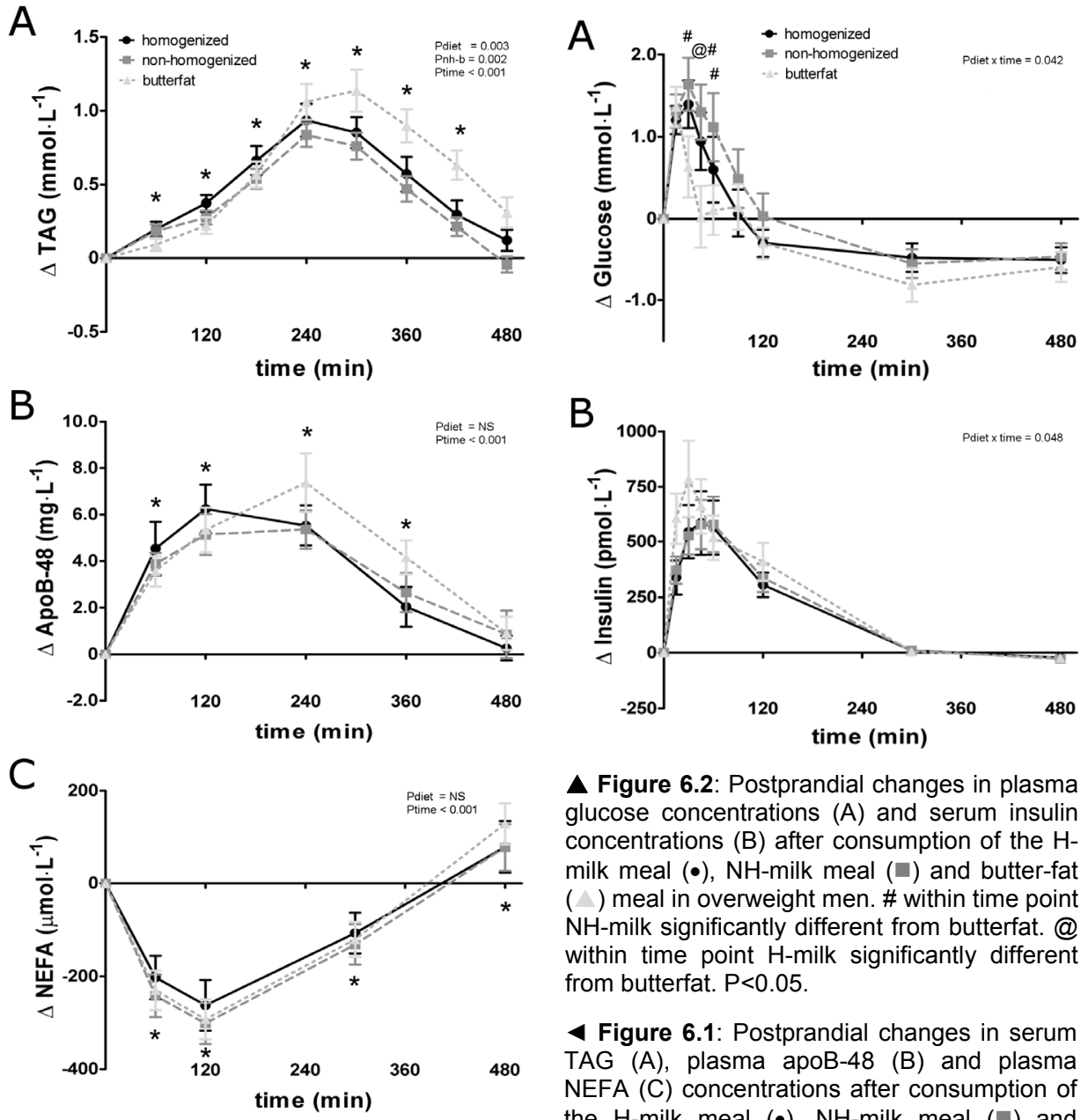

A Figure 6.2: Postprandial changes in plasma glucose concentrations (A) and serum insulin concentrations (B) after consumption of the $\mathrm{H}$ milk meal $(\bullet)$, NH-milk meal $(\square)$ and butter-fat ( $)$ meal in overweight men. \# within time point NH-milk significantly different from butterfat. @ within time point $\mathrm{H}$-milk significantly different from butterfat. $\mathrm{P}<0.05$.

4 Figure 6.1: Postprandial changes in serum TAG (A), plasma apoB-48 (B) and plasma NEFA (C) concentrations after consumption of the $\mathrm{H}$-milk meal $(\bullet)$, $\mathrm{NH}$-milk meal $(\square)$ and butterfat $(\triangle)$ meal in overweight men. * significantly different compared to baseline $(P<0.05)$. 
Table 6.3: Calculated iAUC or dAUC after H-milk, NH-milk or the butterfat meal

\begin{tabular}{|c|c|c|c|c|c|c|c|c|c|}
\hline & \multicolumn{3}{|c|}{ H-milk } & \multicolumn{3}{|c|}{ NH-milk } & \multicolumn{3}{|c|}{ butterfat } \\
\hline${ }^{1} \mathrm{TAG}, \mathrm{mmol} \cdot \mathrm{min} \cdot \mathrm{L}^{-1}$ & 240 & \pm & $28.3^{\mathrm{AB}}$ & 198 & \pm & $21.3^{\mathrm{A}}$ & 289 & \pm & $30.7^{\mathrm{B}}$ \\
\hline${ }^{1}$ apoB-48, $g \cdot \min \cdot L^{-1}$ & 1.88 & \pm & 0.283 & 1.80 & \pm & 0.207 & 2.17 & \pm & 0.310 \\
\hline${ }^{2} \mathrm{NEFA}, \mathrm{mol} \cdot \mathrm{min} \cdot \mathrm{L}^{-1}$ & 1.13 & \pm & 0.195 & 1.25 & \pm & 0.175 & 1.17 & \pm & 0.154 \\
\hline${ }^{1}$ glucose, $\mathrm{mmol} \cdot \min \cdot L^{-1}$ & 96.8 & \pm & 23.2 & 118 & \pm & 25.5 & 70.4 & \pm & 22.9 \\
\hline${ }^{1}$ insulin, $\mathrm{nmol} \cdot \min \cdot \mathrm{L}^{-1}$ & 13.7 & \pm & 2.61 & 14.4 & \pm & 2.52 & 17.0 & \pm & 3.31 \\
\hline${ }^{1} \mathrm{IL}-6, n g \cdot \min \cdot \mathrm{L}^{-1}$ & 297 & \pm & 55.5 & 267 & \pm & 65.6 & 153 & \pm & 43.8 \\
\hline${ }^{2} \mathrm{IL}-8, \mathrm{ng} \cdot \min \cdot \mathrm{L}^{-1}$ & 254 & \pm & 95.3 & 198 & \pm & 27.2 & 503 & \pm & 175 \\
\hline${ }^{2} \mathrm{TNFa}, n g \cdot \min \cdot L^{-1}$ & 169 & \pm & 42.9 & 196 & \pm & 35.3 & 280 & \pm & 68.4 \\
\hline${ }^{2} \mathrm{SICAM}-1, \mu \mathrm{g} \cdot \min \cdot \mathrm{L}^{-1}$ & 8.94 & \pm & 1.92 & 7.39 & \pm & 1.44 & 9.58 & \pm & 2.98 \\
\hline${ }^{2} \mathrm{sVCAM}-1, \mu \mathrm{g} \cdot \min \cdot \mathrm{L}^{-1}$ & 15.3 & \pm & 2.89 & 9.75 & \pm & 1.48 & 13.6 & \pm & 3.88 \\
\hline${ }^{1} \mathrm{WBC}, 10^{9} \mathrm{ce} / \mathrm{s} \cdot \mathrm{min} \cdot \mathrm{L}^{-1}$ & 231 & \pm & $40.4^{\mathrm{A}}$ & 119 & \pm & $23.5^{\mathrm{B}}$ & 135 & \pm & $36.0^{\mathrm{AB}}$ \\
\hline${ }^{1}$ neutrophils, $10^{9} \mathrm{cells} \cdot \mathrm{min} \cdot \mathrm{L}^{-1}$ & 245 & \pm & 32.1 & 145 & \pm & 30.3 & 192 & \pm & 55.4 \\
\hline${ }^{2}$ lymphocytes, $10^{9} \mathrm{cells} \cdot \mathrm{min} \cdot \mathrm{L}^{-1}$ & 70.9 & \pm & 24.4 & 99.5 & \pm & 24.3 & 99.0 & \pm & 32.3 \\
\hline${ }^{1} \mathrm{MAW}, \mu \mathrm{m} \cdot \min$ & 506 & \pm & 204 & 471 & \pm & 149 & 469 & \pm & 118 \\
\hline${ }^{2} \mathrm{MVW}, \mu \mathrm{m} \cdot \min$ & 477 & \pm & 132 & 572 & \pm & 149 & 564 & \pm & 134 \\
\hline
\end{tabular}

Values with different superscripts differ significantly; ${ }^{1}$ iAUC, ${ }^{2}$ dAUC

Table 6.4: Calculated peak changes after H-milk, NH-milk or the butterfat meal

\begin{tabular}{|c|c|c|c|c|c|c|c|c|c|}
\hline \multirow[b]{2}{*}{$\mathrm{TAG}, \mathrm{mmo} \cdot \mathrm{L}^{-1}$} & \multicolumn{3}{|c|}{ H-milk } & \multicolumn{3}{|c|}{ NH-milk } & \multicolumn{3}{|c|}{ butterfat } \\
\hline & 1.04 & \pm & $0.10^{\mathrm{AB}}$ & 0.90 & \pm & $0.09^{A}$ & 1.32 & \pm & $0.13^{\mathrm{B}}$ \\
\hline apoB-48, $m g \cdot L^{-1}$ & 7.74 & \pm & 1.06 & 7.38 & \pm & 0.88 & 8.45 & \pm & 1.05 \\
\hline $\mathrm{NEFA}, \mu \mathrm{mol} \cdot \mathrm{L}^{-1}$ & -271 & \pm & 54.1 & -308 & \pm & 44.3 & -293 & \pm & 43.2 \\
\hline glucose, $\mathrm{mmol} \cdot \mathrm{L}^{-1}$ & 1.95 & \pm & $0.26^{\mathrm{AB}}$ & 2.37 & \pm & $0.29^{A}$ & 1.49 & \pm & $0.27^{\mathrm{B}}$ \\
\hline insulin, $\mathrm{pmol} \cdot \mathrm{L}^{-1}$ & 118 & \pm & 22.9 & 122 & \pm & 19.4 & 140 & \pm & 28.3 \\
\hline $\mathrm{IL}-6, n g \cdot \mathrm{L}^{-1}$ & 1.55 & \pm & 0.318 & 1.21 & \pm & 0.236 & 0.777 & \pm & 0.191 \\
\hline IL-8, $n g \cdot L^{-1}$ & -0.891 & \pm & 0.232 & -0.814 & \pm & 0.156 & -1.29 & \pm & 0.492 \\
\hline $\mathrm{TNFa}, n g \cdot L^{-1}$ & -0.800 & \pm & 0.130 & -0.754 & \pm & 0.145 & -1.28 & \pm & 0.242 \\
\hline sICAM-1, $\mu g \cdot L^{-1}$ & -44.5 & \pm & 8.30 & -36.7 & \pm & 7.98 & -47.7 & \pm & 12.0 \\
\hline $\mathrm{sVCAM}-1, \mu g \cdot L^{-1}$ & -73.2 & \pm & 11.9 & -46.1 & \pm & 9.71 & -69.6 & \pm & 14.6 \\
\hline WBC, $10^{9} \cdot L^{-1}$ & 0.906 & \pm & 0.158 & 0.683 & \pm & 0.127 & 1.16 & \pm & 0.586 \\
\hline neutrophils, $10^{9} \cdot L^{-1}$ & 0.894 & \pm & 0.0968 & 0.544 & \pm & 0.100 & 0.661 & \pm & 0.204 \\
\hline Iymphocytes, $10^{9} \cdot L^{-1}$ & -0.283 & \pm & 0.0772 & -0.450 & \pm & 0.0857 & -0.411 & \pm & 0.103 \\
\hline MAW, $\mu m$ & 1.79 & \pm & 0.622 & 1.95 & \pm & 0.562 & 2.13 & \pm & 0.437 \\
\hline MVW, $\mu m$ & -2.10 & \pm & 0.477 & -2.24 & \pm & 0.523 & -2.21 & \pm & 0.515 \\
\hline $\mathrm{AVr}, 10^{-2}$ & 1.88 & \pm & 0.60 & 1.88 & \pm & 0.587 & 2.24 & \pm & 0.518 \\
\hline
\end{tabular}

Values with different superscripts differ significantly 


\section{RESULTS}

\section{Postprandial lipids}

Fasting baseline serum TAG concentrations were not different between the meals $(P=0.891)$. Also, the diet time interaction term did not reach statistical significance $(P=0.261)$. Compared to baseline, serum TAG concentrations were significantly increased over time $(P<0.001)$ at all time points (all $P<0.001$ ), except after 480 min (Figure 6.1A). The diet effect also reached statistical significance $(P=0.003)$ and serum TAG responses were on average $0.18 \pm 0.05 \mathrm{mmol} / \mathrm{L}$ lower after the $\mathrm{NH}$-milk meal as compared to the butterfat meal $(P=0.002)$. This was also reflected by differences in the iAUC (Table 6.3, $\mathrm{P}=0.022$ ) and peak changes (Table 6.4, $\mathrm{P}=0.01$ ).

Baseline plasma concentrations of apoB-48 were not different between the meals $(P=0.886)$ and the diet-time interaction term did not reach statistical significance $(P=0.654)$. However, apoB-48 increased significantly over time $(P<0.01)$. As compared to baseline, concentrations were significantly increased after 60, 120, 240 and 360 min (all $P<0.01$; Figure 6.1B). No diet effects $(P=0.788)$ or differences in the iAUC $(P=0.289)$ or peak changes $(P=0.430)$ were found, however a trend for a delayed time to peak was found after the H-milk meal (Table 6.5, $\mathrm{P}=0.053$ ).

Baseline concentrations of NEFA were not different between the meals $(P=0.288)$. No significant diet time interaction was found $(P=0.918)$. Over time, NEFA concentrations changed significantly $(P<0.001)$. Compared to baseline, concentrations were significantly decreased 60,120 and $300 \mathrm{~min}$ after meal consumption and increased after $480 \mathrm{~min}(P<0.001$ for all; Figure 6.1C). Diet effects $(P=0.694)$, the dAUC (Table 6.3, $P=0.656)$ and other parameters (Tables 6.4 and 6.5) were not significantly different between the meals.

\section{Postprandial glycemia}

Baseline glucose concentrations were not different between the meals $(P=0.647)$. Time courses for plasma glucose differed significantly between the meals $(P=0.044$ for diet-time interaction; Figure 6.2A). Fifteen min after consumption of the butterfat meal, glucose concentrations decreased and had returned to baseline after $45 \mathrm{~min}$. Compared to the butterfat meal, concentrations on the $\mathrm{NH}$-milk meal were higher after $30 \mathrm{~min}(0.92 \pm 0.37$ $\mathrm{mmol} / \mathrm{L} ; \mathrm{P}=0.038), 45 \mathrm{~min}(1.19 \pm 0.37 \mathrm{mmol} / \mathrm{L} ; \mathrm{P}=0.004)$ and $60 \mathrm{~min}(1.01 \pm$ $0.36 \mathrm{mmol} / \mathrm{L} ; \mathrm{P}=0.017)$ and on the $\mathrm{H}$-milk meal after $45 \mathrm{~min}(1.12 \pm 0.37$ $\mathrm{mmol} / \mathrm{L} ; \mathrm{P}=0.008)$. The iAUC tended to be higher after the $\mathrm{NH}$-milk meal as compared to the butterfat meal (Table 6.3, $\mathrm{P}=0.094$ ) and the peak change 
was significantly higher after the $\mathrm{NH}$-milk as compared to the butterfat meal (Table 6.4, $\mathrm{P}=0.004$ ).

Baseline insulin concentrations were not different between the meals $(P=0.548)$. A significant diet-time interaction was found $(P=0.036$; Figure 6.2B). Post-hoc analyses however, did not show any significant differences between the diets at the different time points. Insulin concentrations however tended to be higher 15 min after intake of the butterfat meal as compared to the $\mathrm{H}$-milk meal $(\mathrm{P}=0.062)$, and $30 \mathrm{~min}$ after the butterfat meal as compared to the $\mathrm{NH}$-milk meal $(\mathrm{P}=0.081)$. Other parameters were comparable between the meals (Tables 6.3, 6.4 and 6.5).

Table 6.5: Calculated peak times after H-milk, $\mathrm{NH}$-milk or the butterfat meal

\begin{tabular}{|c|c|c|c|c|c|c|c|c|c|}
\hline \multirow[b]{2}{*}{ TAG, $\min$} & \multicolumn{3}{|c|}{ H-milk } & \multicolumn{3}{|c|}{ NH-milk } & \multicolumn{3}{|c|}{ butterfat } \\
\hline & 247 & \pm & 14.4 & 268 & \pm & 12.7 & 275 & \pm & 17.1 \\
\hline apoB-48, $\min$ & 140 & \pm & $20.6^{\mathrm{A}}$ & 180 & \pm & $23.8^{A B}$ & 210 & \pm & $21.3^{B}$ \\
\hline NEFA, $\min$ & 110 & \pm & 11.1 & 117 & \pm & 3.33 & 117 & \pm & 3.33 \\
\hline glucose, $\min$ & 29.6 & \pm & 3.24 & 31.7 & \pm & 5.44 & 20.3 & \pm & 3.14 \\
\hline insulin, $\min$ & 43.3 & \pm & 3.41 & 36.7 & \pm & 4.24 & 35.8 & \pm & 5.96 \\
\hline IL-6, $\min$ & 340 & \pm & 37.9 & 373 & \pm & 27.2 & 313 & \pm & 41.3 \\
\hline IL-8, $\min$ & 217 & \pm & 40.6 & 187 & \pm & 36.3 & 183 & \pm & 35.5 \\
\hline TNFa, $\min$ & 227 & \pm & 38.1 & 193 & \pm & 35.8 & 243 & \pm & 35.1 \\
\hline sICAM-1, min & 207 & \pm & 38.9 & 167 & \pm & 37.1 & 237 & \pm & 38.0 \\
\hline sVCAM-1, $\min$ & 193 & \pm & 35.8 & 200 & \pm & 40.9 & 237 & \pm & 38.3 \\
\hline WBC, $\min$ & 313 & \pm & 43.3 & 380 & \pm & 45.8 & 303 & \pm & 50.5 \\
\hline neutrophils, $\min$ & 280 & \pm & 43.4 & 300 & \pm & 49.7 & 223 & \pm & 37.8 \\
\hline lymphocytes, $\min$ & 123 & \pm & 26.3 & 107 & \pm & 7.75 & 103 & \pm & 6.52 \\
\hline MAW, $\min$ & 212 & \pm & 49.9 & 184 & \pm & 48.4 & 240 & \pm & 46.0 \\
\hline $\mathrm{MVW}, \min$ & 282 & \pm & 47.1 & 240 & \pm & 46.0 & 311 & \pm & 44.9 \\
\hline $\mathrm{AVr}, \min$ & 219 & \pm & 41.5 & 205 & \pm & 45.8 & 219 & \pm & 38.8 \\
\hline
\end{tabular}

Values with different superscripts differ significantly

\section{White blood cell counts}

Baseline WBC were not different between the meals $(P=0.487)$, but the time courses were $(P=0.040$ for diet time interaction; Figure 6.3A). Two hours after the $\mathrm{H}$-milk meal, WBC counts were significantly higher as compared to the $\mathrm{NH}$-milk meal $\left(0.58 \pm 0.17 \cdot 10^{9}\right.$ cells/L; $\left.P=0.002\right)$. The WBC iAUC was significantly higher $\left(129 \pm 45.9 \cdot 10^{9}\right.$ cells $\cdot \mathrm{min} / \mathrm{L}$; Table $\left.6.3, \mathrm{P}=0.025\right)$ after the $\mathrm{H}$-milk meal as compared to the $\mathrm{NH}$-milk meal.

Baseline and postprandial neutrophil counts (Figure 6.3B) and lymphocyte counts (Figure 6.3C) were not different between the meals. The neutrophil count increased after all meals $(P<0.001)$, whereas the lymphocyte count decreased after all meals $(P<0.001)$. Other parameters for the white blood cells were comparable between the meals (Tables 6.4 and 6.5). 


\section{Inflammatory and endothelial markers}

Baseline plasma IL-6 concentrations were not different between the meals $(P=0.940)$. The time courses of IL-6 concentrations were significantly different between the meals $(P=0.027$ for diet time interaction; Figure 6.4A). IL-6 concentrations were significantly higher after the $\mathrm{H}$-milk meal as compared to the butterfat meal at $\mathrm{T}=120(0.64 \pm 0.24 \mathrm{ng} / \mathrm{L} ; \mathrm{P}=0.026)$ and $\mathrm{T}=480(0.88 \pm$ $0.24 \mathrm{ng} / \mathrm{L} ; \mathrm{P}=0.001)$. Moreover, IL-6 was increased after the $\mathrm{NH}$-milk meal as compared to the butterfat meal at $\mathrm{T}=240(0.60 \pm 0.24 \mathrm{ng} / \mathrm{L} ; \mathrm{P}=0.036)$. These findings were also reflected by the iAUC, which was significantly higher after the $\mathrm{H}$-milk meal than after the butterfat meal (Table 6.3, $\mathrm{P}<0.001$ ).

Baseline plasma concentrations of IL-8 were not different between the meals $(P=0.293)$. The diet time interaction did not reach statistical significance $(P=0.290)$ and the diet effect nearly reached statistical significance $(P=0.051$; Figure 6.4B). IL-8 did not change over time ( $P=0.195)$.

Baseline plasma TNFa concentrations were comparable between the meals $(P=0.982)$ and the diet time interaction term did not reach statistical significance $(P=0.254)$. Concentrations of TNFa were different between the diets $(P=0.01$; Figure 6.4C) and were on average $0.50 \pm 0.16 \mathrm{ng} / \mathrm{L}$ higher after the $\mathrm{NH}$-milk meal as compared to the butterfat meal $(P=0.007)$. As compared to baseline, TNFa was significantly decreased after $120 \mathrm{~min}(-0.42 \pm 0.15$ $\mathrm{ng} / \mathrm{L} ; \mathrm{P}=0.024)$.

Baseline plasma concentrations of sICAM-1 were comparable between the meals $(P=0.591)$ and the diet time interaction term was not significant $(P=0.986$; Figure 6.4D). Concentrations of SICAM-1 changed over time $(\mathrm{P}<0.001)$ and were significantly decreased $2 \mathrm{~h}$ after meal consumption $(-22.1$ $\pm 5.92 \mu \mathrm{g} / \mathrm{L} ; P=0.001)$. No diet effects were found $(P=0.190)$.

Baseline plasma sVCAM-1 concentrations were comparable between the meals $(P=0.444)$ and the diet time interaction term did not reach statistical significance $(P=0.872$; Figure 6.4E). There was a trend for diet effects $(P=0.061)$. Concentrations of sVCAM-1 did not change over time $(P=0.281)$. All other parameters for IL-6, IL-8, TNF $\alpha$, sICAM-1 and sVCAM-1 were comparable between the meals (Tables 6.3, 6.4 and 6.5). 

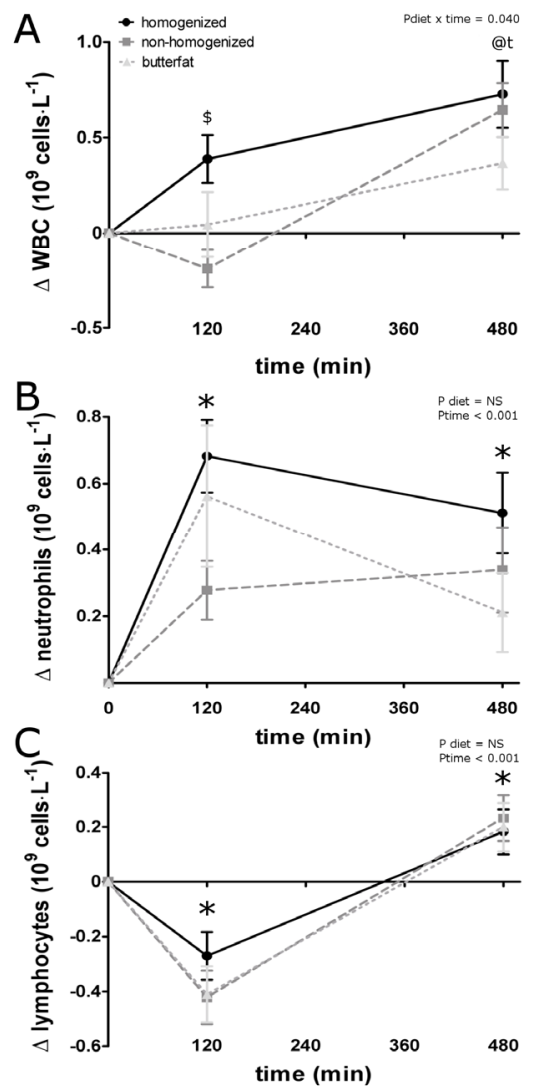

$\Delta$ Figure 6.3: Postprandial changes in plasma WBC (A), neutrophil counts (B), and lymphocyte counts $(C)$ after consumption of the $\mathrm{H}$-milk meal $(\bullet), \mathrm{NH}$-milk meal $(\square)$ and butterfat $(\triangle)$ meal in overweight men. * significantly different compared to baseline. @ within time point $\mathrm{H}$ milk significantly different from butterfat. \$ within time point $\mathrm{H}$-milk significantly different from $\mathrm{NH}$ milk. $\mathrm{P}<0.05$.

- Figure 6.4: Postprandial changes in plasma concentrations of IL-6 (A), IL-8 (B), TNFa (C), sICAM-1 (D) and sVCAM-1 (E) after consumption of the $\mathrm{H}$-milk meal $(\bullet), \mathrm{NH}$-milk meal $(\square)$ and butterfat $(\triangle)$ meal in overweight men. * significantly different compared to baseline. \# within time point $\mathrm{NH}-$ milk significantly different from butterfat. @ within time point $\mathrm{H}$-milk significantly different from butterfat. \$ within time point $\mathrm{H}$-milk significantly different from $\mathrm{NH}-$ milk. $\mathrm{P}<0.05$.
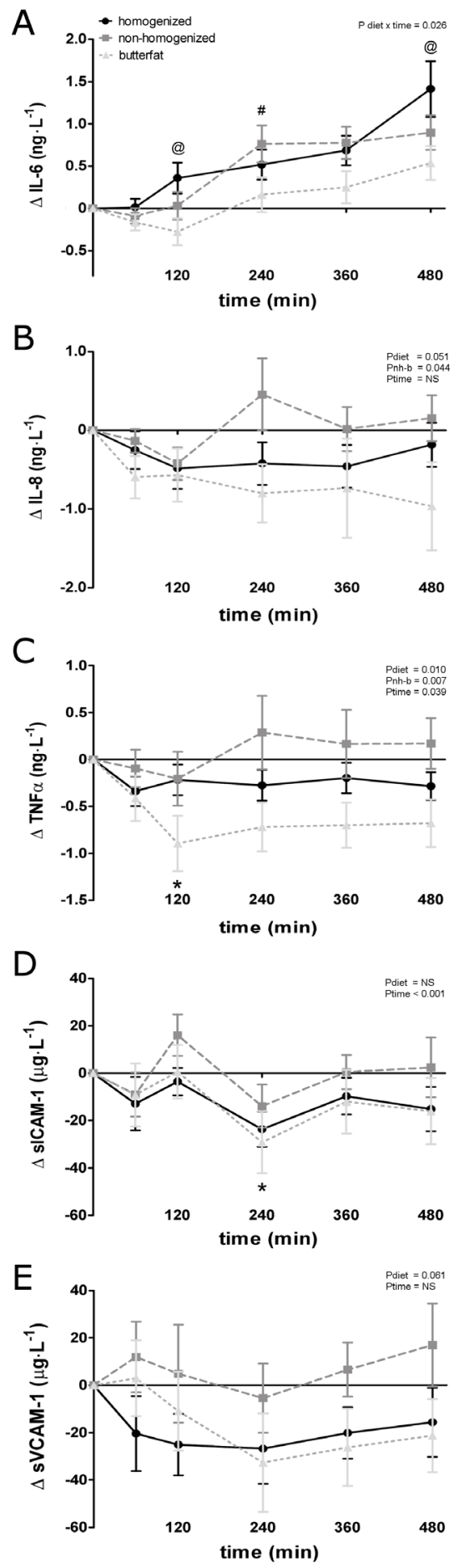


\section{Retinal imaging}

All baseline variables were comparable between the meals $(P>0.05)$. The mean artery width tended to increase over time $(P=0.069$; Figure 6.5A), but was not different between the meals $(P=0.939)$. As compared to baseline, the mean vein width however, was significantly decreased 4 hours after meal consumption $(-1.03 \pm 0.402 \mu \mathrm{m} ; \mathrm{P}=0.024)$, but no differences between the meals were found $(P=0.910$; Figure 6.6B). These changes were also reflected by the AV-ratio, which was significantly increased after 4 hours as compared to baseline $(0.012 \pm 0.004 ; P=0.013)$. No differences in the AV-ratio were found between the meals $(P=0.972$; Figure 6.6C). All other parameters for retinal imaging were comparable between the meals (Tables 6.3, 6.4 and 6.5).

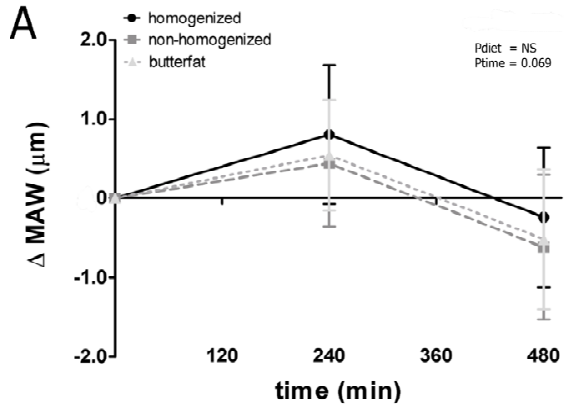

B

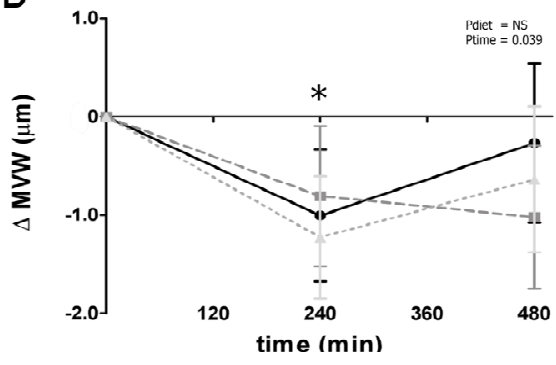

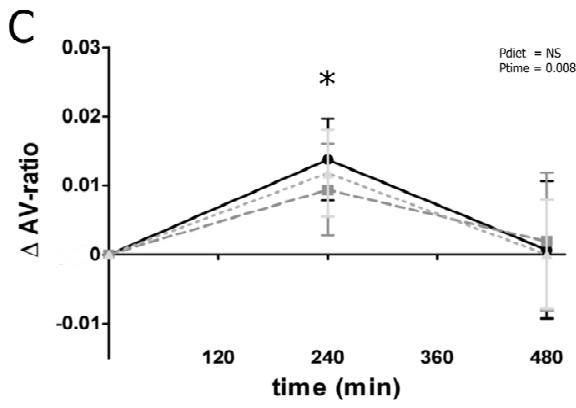

Figure 6.5: Postprandial changes in retinal MAW (A), MVW (B), and AV-ratio (C) after consumption of the $\mathrm{H}$-milk meal $(\bullet), \mathrm{NH}$ milk meal $(\square)$ and butterfat $(\triangle)$ meal in overweight men. * significantly different compared to baseline $(P<0.05)$. 


\section{DISCUSSION}

\section{Postprandial lipemic response}

In this study with overweight men, we found that homogenization of milk did not affect postprandial lipemia. Homogenization decreases milk fat particle size from on average $4 \mu \mathrm{m}$ to $1 \mu \mathrm{m}$ (17), thereby greatly increasing its surface area. It could therefore be speculated that intestinal lipolysis rates of TAG would be higher after $\mathrm{H}$-milk as compared to $\mathrm{NH}$-milk (22) and absorption rates faster. However, increased concentrations of NEFA in the intestine may slow down gastric emptying through the stimulation of cholecystokinin (23). On the other hand, due to homogenization, proteins (mainly casein) attach to the MFGM. This translocation may accelerate digestion and absorption, as in a minipig model the aggregation of casein in the stomach was lower for homogenized pasteurized milk than for raw and untreated milk (24), resulting in an increased gastric emptying rate (25). Michalski et al. (26), however, force-fed rats dairy formulations with milk fat varying in supramolecular structure. As plasma TAG appearance was lower in rats consuming homogenized fat, the authors hypothesized that gastric emptying was slower after homogenized cream. Thus, based on these conflicting findings, it is difficult to predict effects of homogenization on postprandial lipemia. We found no differences in postprandial TAG concentrations or peak times between homogenized and non-homogenized milk. However, TAG concentrations after butterfat were increased as compared to $\mathrm{NH}$-milk. In contrast, Clemente et al. (13) reported in type 2 diabetics increased postprandial TAG concentrations after the consumption of a milk meal as compared to a butter meal (13). In that study, the difference in TAG concentrations between the butter and milk meal was not related to gastric emptying, which was comparable between these meals. However, the source and the type of proteins were different as in the butter meal protein was mainly provided by lean jam and in the milk meal it was provided by milk. Moreover, the jam in the butter meal also provided small part of the fat content, which may have affected the results.

As compared to the H-milk meal, the apoB-48 peak after the butterfat meal was however delayed, which may suggest a delayed absorption of fat from butter into chylomicrons as compared to the two milk meals. Fat in milk is present as small droplets, whereas in butter fat is present as large aggregates, which may have slowed down emulsion and hydrolysis (27). 


\section{Postprandial glycemic response}

Postprandial glucose concentrations were the highest after $\mathrm{NH}$-milk and $\mathrm{H}$ milk as compared to the butterfat meal. These increased glucose concentrations were likely the result of the lower insulin responses after these two meals as compared to the butterfat meal, since carbohydrate contents and sources were comparable between the meals. Why the insulin response was increased following the butterfat meal is not evident. It is known that protein increases insulin responses, but it is unlikely that the additional $2.1 \mathrm{~g}$ of protein in the butter fat meal would have increased the maximum insulin response by $30 \%$.

In contrast to our study, Tholstrup et al. (14) found in lean healthy men that meals rich in either milk, butter or cheese, with similar amounts of lactose and total milk protein as in our study, comparable peak postprandial insulin concentrations after the butter meal and milk meal. Unfortunately, they did not measure insulin at $T=15 \mathrm{~min}$, where we observed the largest difference. It is also possible that the effect is more pronounced in our study population, because our participants were slightly more insulin resistant, as suggested by a higher HOMAir.

\section{Postprandial inflammatory and endothelial response}

Compared to $\mathrm{NH}$-milk, we found a higher iAUC and a higher total count for WBC 2 hours after the intake of the H-milk meal. This effect was not longer evident after 8 hours. Effects were mainly due to increases in neutrophils. This would agree with an earlier postprandial study by van Oostrom et al. (28) after consumption of a glucose meal, a fat meal or a mixed meal. In that study, water consumption had no effects. In two other studies by the same group $(29,30)$, WBC increased after a high-fat meal but not after a water control. In these two latter studies neutrophils increased over time, but changes between the high-fat meal and water control did not reach statistical significance. In one study (29), however, several activation markers of mainly neutrophils were increased after the high-fat meal as compared to the water control. Possibly, activation of neutrophils may be more responsive to meal effects than neutrophil counts. Several studies have suggested that activated neutrophils stimulate the activation of endothelial cells $(31,32)$. Unfortunately we did not measure neutrophil activation markers in our study.

Except for an increased WBC, we did not observe any differences between the H-milk and the NH-milk meal in TNFa, IL-6, IL-8, sICAM-1 and sVCAM-1 and measures of the retinal vasculature, suggesting that the homogenization of milk does not markedly affect inflammatory and vascular responses directly after meal consumption. We did however find consistently lower concentrations of IL- 6 and TNFa when fat was presented as butter, suggesting 
that the structure of fat in the meal is important. Noteworthy, the butterfat meal showed the highest TAG response. Whether these findings suggest that postprandial TAG may not stimulate the release of plasma inflammatory markers is not known. Several studies have shown that postprandial lipemia correlates with inflammation $(28,33)$, but a causal effect of postprandial TAG on the release of inflammatory markers has not been established in vivo.

Since cytokines, i.e. mainly IL-6 and IL-8, are responsible for the recruitment of WBC $(28,34)$, we examined whether iAUCs of cytokine concentrations were correlated to those of total WBC, neutrophil and lymphocyte counts. However, no significant relationships were found (data not shown).

Except for a small decrease in retinal vein width and a small increase in the AV-ratio over time, we did not find any differences between the meals in the retinal vasculature. As far as we know, we are the first to study the postprandial retinal vascular responses. Unfortunately, we cannot discriminate whether the measured responses are a result of the fat load consumed or due to circadian variation. More research is therefore warranted to establish the response of the retinal vasculature after a high-fat meal.

\section{Conclusion}

The findings of our study do not indicate a major role for homogenization of milk on the acute postprandial responses of lipids, inflammatory markers, endothelial markers and measures of the retinal vasculature. We did however find clear - potentially beneficial and unbeneficial - differences when fat was consumed as butter. To what extent these findings can be extrapolated to the longer-term and translate into health effects warrants further investigation. 


\section{REFERENCES}

1. Thomsen C, Storm H, Holst JJ, Hermansen K. Differential effects of saturated and monounsaturated fats on postprandial lipemia and glucagon-like peptide 1 responses in patients with type 2 diabetes. Am J Clin Nutr 2003;77:605-11.

2. Bansal S, Buring JE, Rifai N, Mora S, Sacks FM, Ridker PM. Fasting compared with nonfasting triglycerides and risk of cardiovascular events in women. JAMA 2007;298:309-16.

3. Patsch JR, Miesenbock G, Hopferwieser T, et al. Relation of triglyceride metabolism and coronary artery disease. Studies in the postprandial state. Arterioscler Thromb 1992;12:1336-45.

4. Nordestgaard BG, Benn M, Schnohr P, Tybjaerg-Hansen A. Nonfasting triglycerides and risk of myocardial infarction, ischemic heart disease, and death in men and women. JAMA 2007;298:299-308.

5. Burdge GC, Calder PC. Plasma cytokine response during the postprandial period: a potential causal process in vascular disease? Br J Nutr 2005;93:3-9.

6. Thomsen C, Rasmussen O, Lousen T, et al. Differential effects of saturated and monounsaturated fatty acids on postprandial lipemia and incretin responses in healthy subjects. Am J Clin Nutr 1999;69:1135-43.

7. Mekki N, Charbonnier M, Borel P, et al. Butter differs from olive oil and sunflower oil in its effects on postprandial lipemia and triacylglycerol-rich lipoproteins after single mixed meals in healthy young men. J Nutr 2002;132:3642-9.

8. Sauvant P, Mekki N, Charbonnier M, Portugal H, Lairon D, Borel P. Amounts and types of fatty acids in meals affect the pattern of retinoids secreted in human chylomicrons after a high-dose preformed vitamin A intake. Metabolism 2003;52:514-9.

9. Nielsen NS, Marckmann P, Hoy C. Effect of meal fat quality on oxidation resistance of postprandial VLDL and LDL particles and plasma triacylglycerol level. $\mathrm{Br} \mathrm{J}$ Nutr 2000;84:855-63.

10. Oakley FR, Sanders TA, Miller GJ. Postprandial effects of an oleic acid-rich oil compared with butter on clotting factor VII and fibrinolysis in healthy men. Am J Clin Nutr 1998;68:1202-7.

11. O'Dea K, Nestel PJ, Antonoff L. Physical factors influencing postprandial glucose and insulin responses to starch. Am J Clin Nutr 1980;33:760-5.

12. Bjorck I, Granfeldt Y, Liljeberg H, Tovar J, Asp NG. Food properties affecting the digestion and absorption of carbohydrates. Am J Clin Nutr 1994;59:699S-705S.

13. Clemente G, Mancini M, Nazzaro F, et al. Effects of different dairy products on postprandial lipemia. Nutr Metab Cardiovasc Dis 2003;13:377-83.

14. Tholstrup T, Hoy CE, Andersen LN, Christensen RD, Sandstrom B. Does fat in milk, butter and cheese affect blood lipids and cholesterol differently? J Am Coll Nutr 2004;23:169-76.

15. Lewis GF, O'Meara NM, Soltys PA, et al. Fasting hypertriglyceridemia in noninsulindependent diabetes mellitus is an important predictor of postprandial lipid and lipoprotein abnormalities. J Clin Endocrinol Metab 1991;72:934-44.

16. O'Meara NM, Lewis GF, Cabana VG, Iverius PH, Getz GS, Polonsky KS. Role of basal triglyceride and high density lipoprotein in determination of postprandial lipid and lipoprotein responses. J Clin Endocrinol Metab 1992;75:465-71.

17. Michalski MC. On the supposed influence of milk homogenization on the risk of CVD, diabetes and allergy. Br J Nutr 2007;97:598-610.

18. Oster KA, Oster JB, Ross DJ. Immune response to bovine xanthine oxidase in atherosclerotic patients. Am Lab 1974;Aug:41-47.

19. Behandeling en preventie van coronaire hartziekten door verlaging van de plasma cholesterolconcentratie. (Treatment and prevention of coronary heart disease by lowering plasma cholesterol concentrations.). Utrecht, Netherlands. Centraal begeleidingsorgaan voor de intercollegiale toetsing 1998 (in Dutch).

20. Westenbrink S, Jansen-van der Vliet M, Brants HAM, et al., eds. NEVO-tabel 2006 Nederlands voedingsstoffenbestand. 2006 ed. Zeist: NEVO, 2006.

21. Stewart CV, Tsai CL, Roysam B. The dual-bootstrap iterative closest point algorithm with application to retinal image registration. IEEE Trans Med Imaging 2003;22:137994. 
22. Armand $\mathrm{M}$, Pasquier $\mathrm{B}$, Andre $\mathrm{M}$, et al. Digestion and absorption of 2 fat emulsions with different droplet sizes in the human digestive tract. Am J Clin Nutr 1999;70:1096-106.

23. Borel $\mathrm{P}$, Armand $\mathrm{M}$, Pasquier B, et al. Digestion and absorption of tube-feeding emulsions with different droplet sizes and compositions in the rat. JPEN J Parenter Enteral Nutr 1994;18:534-43.

24. Buchheim W. Zum Einfluss unterschiedlicher technologischer Behandlung von Milch auf die Verdauungsvorgange im Magen. IV. Elektronenmikroskopische Charakterisierung des Koagulums und lipolytischer Vorgange im Magen. (Influence of different technological treatments of milk on digestion in the stomach. IV. Electron microscopic characterization of the coagulum and of lipolytic processes in the stomach). Milchwissenschaft 1984;39:271-275.

25. Meisel H, Hagemeister $\mathrm{H}$. Zum Einfluss unterschiedlicher technologischer Behandlung von Milch auf die Verdauungsvorgange im Magen. II. Magenpassage verschiedener Milchinhaltsstoffe. (Influence of different technological treatments of milk on digestion in the stomach. II. Gastric passage of different milk constituents). Milchwissenschaft 1984;39:262-266.

26. Michalski MC, Soares AF, Lopez C, Leconte N, Briard V, Geloen A. The supramolecular structure of milk fat influences plasma triacylglycerols and fatty acid profile in the rat. Eur J Nutr 2006;45:215-24.

27. German J, Dillard C. Fractionated milk fat: composition, structure, and functional properties. Food Technol 1998;52:33.

28. van Oostrom AJ, Sijmonsma TP, Verseyden C, et al. Postprandial recruitment of neutrophils may contribute to endothelial dysfunction. J Lipid Res 2003;44:576-83.

29. van Oostrom AJ, Rabelink TJ, Verseyden C, et al. Activation of leukocytes by postprandial lipemia in healthy volunteers. Atherosclerosis 2004;177:175-82.

30. Van Oostrom AJ, Sijmonsma TP, Rabelink TJ, Van Asbeck BS, Cabezas MC. Postprandial leukocyte increase in healthy subjects. Metabolism 2003;52:199-202.

31. Schratzberger P, Dunzendorfer S, Reinisch N, Kahler CM, Herold M, Wiedermann CJ. Release of chemoattractants for human monocytes from endothelial cells by interaction with neutrophils. Cardiovasc Res 1998;38:516-21.

32. Bae JH, Bassenge $\mathrm{E}, \mathrm{Kim} \mathrm{KB}$, et al. Postprandial hypertriglyceridemia impairs endothelial function by enhanced oxidant stress. Atherosclerosis 2001;155:517-23.

33. Nappo F, Esposito K, Cioffi M, et al. Postprandial endothelial activation in healthy subjects and in type 2 diabetic patients: role of fat and carbohydrate meals. J Am Coll Cardiol 2002;39:1145-50.

34. van Wijk JP, Cabezas MC, Coll B, Joven J, Rabelink TJ, de Koning EJ. Effects of rosiglitazone on postprandial leukocytes and cytokines in type 2 diabetes. Atherosclerosis 2006;186:152-9. 



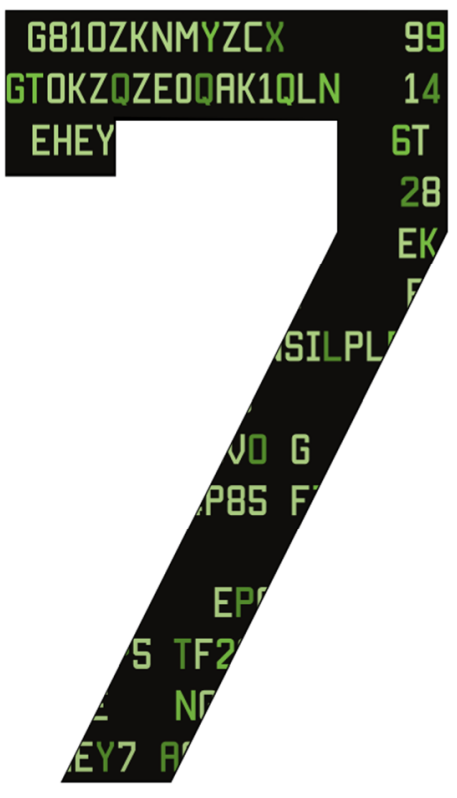

GENERAL DISCUSSION 


\section{INTRODUCTION}

Cardiovascular disease (CVD) is one of the main causes of death worldwide. Considering that the global incidence of obesity and the metabolic syndrome, major risk factors for developing $\operatorname{CVD}(1,2)$ is rising at an alarming rate $(3,4)$, researchers from many different disciplines aim to increase our understanding of the causes and progression of these conditions, and on possible intervention strategies to prevent or even cure their clinical manifestations. One important approach is to focus on lifestyle intervention strategies, including nutritional interventions.

Several observational studies have suggested that an increased intake of dairy products may be related to a decreased risk for developing the metabolic syndrome, CVD and type 2 diabetes mellitus (5-11). This relationship may not be restricted to low-fat dairy products alone (6-8). Dairy products may therefore have added value in the development of dietary intervention strategies. However, data from intervention studies is scarce. Further, most intervention studies have been performed in the fasted state and only a few studies have investigated postprandial responses. As most people in the Western world consume on average at least three meals per day and postprandial metabolic processing may take up to 8 hours, most time of the day is spent in a postprandial state. Therefore, the studies described in this thesis were designed to increase our understanding of the effects of dairy products, their components and their food matrix on postprandial metabolic risk markers for CVD.

\section{DAIRY CONSUMPTION AND METABOLIC SYNDROME AND CVD}

Several cross-sectional epidemiological studies have related the intake of dairy products to the incidence of the metabolic syndrome or its characteristics and to the risk to develop CVD. A cross-sectional study in 827 Tehranian men and women ranging from 18-74 y showed that subjects within the highest quartile of dairy intake, comprising of milk, yogurt and cheese, had significantly reduced odds ratios (OR) for developing the metabolic syndrome or hypertension or an increased waist circumference, as compared to those within the lowest quartile of dairy intake (5). ORs weakened after adjustment for calcium intake, but remained statistically significant. It should be noted however, that it is hard to differentiate between calcium intake and dairy intake, since dairy products were the main calcium source in the diet. Comparable results were found in a population-based prospective study in 3157 young black and white adults, showing that overweight individuals with $\geq 35$ dairy servings per week had a $79 \%$ lower chance of developing the metabolic syndrome as compared to individuals with $<10$ servings per week 
(6). Furthermore, in two studies in middle-aged men, ORs for developing the metabolic syndrome were significantly decreased in the highest quintile (7) or quartile (8) of total dairy intake as compared to the lowest ones. ORs for the metabolic syndrome decreased with increased dairy intake, regardless of the dairy products consumed (6-8). Moreover, decreased risks for developing the metabolic syndrome were found in several recent observational studies (1215), whereas in 3 studies no association was found for total dairy intake (1618). In contrast, in some studies ORs for high-fat dairy products were slightly higher than those for low-fat dairy products $(6,8)$, whereas in one study (18) only full-fat dairy was inversely associated with the risk for developing the metabolic syndrome, whereas low-fat dairy was not.

Regarding CVD, total dairy consumption was inversely associated with mortality in Japanese women (19) and with the incidence of myocardial infarction (20), whereas in a recent meta-analysis only milk, but not total dairy consumption, modestly decreased the relative risk for CVD (21). On the other hand, 3 other observational studies found that total dairy intake was not related to CVD incidence (22) or CVD mortality $(23,24)$, whereas full-fat dairy was beneficial $(24,25)$ or harmful $(23)$. Finally, relative risks $(9,10)$ for type 2 diabetes or acute coronary syndrome (11) decreased only with low-fat dairy products.

Even though several of the earlier studies $(5-8,12-15,18)$ have indicated a relation between an increased dairy intake and a decreased incidence of the metabolic syndrome, causal effects can only be derived from intervention studies. Furthermore, regarding the fatty-acid composition of high-fat dairy products, these presumed beneficial effects might be surprising. Therefore, we aimed to increase our understanding of dairy products and some of its characteristics on postprandial metabolism.

\section{ABSORPTION OF CHOLESTEROL AND FATTY ACIDS}

Although an increased consumption of high-fat dairy products may be related to a decreased incidence of metabolic syndrome, these products contain relatively large amounts of cholesterol and saturated fatty acids, which are well known for their detrimental effects on the serum lipoprotein profile. As compared to polyunsaturated fatty acids, saturated fatty acids may increase the serum triacylglycerol (TAG) response after a meal (26) and increase LDL cholesterol concentrations by down-regulation of LDL-receptor mediated catabolism $(27,28)$, which may ultimately increase the risk of cardiovascular disease $(29,30)$.

Short-chain ( $<6$ carbon atoms (C)) and medium-chain (6-12 C) fatty acids are absorbed passively in the intestine and released directly from the intestinal 
capillaries into the portal circulation, which does not result into a lipemic response. In contrast, long-chain (13-20 C; LCFA) and very long-chain (>20 C) fatty acids are at least partially absorbed actively by specific fatty acid transport proteins, including Fatty Acid Transport Protein-4 (FATP-4), Fatty Acid Translocase (FAT)/CD36 and plasma membrane-bound Fatty Acid Binding Protein (FABPpm), and incorporated into chylomicrons, which are released into the vena subclavia via lymphatic vessels, thereby eliciting a lipemic response. Dietary cholesterol, on the other hand, is absorbed passively, actively by Niemann-Pick C1 like 1 (NPC1L1), or excreted back into the intestinal lumen by ATP Binding Cassette G5 (ABCG5) and G8 (ABCG8). Adenosine-triphosphate (ATP) binding cassette $A 1$ (ABCA1) mediates the efflux of cellular cholesterol into lipid-poor apolipoproteins to form nascent HDL. Concerning the metabolic syndrome, there is an ongoing discussion whether these patients are characterized by elevated and/or accelerated intestinal cholesterol absorption or not, since subjects can be characterized as cholesterol absorbers (with a low cholesterol synthesis) or as cholesterol synthesizers (with a low cholesterol absorption) (31). It has been suggested that subjects with the metabolic syndrome are rather cholesterol synthesizers than absorbers (32).

Lipoprotein metabolism is often disturbed in the metabolic syndrome and cholesterol and LCFA transporter levels in the intestine may play a pivotal role. However, since no data was available in humans, we measured the distribution patterns of the most important transport proteins involved in the uptake of cholesterol and LCFA along the human duodenal-colonic axis in human post-mortem intestinal biopsies (chapter 3).

A study in rats (33) suggested that when cholesterol was administered in crystallized form it was absorbed proximally, whereas in an oil phase, which is more similar to micelles in the human situation, uptake occurred more distally. On the other hand, patients undergoing Roux-en-Y gastric bypass surgery showed a significant decrease in cholesterol uptake (34). However, since cholesterol uptake was not completely abolished, it can be concluded that also the more distal segments could absorb cholesterol. Moreover, several in vivo studies in pigs (35-37) have shown that cholesterol uptake predominantly occurred in the jejunum. Therefore, we expected to find the highest levels of transporters in the proximal intestine.

We found for the transport proteins NPC1L1, ABCA1, ABCG8, FAT/CD36 and FABPpm the highest protein levels in the ileum. For ABCG5 and FATP-4, levels were comparable in all segments. Noteworthy, we also found a significant amount of transporters in the colon. Our findings therefore indicate that the ileum plays an important role in transporter-mediated uptake of both cholesterol and LCFA, especially when considering its large surface area as 
compared to that of the duodenum and colon. In one study, transporter protein levels were studied in intestinal biopsies, which were derived from healthy subjects and from patients with Crohn's disease. Samples were pooled and the highest protein levels were found in the jejunum (38). Crohn's Disease patients, however, often display decreased cholesterol uptake with a compensatory increase in cholesterol synthesis $(39,40)$, which may affect the distribution of transporters over the intestinal tract and explain the difference with our study. When membrane proteins were separated from the total lysates, FA transport proteins were found only in the proximal intestine (41, 42). However, if total cell lysates were analyzed as in our study, FA transport proteins were also found in the ileum and colon (43-45). Thus, the transport proteins may not be solely bound to the brush border membrane, but may also be stored within cells and used depending on nutritional needs. In support, meal composition has previously been shown to affect transporter mRNA levels $(42,46)$.

The relatively high levels of transporter proteins in more distal segments in our study may be explained by the relatively low intraluminal availability of cholesterol and LCFA in these segments. Levels are relatively the highest in the duodenum, and fatty acids and cholesterol can easily be absorbed by the relevant transport proteins. Also, passive diffusion of FA is more likely to occur. More distally, cholesterol and FA bioavailability is lower and more transport proteins may be required to achieve the required uptake of cholesterol and FA.

\section{Conclusions on absorption of fatty acids and cholesterol}

Based on the distribution patterns and segmental surface areas, the most important site for transporter-mediated uptake of cholesterol and fatty acids in humans is probably the ileum. However, the uptake of these nutrients may not be restricted to this segment alone. As a matter of fact, transporter proteins were found in all segments, even in colon. It should be considered however, that our protein data only covers the active uptake and not the passive absorption, which may be higher in the proximal intestine due to higher bioavailability. Also, protein activity and functionality were not studied.

\section{POSTPRANDIAL LIPEMIA}

After absorption, the long-chain and very long-chain fatty acids are reesterified into TAG and incorporated into apolipoprotein B-48-rich chylomicrons in the intestine. While these chylomicrons travel towards the liver, the TAG content is hydrolyzed by lipoprotein lipase (LPL) and the released fatty acids are delivered either as energy source to fat-utilizing 
tissues, or to fat-storing tissues, where these fatty acids are re-esterified into TAG. Hydrolysis, in combination with exchange of TAG between chylomicrons and the free fatty acid pool, leads to the formation of chylomicron remnants, which are removed from the circulation mainly by the chylomicron-remnant receptor and LDL receptor-related protein (LRP) (47-49). Several studies have shown a positive correlation between the level and duration of postprandial lipemia and CVD. In addition, patients with the metabolic syndrome often show an increased lipemic response (50-53).

There are numerous factors that determine the level of postprandial lipemia. Obviously, dietary fatty acids are a prerequisite for a postprandial lipemic response and fat-related determinants of lipemia include the amount of fat and the fatty-acid composition, e.g. chain length, degree of saturation, TAG structure, and solid fat content.

\section{Effects of fatty acid type on postprandial lipemia}

Because of the proposed relation of dairy consumption with CVD and the metabolic syndrome, it is important to know how lipemic responses of dairy fat compare to those of other fats and oils. This is unclear, as both increased and decreased postprandial lipemic responses have been found after butterfat as compared to for example oils rich in linoleic acid $(54,55)$, which is one of the most common substitutes for saturated fats in the diet. Since in the latter studies test fats were consumed as a spread or were added to tomato sauce (54) or soup (55), the differences in postprandial lipemic responses were probably not merely due to the difference in type of fatty acid consumed, but were also affected by the solid fat content due to the difference in temperature. Therefore, we compared in overweight men the postprandial lipemic responses after the consumption of isoenergetic muffins containing butter or margarine (chapter 4). Although the solid fat content still varied between the products as butter has a higher melting point than margarine, the fats were provided in a typical food matrix.

We found a comparable iAUC for serum TAG between the meals. However, peak time was significantly delayed and the iAUC in the late postprandial phase was significantly higher after butterfat. It should be noted however that the lipemic response is a resultant of absorption and clearance and it was therefore not possible to identify which of these two processes was affected. The comparable apoB-48 response suggested that the number of chylomicrons released was comparable between the fats, but chylomicron size may have differed between meals, as in rats larger chylomicrons were found after safflower oil as compared to coconut oil (56). As large chylomicrons are cleared faster from the circulation than small chylomicrons and increased LPL-activity was found after linoleic acid as compared to 
palmitic and stearic acids (57), the clearance rate after (n-6) PUFA intake may have been increased. It remains unclear whether also the absorption was different between the meals.

\section{Effects of the food matrix on postprandial lipemia}

As the physical structure of carbohydrate-rich foods affects postprandial responses $(58,59)$, this may also be true for fat-rich foods. Several studies have been performed comparing postprandial lipemic responses to different fats $(54,55)$ or to different dairy products $(60)$, without adequately accounting for differences in the food matrix. Regarding possible effects of the food matrix of dairy products, there has been a lot of discussion whether homogenization of milk is unhealthy or not. Homogenized milk is characterized by smaller fat globules in the emulsion and alterations in the structure of the milk fat globule membrane (MFGM) (61). Whether consumption of homogenized milk alters postprandial responses as compared to non-homogenized milk has never been studied in humans. Therefore, we compared in overweight men side-byside the effects of homogenized milk, non-homogenized (unprocessed) milk and butterfat (chapter 6). We found no differences in postprandial TAG concentrations or peak times between homogenized and non-homogenized milk, despite the difference in fat structure due to homogenization. Based on changes in TAG, apolipoprotein B-48 and non-esterified fatty acid concentrations, we found no evidence for faster digestion, absorption or intestinal lipolysis rates due to the increased surface area of the fat droplets and alterations to the MFGM, as suggested by a minipig model (62). Unfortunately, since we did not measure gastric emptying, a decrease in this parameter after homogenized milk intake as suggested from a rat study (63) could not be confirmed.

After butterfat, TAG concentrations were increased as compared to $\mathrm{NH}$-milk, which was accompanied by a trend for delayed apolipoprotein B-48 peak concentrations. This suggests a delayed absorption and incorporation of fat from butter into chylomicrons as compared to the two milk meals, which may be explained by the fat structure. In milk, fat is present as small droplets, whereas in butter it is present as large aggregates, which may have slowed down emulsion and hydrolysis (64). In contrast, in type 2 diabetics increased postprandial TAG concentrations after the consumption of a milk meal as compared to a butter meal (60) were found. In that study, the difference in TAG concentrations between the meals was not related to gastric emptying. In this study (60) however, a high-protein jam was added to the butter meal in order to match the protein contents between the meals. Unfortunately, the types of proteins in the jam were not specified. Arguably, these proteins may have resulted in a higher insulinemic response as different proteins or amino 
acid mixtures have been shown to affect insulin responses differently (65). This increased insulinemic response may have resulted in the rerouting of free fatty acids from the liver towards adipose tissue, which may have downregulated hepatic VLDL synthesis.

\section{Conclusions on postprandial lipemia}

Despite many studies, effects of dairy fat on postprandial lipemia are inconclusive. As compared to margarine, we found that butter did not affect the iAUC of lipemia nor the peak concentrations, but the peak time was delayed. However, since the TAG response is the resultant of both absorption and clearance, differences in one process may level off differences in the other, but this could not be determined from our study. Furthermore, it is clear that the food matrix affects postprandial lipemia as we found increased postprandial TAG concentrations and also a delayed response as indicated by apoB-48 concentrations after butter as compared to $\mathrm{NH}$-milk. This indicates that the food matrix may be an important confounder when comparing trials studying the effects of fats on postprandial metabolism.

\section{POSTPRANDIAL INFLAMMATION AND ENDOTHELIAL ACTIVA- TION}

The metabolic syndrome is characterized by a low-grade fasting inflammatory state (66) and atherosclerosis is also categorized as an inflammatory disease. As the processes involved in the development of atherosclerosis also occur postprandially, nutrition may play a crucial role in modulating the responses. However, little is known on the effects of dietary composition and the food matrix on markers of low-grade systemic inflammation and endothelial activation, which are both involved in the process of atherosclerosis (67).

\section{Effects of fatty acid type on postprandial inflammatory markers and endothelial activation}

Exchanging saturated fatty acids for (n-6) PUFA in overweight men resulted in decreased interleukin (IL)-6, tumor necrosis factor (TNF)a, soluble TNF receptor 2 and decreased concentrations of SVCAM-1. On the other hand, no differences in IL- 6 were found in lean and obese women when SFA was exchanged for MUFA or (n-6) PUFA (68). Possibly, these inconsistencies may be explained by gender differences and the dissimilarity in linoleic acid content of the meals between our study (3\% vs. $33 \%$ of total fatty acids) and their study (4\% vs. $19 \%$ ) (68). A comparable reduction in TNFa concentrations was found in abdominally obese men (69), and in both men and women covering 
a broad range of adiposity (70) after consuming a high-fat meal. The lack of a clear description of the study meals, however $(69,70)$, makes it difficult to relate these results to our findings. On the other hand, when healthy participants and type 2 diabetic patients consumed a test meal rich in SFA and MUFA (71), a time-dependent increase in TNF $\alpha$ concentrations was found. An increase in TNF $\alpha$ after SFA could not be confirmed in our study. Of course, study populations differed and unfortunately in that study no meal with (n-6) PUFA was included.

Although sICAM-1 and SVCAM-1 concentrations did not change over time, we found a meal-dependent reduction in SVCAM-1 concentrations and a trend for lower sICAM-1 concentrations after margarine. In contrast, several other studies with healthy participants, type 2 diabetic patients and hyperlipidemic participants found postprandial increases after fat loads mainly providing SFA (71-73), whereas others found no responses after a mixed meal with mainly SFA and MUFA (74) or even found decreased concentrations in premature CHD patients and healthy controls (75) or mildly obese men (76) after a highfat meal with MUFA or (n-6) PUFA. Clearly, large differences exist in postprandial sICAM-1 and SVCAM-1 responses, which indicates very large between-subject variations.

Thus, our findings indicate that exchanging SFA from butterfat for ( $n-6)$ PUFA in a mixed meal affects several postprandial markers of inflammation and endothelial activation in overweight men, but the impact of these findings for other population groups and on long-term health remains to be elucidated.

\section{Effects of dairy constituents on postprandial inflammatory markers and endothelial activation}

Because of the possible relation between dairy consumption and CVD and the metabolic syndrome, it may be hypothesized that dairy products contain constituents that negate the potential deleterious effects of SFA and cholesterol. In a recent cross-sectional survey, it was found that fasting concentrations of C-reactive protein (CRP), IL-6 and TNF $\alpha$ were reduced, when low-fat dairy intake increased from less than 8 servings per week to between 11 and 14 servings, or more than 14 servings per week (77). For fullfat dairy, the differences in IL- 6 and TNFa were less significant, but still present. Moreover, in an intervention study with overweight and obese subjects (78), the consumption of a dairy-based smoothie 3 times per day for 28 days significantly reduced fasting serum CRP, IL-6, TNF $\alpha$ and monocyte chemoattractant protein-1 (MCP-1) concentrations and oxidative stress as compared to consumption of an isocaloric soy-based smoothie with a comparable macronutrient composition. Which constituents were responsible 
for the effects observed remained unclear, since the experimental products differed not only in the source of protein, but also in calcium content.

The aim of the last study was to identify the constituents from dairy that may modulate postprandial inflammatory and endothelial responses (chapter 5). For this, overweight men consumed at four different occasions butter cake with either water, water with calcium, water with calcium and total milk protein, or milk. We found that both the milk meal and the protein meal reduced sICAM-1 and SVCAM-1 concentrations as compared to the other meals, whereas TNF $\alpha$ concentrations were decreased after the control meal as compared to the other meals. Despite an increase over time, IL-6 and IL-8 concentrations were not different between the meals.

No differences in 3h-postprandial IL-6 and TNFa responses were found when overweight subjects consumed single meals consisting of $50 \mathrm{~g}$ butter, $115 \mathrm{~mL}$ cream, $110 \mathrm{~g}$ cheese, $600 \mathrm{~mL}$ yogurt or $400 \mathrm{~mL}$ reduced fat milk (79). In accordance, Pal et al. (80) found that postprandial IL-6 and TNFa were not differently affected when overweight postmenopausal women consumed a standardized breakfast supplemented with either $45 \mathrm{~g}$ sodium casein isolate, $45 \mathrm{~g}$ whey protein isolate, or $45 \mathrm{~g}$ glucose. The results of these studies (79, $80)$ are difficult to compare with our study due to differences in study design. $\mathrm{Pal}$ et al. (80) compared the effects of exchanging glucose for two different protein sources to a standardized breakfast with an equal fat content, while in our study we used a water control. Moreover, Nestel et al. (79) compared different dairy products with each other and to a low-fat control meal, whereas we compared it to a breakfast with equal fat content.

We found that the consumption of the control and calcium meals caused a small increase in plasma sICAM-1 and sVCAM-1 over time, whereas adding milk or milk protein to the high-fat breakfast reduced concentrations of SICAM1 and sVCAM- 1 up to $2 \mathrm{~h}$ after meal consumption, which may indicate that mainly milk protein is responsible for the reductions found in adhesion molecules. Since a strong correlation between insulin responses and SICAM1 has been shown (74), protein may decrease sICAM-1 through insulin stimulation, but we did not find such a correlation.

It must be noted however, that milk protein was ingested together with calcium, so the effects of milk protein may be dependent on the presence of calcium. However, since milk tended to induce even larger reductions in adhesion molecules, other nutrients may be involved as well. Arguably, the complex dairy matrix may also have modulated the effects of the individual constituents. Our data indicate that consuming $500 \mathrm{~mL}$ of skimmed milk or a milk protein drink with a high-fat meal may increase concentrations of TNFa in overweight men. On the other hand, postprandial responses of sICAM-1 
and SVCAM-1 may be improved by consuming milk, which may be partially, but not solely, attributable to the protein fraction.

\section{Effects of the food matrix on postprandial inflammatory markers and endothelial activation}

In order to test for possible effects of the food matrix on postprandial inflammatory and endothelial responses, we compared meals containing homogenized milk, non-homogenized (unprocessed) milk and butterfat (chapter 6). These meals only differed in fat structure. As already stated, fat in butter is present as large aggregates, whereas fat in unprocessed milk is present as relatively large droplets. Due to homogenization and pasteurization fat droplets decrease in size, which results in major changes in the composition of the milk fat globule membrane (MFGM), which has been postulated to increase vascular damage by an increased endothelial presence of several oxidation-inducing proteins, e.g. bovine xanthine oxidase (81). Effects of homogenization on postprandial inflammatory markers and endothelial activation have never been tested before.

We found that homogenization of milk increased the iAUC and total count of white blood cells, which was mainly due to increases in neutrophils. Changes in neutrophils however, were not statistically different between the meals. As activation markers of mainly neutrophils were increased after a high-fat meal as compared to a water control in one study (82), it may be that the activation of neutrophils may be more responsive to meal effects than neutrophil counts. Moreover, several studies have suggested that activated neutrophils stimulate the activation of endothelial cells $(83,84)$. Unfortunately, we did not measure neutrophil activation markers.

On the other hand, markers of inflammation and endothelial activation, and measures of the retinal vasculature were not affected by homogenization. We did however find consistently lower concentrations of IL- 6 and TNFa, when fat was presented as butter, suggesting that the structure of fat in the meal is important. Changes in these markers did not correlate with postprandial TAG concentrations. Whether this suggests that postprandial TAG may not stimulate the release of plasma inflammatory markers is not known. Although correlations between lipemia and inflammation have been found $(71,85)$, causality has not been established in vivo.

Altogether, these findings do not indicate a major role for homogenization of milk on the acute postprandial responses of inflammatory markers and endothelial activation. 


\section{Conclusions on postprandial inflammation and endothelial activation}

Our findings clearly indicate a role for food composition in modulating postprandial inflammatory and endothelial responses, as exchanging SFA from butterfat for (n-6) PUFA decreased several postprandial markers of inflammation and endothelial activation in overweight men. We also found that the major dairy constituents differently affected postprandial inflammatory and endothelial responses, with possibly beneficial effects of dairy protein on adhesion molecules. An important role for the food matrix was found, as butter affected these responses differently from milk. Homogenization however, did not elicit major changes in postprandial inflammatory and endothelial responses.

Despite the presence of several studies addressing differences in inflammatory and endothelial markers between different fatty acids and various dairy products, the large differences in study populations and test meal compositions makes it difficult to compare the results and warrants the implementation of a standardized study protocol for postprandial tests.

\section{GENERAL CONCLUSIONS}

Although an inverse association between dairy intake and the metabolic syndrome and CVD has been shown in several observational studies, causal relations cannot be derived from these studies. In our intervention studies we aimed to increase our understanding and establish possible effects of dairy fat, protein, calcium and also of the food matrix of dairy products on postprandial responses.

We found that the transporter-mediated absorption of fatty acids and cholesterol in humans may predominantly take place in the ileum, but may also take place in the other segments. It should be considered however, that also passive uptake of LCFA occurs, which may be higher in the proximal intestine due to its higher bioavailability.

Regarding dairy products, we showed that exchanging SFA from butterfat for (n-6) PUFA improved postprandial lipemia and inflammatory and endothelial responses. We also showed that especially dairy protein may improve postprandial adhesion molecules and that the food matrix is an important determinant of postprandial lipemia, inflammation and endothelial activation.

\section{FUTURE DIRECTIONS}

In our studies we focused on the acute effects. Future studies should therefore be undertaken, in which postprandial responses are compared when dairy fat 
is consumed in different food matrices over a longer period of time, for instance a few weeks. Also, since our results indicated that milk differently affected postprandial responses when compared to a mixture of calcium and milk protein, other dairy constituents may be important as well. Future studies should try to define if this assumption is true and try to determine these constituents. As low-fat dairy products may be part of a diet to prevent the metabolic syndrome, it is also important to understand underlying mechanisms. As we performed our tests in a population at risk for the metabolic syndrome and CVD, it would also be interesting to study effects of dairy in subjects who already have developed the metabolic syndrome or CVD, in order to see if dairy products may slow down the progression or even regress the clinical manifestations of these conditions. 


\section{REFERENCES}

1. Gogia A, Agarwal PK. Metabolic syndrome. Indian J Med Sci 2006;60:72-81.

2. Grundy SM. Cardiovascular and metabolic risk factors: how can we improve outcomes in the high-risk patient? Am J Med 2007;120:S3-8; discussion S9.

3. Zimmet P, Alberti KG, Shaw J. Global and societal implications of the diabetes epidemic. Nature 2001;414:782-7.

4. Cameron AJ, Shaw JE, Zimmet PZ. The metabolic syndrome: prevalence in worldwide populations. Endocrinol Metab Clin North Am 2004;33:351-75, table of contents.

5. Azadbakht L, Mirmiran P, Esmaillzadeh A, Azizi F. Dairy consumption is inversely associated with the prevalence of the metabolic syndrome in Tehranian adults. Am J Clin Nutr 2005;82:523-30.

6. Pereira MA, Jacobs DR, Jr., Van Horn L, Slattery ML, Kartashov AI, Ludwig DS. Dairy consumption, obesity, and the insulin resistance syndrome in young adults: the CARDIA Study. JAMA 2002;287:2081-9.

7. Ruidavets JB, Bongard V, Dallongeville J, et al. High consumptions of grain, fish, dairy products and combinations of these are associated with a low prevalence of metabolic syndrome. J Epidemiol Community Health 2007;61:810-7.

8. Elwood PC, Pickering JE, Fehily AM. Milk and dairy consumption, diabetes and the metabolic syndrome: the Caerphilly prospective study. J Epidemiol Community Health 2007;61:695-8.

9. Choi HK, Willett WC, Stampfer MJ, Rimm E, Hu FB. Dairy consumption and risk of type 2 diabetes mellitus in men: a prospective study. Arch Intern Med 2005;165:997-1003.

10. van Dam RM, Hu FB, Rosenberg L, Krishnan S, Palmer JR. Dietary calcium and magnesium, major food sources, and risk of type 2 diabetes in U.S. black women. Diabetes Care 2006;29:2238-43.

11. Kontogianni MD, Panagiotakos DB, Chrysohoou C, Pitsavos C, Stefanadis C. Modelling dairy intake on the development of acute coronary syndromes: the CARDIO2000 study. Eur J Cardiovasc Prev Rehabil 2006;13:791-7.

12. Samara A, Herbeth B, Ndiaye NC, et al. Dairy product consumption, calcium intakes, and metabolic syndrome-related factors over 5 years in the STANISLAS study. Nutrition 2012.

13. Fumeron F, Lamri A, Abi Khalil C, et al. Dairy consumption and the incidence of hyperglycemia and the metabolic syndrome: results from a french prospective study, Data from the Epidemiological Study on the Insulin Resistance Syndrome (DESIR). Diabetes Care 2011;34:813-7.

14. Fumeron F, Lamri A, Emery N, et al. Dairy products and the metabolic syndrome in a prospective study, DESIR. J Am Coll Nutr 2011;30:454S-63S.

15. Lutsey PL, Steffen LM, Stevens J. Dietary intake and the development of the metabolic syndrome: the Atherosclerosis Risk in Communities study. Circulation 2008;117:75461.

16. Snijder MB, van Dam RM, Stehouwer CD, Hiddink GJ, Heine RJ, Dekker JM. A prospective study of dairy consumption in relation to changes in metabolic risk factors: the Hoorn Study. Obesity (Silver Spring) 2008;16:706-9.

17. Snijder MB, van der Heijden AA, van Dam RM, et al. Is higher dairy consumption associated with lower body weight and fewer metabolic disturbances? The Hoorn Study. Am J Clin Nutr 2007;85:989-95.

18. Louie JC, Flood VM, Rangan AM, et al. Higher regular fat dairy consumption is associated with lower incidence of metabolic syndrome but not type 2 diabetes. Nutr Metab Cardiovasc Dis 2012.

19. Kondo I, Ojima T, Nakamura M, et al. Consumption of Dairy Products and Death From Cardiovascular Disease in the Japanese General Population: The NIPPON DATA80. J Epidemiol 2013;23:47-54.

20. Patterson E, Larsson SC, Wolk A, Akesson A. Association between Dairy Food Consumption and Risk of Myocardial Infarction in Women Differs by Type of Dairy Food. J Nutr 2013;143:74-9.

21. Soedamah-Muthu SS, Ding EL, Al-Delaimy WK, et al. Milk and dairy consumption and incidence of cardiovascular diseases and all-cause mortality: dose-response metaanalysis of prospective cohort studies. Am J Clin Nutr 2011;93:158-71. 

products and its association with incidence of cardiovascular disease: the Malmo diet and cancer cohort. Eur J Epidemiol 2011;26:609-18.

23. van Aerde MA, Soedamah-Muthu SS, Geleijnse JM, et al. Dairy intake in relation to cardiovascular disease mortality and all-cause mortality: the Hoorn Study. Eur J Nutr 2012.

24. Bonthuis M, Hughes MC, Ibiebele TI, Green AC, van der Pols JC. Dairy consumption and patterns of mortality of Australian adults. Eur J Clin Nutr 2010;64:569-77.

25. de Oliveira Otto MC, Mozaffarian D, Kromhout D, et al. Dietary intake of saturated fat by food source and incident cardiovascular disease: the Multi-Ethnic Study of Atherosclerosis. Am J Clin Nutr 2012;96:397-404.

26. Thomsen C, Storm H, Holst JJ, Hermansen K. Differential effects of saturated and monounsaturated fats on postprandial lipemia and glucagon-like peptide 1 responses in patients with type 2 diabetes. Am J Clin Nutr 2003;77:605-11.

27. Nicolosi RJ, Stucchi AF, Kowala MC, Hennessy LK, Hegsted DM, Schaefer EJ. Effect of dietary fat saturation and cholesterol on LDL composition and metabolism. In vivo studies of receptor and nonreceptor-mediated catabolism of LDL in cebus monkeys. Arteriosclerosis 1990;10:119-28.

28. Spady DK, Bilheimer DW, Dietschy JM. Rates of receptor-dependent and -independent low density lipoprotein uptake in the hamster. Proc Natl Acad Sci U S A 1983;80:3499503.

29. Kromhout D, Menotti A, Bloemberg B, et al. Dietary saturated and trans fatty acids and cholesterol and 25-year mortality from coronary heart disease: the Seven Countries Study. Prev Med 1995;24:308-15.

30. Sacks FM, Katan M. Randomized clinical trials on the effects of dietary fat and carbohydrate on plasma lipoproteins and cardiovascular disease. Am J Med 2002;113 Suppl 9B:13S-24S.

31. Miettinen TA, Strandberg TE, Gylling H. Noncholesterol sterols and cholesterol lowering by long-term simvastatin treatment in coronary patients: relation to basal serum cholestanol. Arterioscler Thromb Vasc Biol 2000;20:1340-6.

32. Gylling $\mathrm{H}$, Hallikainen $\mathrm{M}$, Kolehmainen $\mathrm{M}$, et al. Cholesterol synthesis prevails over absorption in metabolic syndrome. Transl Res 2007;149:310-6.

33. Sylven $\mathrm{C}$, Nordstrom $\mathrm{C}$. The site of absorption of cholesterol and sitosterol in the rat small intestine. Scand J Gastroenterol 1970;5:57-63.

34. Pihlajamaki J, Gronlund S, Simonen M, et al. Cholesterol absorption decreases after Roux-en-Y gastric bypass but not after gastric banding. Metabolism 2009.

35. Pakarinen M, Miettinen TA, Kuusanmaki P, Vento P, Kivisto T, Halttunen J. Effect of ileal autotransplantation on cholesterol, bile acids, and biliary lipids in pigs with proximal small bowel resection. Hepatology 1997;25:1315-22.

36. Pakarinen MP, Halttunen J, Kuusanmaki P, Lauronen J, Miettinen TA. Absorption, excretion, and distribution of plant sterols after proximal gut resection and autotransplantation of porcine ileum. Lipids 1998;33:267-76.

37. Pakarinen MP, Miettinen TA, Kuusanmaki $P$, et al. Adaptive lipid metabolism after ileal autotransplantation in pigs with proximal gut resection. Surgery 1997;122:950-61.

38. Sane AT, Sinnett D, Delvin E, et al. Localization and role of NPC1L1 in cholesterol absorption in human intestine. J Lipid Res 2006;47:2112-20.

39. Hrabovsky V, Zadak Z, Blaha V, et al. Cholesterol metabolism in active Crohn's disease. Wien Klin Wochenschr 2009;121:270-5.

40. Hakala K, Vuoristo M, Miettinen TA. Serum cholesterol, cholesterol precursors and plant sterols in different inflammatory bowel diseases. Digestion 1996;57:83-9.

41. Lobo MV, Huerta L, Ruiz-Velasco N, et al. Localization of the lipid receptors CD36 and CLA-1/SR-BI in the human gastrointestinal tract: towards the identification of receptors mediating the intestinal absorption of dietary lipids. J Histochem Cytochem 2001;49:1253-60.

42. Poirier H, Degrace P, Niot I, Bernard A, Besnard P. Localization and regulation of the putative membrane fatty-acid transporter (FAT) in the small intestine. Comparison with fatty acid-binding proteins (FABP). Eur J Biochem 1996;238:368-73.

43. Chen M, Yang Y, Braunstein E, Georgeson KE, Harmon CM. Gut expression and regulation of FAT/CD36: possible role in fatty acid transport in rat enterocytes. Am J Physiol Endocrinol Metab 2001;281:E916-23. 
44. Nassir F, Wilson B, Han X, Gross RW, Abumrad NA. CD36 is important for fatty acid and cholesterol uptake by the proximal but not distal intestine. J Biol Chem 2007;282:19493-501.

45. Wang Q, Herrera-Ruiz D, Mathis AS, Cook TJ, Bhardwaj RK, Knipp GT. Expression of PPAR, RXR isoforms and fatty acid transporting proteins in the rat and human gastrointestinal tracts. J Pharm Sci 2005;94:363-72.

46. Ockner RK, Manning JA. Fatty acid-binding protein in small intestine. Identification, isolation, and evidence for its role in cellular fatty acid transport. J Clin Invest 1974;54:326-38.

47. Brown MS, Goldstein JL. A receptor-mediated pathway for cholesterol homeostasis. Science 1986;232:34-47.

48. Herz J, Qiu SQ, Oesterle A, DeSilva HV, Shafi S, Havel RJ. Initial hepatic removal of chylomicron remnants is unaffected but endocytosis is delayed in mice lacking the low density lipoprotein receptor. Proc Natl Acad Sci U S A 1995;92:4611-5.

49. Out R, Kruijt JK, Rensen PC, et al. Scavenger receptor BI plays a role in facilitating chylomicron metabolism. J Biol Chem 2004;279:18401-6.

50. Bansal S, Buring JE, Rifai N, Mora S, Sacks FM, Ridker PM. Fasting compared with nonfasting triglycerides and risk of cardiovascular events in women. JAMA 2007;298:309-16.

51. Patsch JR, Miesenbock G, Hopferwieser T, et al. Relation of triglyceride metabolism and coronary artery disease. Studies in the postprandial state. Arterioscler Thromb 1992;12:1336-45.

52. Nordestgaard BG, Benn M, Schnohr P, Tybjaerg-Hansen A. Nonfasting triglycerides and risk of myocardial infarction, ischemic heart disease, and death in men and women. JAMA 2007;298:299-308.

53. van Wijk JP, Halkes CJ, Erkelens DW, Castro Cabezas M. Fasting and daylong triglycerides in obesity with and without type 2 diabetes. Metabolism 2003;52:1043-9.

54. Mekki N, Charbonnier M, Borel P, et al. Butter differs from olive oil and sunflower oil in its effects on postprandial lipemia and triacylglycerol-rich lipoproteins after single mixed meals in healthy young men. J Nutr 2002;132:3642-9.

55. Thomsen $\mathrm{C}$, Rasmussen $\mathrm{O}$, Lousen $\mathrm{T}$, et al. Differential effects of saturated and monounsaturated fatty acids on postprandial lipemia and incretin responses in healthy subjects. Am J Clin Nutr 1999;69:1135-43.

56. Levy E, Roy CC, Goldstein R, Bar-On H, Ziv E. Metabolic fate of chylomicrons obtained from rats maintained on diets varying in fatty acid composition. J Am Coll Nutr 1991;10:69-78.

57. Tholstrup T, Sandstrom B, Bysted A, Holmer G. Effect of 6 dietary fatty acids on the postprandial lipid profile, plasma fatty acids, lipoprotein lipase, and cholesterol ester transfer activities in healthy young men. Am J Clin Nutr 2001;73:198-208.

58. O'Dea K, Nestel PJ, Antonoff L. Physical factors influencing postprandial glucose and insulin responses to starch. Am J Clin Nutr 1980;33:760-5.

59. Bjorck I, Granfeldt Y, Liljeberg H, Tovar J, Asp NG. Food properties affecting the digestion and absorption of carbohydrates. Am J Clin Nutr 1994;59:699S-705S.

60. Clemente G, Mancini M, Nazzaro F, et al. Effects of different dairy products on postprandial lipemia. Nutr Metab Cardiovasc Dis 2003;13:377-83.

61. Michalski MC. On the supposed influence of milk homogenization on the risk of CVD, diabetes and allergy. Br J Nutr 2007;97:598-610.

62. Buchheim W. Zum Einfluss unterschiedlicher technologischer Behandlung von Milch auf die Verdauungsvorgange im Magen. IV. Elektronenmikroskopische Charakterisierung des Koagulums und lipolytischer Vorgange im Magen. (Influence of different technological treatments of milk on digestion in the stomach. IV. Electron microscopic characterization of the coagulum and of lipolytic processes in the stomach). Milchwissenschaft 1984;39:271-275.

63. Michalski MC, Soares AF, Lopez C, Leconte N, Briard V, Geloen A. The supramolecular structure of milk fat influences plasma triacylglycerols and fatty acid profile in the rat. Eur J Nutr 2006;45:215-24.

64. German J, Dillard C. Fractionated milk fat: composition, structure, and functional properties. Food Technol 1998;52:33. 
65. van Loon LJ, Saris WH, Verhagen H, Wagenmakers AJ. Plasma insulin responses after ingestion of different amino acid or protein mixtures with carbohydrate. Am J Clin Nutr 2000;72:96-105.

66. Executive Summary of The Third Report of The National Cholesterol Education Program (NCEP) Expert Panel on Detection, Evaluation, And Treatment of High Blood Cholesterol In Adults (Adult Treatment Panel III). JAMA 2001;285:2486-97.

67. Ross R. Atherosclerosis--an inflammatory disease. N Engl J Med 1999;340:115-26.

68. Manning PJ, Sutherland WH, McGrath MM, de Jong SA, Walker RJ, Williams MJ. Postprandial Cytokine Concentrations and Meal Composition in Obese and Lean Women. Obesity (Silver Spring) 2008.

69. Blackburn P, Despres JP, Lamarche B, et al. Postprandial variations of plasma inflammatory markers in abdominally obese men. Obesity (Silver Spring) 2006;14:1747-54.

70. Payette C, Blackburn P, Lamarche B, et al. Sex differences in postprandial plasma tumor necrosis factor-alpha, interleukin-6, and C-reactive protein concentrations. Metabolism 2009;58:1593-601.

71. Nappo F, Esposito K, Cioffi M, et al. Postprandial endothelial activation in healthy subjects and in type 2 diabetic patients: role of fat and carbohydrate meals. J Am Coll Cardiol 2002;39:1145-50.

72. Ceriello A, Quagliaro L, Piconi L, et al. Effect of postprandial hypertriglyceridemia and hyperglycemia on circulating adhesion molecules and oxidative stress generation and the possible role of simvastatin treatment. Diabetes 2004;53:701-10.

73. Marchesi S, Lupattelli G, Lombardini R, et al. Effects of fenofibrate on endothelial function and cell adhesion molecules during post-prandial lipemia in hypertriglyceridemia. J Clin Pharm Ther 2003;28:419-24.

74. Rubin D, Claas S, Pfeuffer M, Nothnagel M, Foelsch UR, Schrezenmeir J. s-ICAM-1 and S-VCAM-1 in healthy men are strongly associated with traits of the metabolic syndrome, becoming evident in the postprandial response to a lipid-rich meal. Lipids Health Dis 2008;7:32.

75. Lundman P, Boquist S, Samnegard A, et al. A high-fat meal is accompanied by increased plasma interleukin-6 concentrations. Nutr Metab Cardiovasc Dis 2007;17:195-202.

76. Plat J, Jellema A, Ramakers J, Mensink RP. Weight loss, but not fish oil consumption, improves fasting and postprandial serum lipids, markers of endothelial function, and inflammatory signatures in moderately obese men. J Nutr 2007;137:2635-40.

77. Panagiotakos DB, Pitsavos CH, Zampelas AD, Chrysohoou CA, Stefanadis Cl. Dairy products consumption is associated with decreased levels of inflammatory markers related to cardiovascular disease in apparently healthy adults: the ATTICA study. J Am Coll Nutr 2010;29:357-64.

78. Zemel MB, Sun X, Sobhani T, Wilson B. Effects of dairy compared with soy on oxidative and inflammatory stress in overweight and obese subjects. Am J Clin Nutr 2010;91:1622.

79. Nestel PJ, Pally S, Macintosh GL, et al. Circulating inflammatory and atherogenic biomarkers are not increased following single meals of dairy foods. Eur $\mathrm{J}$ Clin Nutr 2012;66:25-31.

80. Pal $\mathrm{S}$, Ellis $\mathrm{V}$. Acute effects of whey protein isolate on blood pressure, vascular function and inflammatory markers in overweight postmenopausal women. $\mathrm{Br} \mathrm{J}$ Nutr 2011;105:1512-9.

81. Oster KA, Oster JB, Ross DJ. Immune response to bovine xanthine oxidase in atherosclerotic patients. Am Lab 1974;Aug:41-47.

82. van Oostrom AJ, Rabelink TJ, Verseyden C, et al. Activation of leukocytes by postprandial lipemia in healthy volunteers. Atherosclerosis 2004;177:175-82.

83. Schratzberger P, Dunzendorfer S, Reinisch N, Kahler CM, Herold M, Wiedermann CJ. Release of chemoattractants for human monocytes from endothelial cells by interaction with neutrophils. Cardiovasc Res 1998;38:516-21.

84. Bae JH, Bassenge $\mathrm{E}, \mathrm{Kim} \mathrm{KB}$, et al. Postprandial hypertriglyceridemia impairs endothelial function by enhanced oxidant stress. Atherosclerosis 2001;155:517-23.

85. van Oostrom AJ, Sijmonsma TP, Verseyden C, et al. Postprandial recruitment of neutrophils may contribute to endothelial dysfunction. J Lipid Res 2003;44:576-83. 

SUMMRRY 
The global incidence of the metabolic syndrome, a major risk factor for developing cardiovascular disease (CVD), is rising at an alarming rate. This warrants a detailed understanding of the causes and progression of this metabolic aberration and on possible nutritional intervention strategies to prevent or even cure their clinical manifestations. Within this context, dairy products may fulfill a special role.

Several observational studies have suggested that an increased intake of dairy products may be related to a decreased risk for developing the metabolic syndrome and CVD. This relationship may not be restricted to low-fat dairy products alone. However, intervention studies are scarce and have mostly been performed in the fasted state. As most time of the day is spent in a postprandial state and postprandial lipemia is related to CVD-risk, intervention studies should also focus on postprandial responses. Chapter 2 reviews the effects of the different macronutrients on postprandial lipemic, inflammatory, and endothelial responses and the possible mechanisms involved. Dietary fatty acids are a prerequisite for a postprandial lipemic response. Fat-specific determinants include the amount of fat and the fatty acid composition, e.g. chain length, degree of saturation, triacylglycerol (TAG) structure and solid fat content. Dietary protein and carbohydrates also affect postprandial metabolism of dietary lipids at various steps of digestion, absorption and clearance. Important effects may be found on fatty acid handling, mainly through insulinotropic effects, hereby decreasing the hepatic output of very low-density lipoproteins (VLDL). Regarding the inflammatory and endothelial responses, meal consumption may result in activated endothelium and inflammatory signaling. However, data on macronutrient-specific differences is limited and contrasting.

Although an increased consumption of high-fat dairy products may be related to a decreased incidence of the metabolic syndrome, these products contain relatively large amounts of cholesterol and saturated fatty acids (SFA). As no data was available on the most important sites of uptake of cholesterol and fatty acids in the human intestine, we measured protein levels of the most important transporter proteins involved along the human digestive tract (chapter 3). We found for the transport proteins NPC1L1, ABCA1, ABCG8, FAT/CD36 and FABPpm the highest protein levels in the ileum, whereas for ABCG5 and FATP-4, levels were comparable in all segments. Noteworthy, we also found significant amounts of transporters in the colon. Our findings therefore indicate that the ileum plays an important role in transportermediated uptake of both cholesterol and long-chain fatty acids, (LCFA) especially when considering its large surface area as compared to that of the duodenum and colon. It should be noted however, that results of our study are 
limited to active uptake, and that protein activity and functionality were not studied.

After absorption, fatty acids are incorporated into chylomicrons and released into the circulation, eliciting a lipemic response. Because of the proposed relation of dairy consumption with the metabolic syndrome and CVD, it is important to know how lipemic responses of dairy fat compare to those of other fats and oils. Therefore, in chapter 4, we compared postprandial lipemic, inflammatory and endothelial responses in thirteen overweight men, consuming at different occasions muffins rich in saturated butterfat and muffins rich in ( $n-6)$ polyunsaturated fatty acids (PUFA). The TAG iAUCs were comparable, but after butterfat peak time was significantly delayed and the late iAUC was increased. As lipemia is a resultant of absorption and clearance, it was not possible to identify which of these two processes was affected. The comparable apoB-48 responses suggested that the number of chylomicrons released was comparable between the fats, but that chylomicron size may have differed, resulting in a higher clearance rate after ( $n-6)$ PUFA intake. Exchanging SFA for ( $n-6)$ PUFA resulted in decreased interleukin (IL)6 , tumor necrosis factor (TNF)a, soluble TNF receptor 2 and sVCAM-1 concentrations.

Because of the possible beneficial effects of dairy consumption on CVD and the metabolic syndrome, it may be hypothesized that dairy products contain constituents that negate the potential deleterious effects of SFA and cholesterol. To investigate the dairy constituents involved, chapter 5 reports on postprandial inflammatory and endothelial responses in sixteen overweight men, consuming at different occasions butter cake with $500 \mathrm{~mL}$ of either water, water with calcium, water with calcium and milk protein, or milk. Both the milk meal and the protein meal reduced SICAM-1 and sVCAM-1 concentrations as compared to the other meals, whereas TNFa concentrations were decreased after the control meal as compared to the other meals. Milk protein however, was ingested together with calcium, so the effects of milk protein may be dependent on the presence of calcium. Since milk tended to induce even larger reductions in adhesion molecules, other nutrients may be involved as well. Arguably, the complex dairy matrix may also have modulated the effects of the individual constituents.

Several studies have compared postprandial responses to different fats or dairy products, without adequately accounting for differences in the food matrix. Chapter 6 therefore reports on an intervention study, in which eighteen overweight men consumed in random order homogenized $(\mathrm{H})$ milk, nonhomogenized $(\mathrm{NH})$ milk or butterfat. As compared to $\mathrm{NH}$-milk, H-milk contains smaller fat globules and an altered milk fat globule membrane (MFGM) structure. Except for differences in the food matrix, the meals were 
comparable. No differences in postprandial TAG concentrations or peak times between $\mathrm{H}$ - and $\mathrm{NH}$ - milk were however found. Based on changes in TAG, apoB-48 and non-esterified fatty acid concentrations, we found no evidence for faster digestion, absorption or intestinal lipolysis rates. The structural differences between $\mathrm{NH}$-milk and $\mathrm{H}$-milk increased the iAUC and total count of white blood cells. Markers of inflammation and endothelial activation, and measures of the retinal vasculature were not affected by homogenization. After butterfat, TAG concentrations were increased as compared to $\mathrm{NH}$-milk, which was accompanied by a trend for delayed apoB-48 peak concentrations, suggesting a delayed absorption and incorporation of fat from butter into chylomicrons. Moreover, consistently lower concentrations of IL-6 and TNFa were found, when fat was presented as butter, suggesting that the structure of fat in the meal is important.

The studies described do not unambiguously indicate major alterations in postprandial responses after dairy consumption. Future studies however, should investigate whether the findings reported in this thesis are also valid over a longer period of time, and which other dairy constituents may be involved. Also, studies should be performed in subjects who already have developed the metabolic syndrome or CVD, to determine if dairy products may slow down the progression or even regress the clinical manifestations of these conditions. 


\section{SRMENURTTING}


Wereldwijd neemt de incidentie van het metabool syndroom, een belangrijke risicofactor voor hart- en vaatziekten (HVZ), met een alarmerende snelheid toe. Daarom is het noodzakelijk om onze kennis over de oorzaken en progressie van deze stofwisselingsaandoening te vergroten, alsmede om voedingsinterventies te ontwikkelen om deze aandoening te voorkomen of te genezen. Binnen deze benadering vervullen zuivelproducten mogelijk een belangrijke rol.

Verschillende observationele studies laten zien dat een verhoogde zuivelconsumptie gerelateerd is aan een verlaagd risico op het ontwikkelen van het metabool syndroom en HVZ; een relatie die zich mogelijk niet enkel beperkt tot magere zuivelproducten. Desalniettemin zijn er maar weinig interventiestudies met zuivelproducten uitgevoerd. In deze interventiestudies werd bloed - om risicofactoren voor HVZ te meten - veelal in de gevaste staat afgenomen. Echter, het grootste deel van de dag wordt doorgebracht in een postprandiale staat en postprandiale lipemie is gerelateerd aan het risico op HVZ.

Hoofdstuk 2 geeft een overzicht van de effecten van de verschillende macronutriënten op postprandiale lipemie, inflammatiemarkers en endotheelmarkers, waarbij ook mogelijke mechanismen zijn beschreven. Voedingsvetzuren zijn een vereiste voor postprandiale lipemie. Vetgerelateerde factoren zijn onder andere de hoeveelheid vet in de voeding en de vetzuursamenstelling, waaronder bijvoorbeeld ketenlengte, mate van verzadiging, triglyceride (TG) structuur en de hoeveelheid vast vet. Tevens kunnen zowel eiwit als koolhydraten in de voeding het postprandiale vetmetabolisme beïnvloeden door effecten op vertering, opname en klaring. Ook zijn er aanzienlijke effecten op de verwerking van vrije vetzuren, voornamelijk door verhoogde insulinewaarden, waardoor de output van very low-density lipoproteins (VLDL) in de lever daalt. Tenslotte kan het nuttigen van een maaltijd leiden tot endotheelactivatie en een verhoging van ontstekingsparameters. Het is niet duidelijk of er in dit opzicht grote verschillen tussen de diverse macronutriënten zijn.

Een verhoogde consumptie van volle zuivelproducten is mogelijk gerelateerd aan een verlaagde incidentie van het metabool syndroom, ondanks het feit dat deze producten relatief veel cholesterol en verzadigd vet bevatten. Aangezien er geen gegevens beschikbaar waren over de belangrijkste locaties van cholesterol- en vetzuuropname in de darm, hebben we de hoeveelheden van de belangrijkste betrokken transporteiwitten bepaald in de darm van de mens (hoofdstuk 3). De grootste hoeveelheden NPC1L1, ABCA1, ABCG8, FAT/CD36 en FABPpm bevonden zich in het ileum, terwijl voor ABCG5 en FATP-4 de hoeveelheden gelijk waren in alle 
darmsegmenten. Opvallend was ook de aanwezigheid van transporters in het colon. Uit de resultaten blijkt dat het ileum een belangrijke rol speelt in transporter-gemedieerde opname van cholesterol en lange keten vetzuren, mede vanwege de grotere oppervlakte van het ileum ten opzichte van het duodenum en colon. Echter, in deze studie is alleen gekeken naar eiwitten betrokken bij de actieve opname van nutriënten, terwijl eiwitactiviteit en functionaliteit niet zijn gemeten.

$\mathrm{Na}$ absorptie en inbouw van vetzuren in chylomicronen worden deze vrijgegeven in de circulatie, waardoor een lipemische respons optreedt. Vanwege het mogelijke verband tussen zuivelconsumptie en het metabool syndroom en HVZ is het van belang om de lipemische respons na het eten van zuivelvet te vergelijken met die van andere vetten en oliën. Daarom hebben we in hoofdstuk 4 bij dertien mannen met overgewicht de postprandiale lipemische, inflammatoire en endotheelresponsen vergeleken van muffins rijk aan botervet of ( $n-6)$ meervoudig onverzadigde vetten (MOV). De TG iAUC was gelijk, maar de serum TG piek trad later op en na die piek was de iAUC verhoogd na botervet. Het was echter onmogelijk om na te gaan of de absorptie of de klaring beïnvloed was, aangezien lipemie de resultante is van beide processen. De vergelijkbare apoB-48 respons suggereerde dat het aantal chylomicronen gelijk was na de twee maaltijden, maar dat de grootte verschillend was, waardoor de klaring na (n-6) MOV mogelijk verhoogd was. (n-6) MOV verlaagde interleukine (IL)-6, tumor necrosis factor (TNF)a, oplosbare TNF receptor 2 , en sVCAM-1 concentraties.

Vanwege de mogelijk positieve effecten van zuivelconsumptie op HVZ en het metabool syndroom, is het interessant om na te gaan of zuivelproducten bestanddelen bevatten die de nadelige effecten van verzadigd vet en cholesterol teniet doen. Om dit te onderzoeken, werden in hoofdstuk 5 de postprandiale inflammatoire en endotheelresponsen vergeleken bij zestien mannen met overgewicht, die op verschillende dagen boterkoek met ofwel water (controle), water met calcium, water met calcium en melkeiwit, of melk aten. Consumptie van zowel melk als melkeiwit verlaagde sICAM-1 en sVCAM-1 concentraties, terwijl TNF $\alpha$ verlaagd was na de controlemaaltijd ten opzichte van de andere maaltijden. Echter, aangezien melkeiwit samen met calcium werd gegeten, kunnen de effecten van melkeiwit afhankelijk zijn van calcium. Aangezien melk gunstigere effecten leek te hebben op de adhesiemoleculen, is het mogelijk dat melk nog andere bestanddelen bevat die de respons beïnvloeden. Bovendien is het mogelijk dat de complexe zuivelmatrix de effecten van de afzonderlijke bestanddelen heeft beïnvloed. Hoewel in meerdere studies de postprandiale responsen na de inname van verschillende vetten of zuivelproducten met elkaar zijn vergeleken, werd hierbij vaak geen rekening gehouden met verschillen in de voedingsmatrix. 
Hoofdstuk 6 beschrijft de resultaten van een interventiestudie waarin achttien mannen met overgewicht ofwel gehomogeniseerde melk $(H)$, nietgehomogeniseerde melk $(\mathrm{NH})$ of botervet consumeerden. In vergelijking met $\mathrm{H}$-melk bevat $\mathrm{NH}$-melk grotere vetdruppels, met een andere structuur en bouw van het melkvetmembraan. Voor de rest waren de maaltijden vergelijkbaar. Postprandiale TGs en piektijden waren vergelijkbaar tussen $\mathrm{H}$ en $\mathrm{NH}$-melk en er waren geen aanwijzingen voor een snellere vertering, absorptie of lipolyse van het vet in de darm. De veranderde structuur tussen $\mathrm{NH}$ - en H-melk verhoogde de iAUC en het aantal witte bloedcellen, maar markers van inflammatie en endotheelactivatie waren vergelijkbaar tussen $\mathrm{H}$ en NH-melk. $\mathrm{Na}$ botervet daarentegen, waren de TG-concentraties hoger dan na NH-melk, met een trend voor een vertraagde apoB-48 piek. Dit suggereert een vertraagde absorptie en inbouw van vet uit boter in chylomicronen. Daarbij vonden we ook lagere IL- 6 en TNF $\alpha$ concentraties na boter, hetgeen suggereert dat de vetstructuur een belangrijke rol speelt.

Uit deze studies komt niet éénduidig naar voren dat de postprandiale respons door het eten van zuivelproducten sterk verandert. In toekomstige studies moet echter worden bekeken of de resultaten, zoals beschreven in dit proefschrift, geëxtrapoleerd kunnen worden naar effecten op de lange termijn en welke andere zuivelbestanddelen verder betrokken kunnen zijn. Verder dienen er studies uitgevoerd te worden bij mensen die reeds het metabool syndroom of HVZ hebben ontwikkeld om vast te stellen of zuivelproducten mogelijk de progressie kunnen vertragen of zelfs de klinische manifestaties van deze aandoeningen kunnen verminderen. 


\section{DANKWOORD}


De afgelopen jaren werden mijns inziens meer gekenmerkt door het stellen van de juiste vragen dan door het zoeken naar de antwoorden. Een van de moeilijkste en vaakst gestelde vragen was toch wel: "Zeg Chris, wat doe je nu eigenlijk, daar in Maastricht...?" Tsja, ik moet eerlijk toegeven dat ik het zelf vaak moeilijk vond om te begrijpen en onder woorden te brengen. Maar na al die jaren heb ik eindelijk een alleszeggend antwoord...DIT!

Graag wil ik een algemeen woord van dank uitspreken naar allen die op de een of andere manier hebben bijgedragen aan dit proefschrift!

Ten eerste wil ik mijn promotor prof. dr. ir. Ronald Mensink bedanken. Ronald, bedankt voor alle kennis en wijsheid, die hebben geleid tot de totstandkoming van dit proefschrift. Doordat steevast bijna iedere vraag werd beantwoord met een vraag, kwam ik met een hoop vragen te zitten ;). Uiteraard heb ik hier zeer veel van geleerd (ook al duurde het misschien wat langer). Verder wil ik je uitermate bedanken voor al het begrip, geduld en ook de persoonlijke interesse die je hebt getoond in de afgelopen jaren. Je was een geweldige baas!

De beoordelingscommissie, bestaande uit prof. dr. M.A. van Baak, prof. dr. E.C.M. Mariman, prof. dr. E.E. Blaak, prof. dr. C.G. Schalkwijk en dr. P.L. Zock, wil ik natuurlijk graag bedanken voor het lezen en beoordelen van dit proefschrift.

Mijn tijd bij Humane Biologie werd gekenmerkt door een komen en gaan van geweldige collega's: Sanne, Dorien, Els, Florence, Nadine, Maurice (ik zou niet durven om jou vergeten te noemen ;) ), Herman, Tineke, Pascal, Noud, Ruth, Julia, Stefan, Kirsten, Julian, Stan en Chantal. Bedankt voor alle gezelligheid! Natuurlijk zijn er een aantal mensen die een speciale vermelding behoeven...

Jogchum en Maurice, tijdens de eindstage van mijn masteropleiding waren jullie mijn begeleiders. Vanaf dag één kon ik altijd bij jullie terecht om jullie enorme kennis te raadplegen. In deze stage is ook de basis gelegd voor hoofdstuk 3 van dit proefschrift. Jogchum, ik denk dat ik jou met recht de meest enthousiaste persoon mag noemen die ik ken. Anja, bedankt voor alle inzet en gezelligheid tijdens de vele uren van het practicum DNA/RNA.

Martine, Maud, Carla, Yvonne en Nina, jullie hebben mij bergen werk uit handen genomen en voor mij talloze ontbijtjes verzorgd en honderden muffins gebakken. Voor dat laatste moet ik denk niet alleen mijn dank uitspreken, 
maar ook mijn excuses maken. Desalniettemin heb IK altijd graag met jullie gewerkt... Maud en Nina, vooral tijdens de laatste studie zijn jullie van onschatbare waarde geweest, voor zowel de voortgang van de studie zelf, als voor het vertier en de korte rookpauzes tussendoor. Nina, je was ook een geweldige kamergenote; wat hebben we gelachen! $\mathrm{Hi}-\mathrm{Hi}$.

Marjolijn, jij was de kameroudste toen ik net aan de slag ging. Voor alle praktische zaken en een goed gesprek kon ik vanaf dag één bij je terecht. Leonie, je was een geweldig kamergenootje! Bedankt voor de gezelligheid, de leuke gesprekken en het gezelschap als we weer eens af moesten reizen naar Wageningen. Ik heb wel nog steeds trauma's van de 'Twilight-vete' tussen jou en Sabine, omdat ik steeds scheidsrechter moest spelen tussen 'team Jacob' en 'team Edward.' Verder ook hartstikke bedankt voor de kalender, die je Sabine cadeau hebt gedaan en waar ik té lang tegenaan heb moeten kijken... ahum. Peter, we hebben niet lang samen op de kamer gezeten, maar het was erg gezellig! lk werd alleen een beetje nerveus als je weer eens in de kast aan het rommelen was.

Uiteraard verdienen de paranimfen een aparte vermelding. Sabine, wij hebben het langst een kamer gedeeld. Steevast begon iedere dag met een kop koffie en een korte bespreking van het wel en wee van de dag of het weekend ervoor, gevolgd door nog een paar koppen koffie. Hoewel we elkaar hebben leren kennen als collega's, ben ik je steeds meer als een vriendin gaan zien. Ik ken maar weinig mensen die zo onbaatzuchtig en oprecht zijn als jij. Daarom vergeef ik je voor de kalender en je poging tot besmetting van het thuisfront met het 'Twilight-virus.'

Rick, van studiegenoten en collega-sneeuwruimers naar collegawetenschappers. Jij in de thee en ik in de melk. Was jij niet degene, die in zijn proefschrift beweerde dat dit niet zo'n goede combinatie was??? In al die jaren heb ik je leren kennen als een oprechte en geïnteresseerde vriend! En ook al zijn we op dit moment geen collega's meer, vrienden zijn we voor het leven! Ik hoop dat we onder ons vieren (met Eveline en Kel) nog vele malen mogen genieten van elkaars gezelschap en van allerlei heerlijke etentjes. Wat goed trouwens dat je gestopt bent met (mee)roken ;).

Een speciaal woord van dank ook aan alle familie en vrienden voor het altijd tonen van interesse en voor alle gezelligheden buiten werktijd om. Kevin en Audrey, hartelijk dank voor het ontwerpen van deze prachtige cover. 
Pap en mam, bedankt voor het bieden van alle kansen, middelen, vertrouwen, steun en liefde!

Gerdy en Sjef, bedankt voor alles wat jullie voor mij en jullie dochter hebben gedaan. Jullie verdienen een lintje.

Lola, lieverd, jij was mijn grootste bron van afleiding en ontspanning en mijn voetenwarmer tijdens de vele uurtjes schrijven. Jij verdient een koekje.

Kel, schat, in de wetenschap is de laatste plaats altijd de belangrijkste... Die verdien jij alleen! De afgelopen jaren zijn de moeilijkste van ons leven geweest. Maar toch hebben we ook een hoop mooie dingen meegemaakt. Ik wil je bedanken voor wie je bent en voor alles wat je doet. Jij bent mijn steun en toeverlaat; en hoewel je geen woord geschreven hebt aan dit proefschrift, is dit boekje ook van jou. Ik hou van jou! 


\section{LIST OF PUBLICATIONS}


Masson CJ, Plat J, Mensink RP, Namiot A, Kisielewski W, Namiot Z, Fuellekrug J, Ehehalt R, Glatz JFC, Pelsers MMAL. Fatty acid- and cholesterol transporter protein expression along the human intestinal tract. PLoS One. 2010 Apr 29;5(4):e10380.

Masson CJ, Mensink RP. Exchanging saturated fatty acids for (n-6) polyunsaturated fatty acids in a mixed meal may decrease postprandial lipemia and markers of inflammation and endothelial activity in overweight men. J Nutr. 2011 May;141(5):816-21.

Masson CJ, Mensink RP. The effects of macronutrients on postprandial lipemic, inflammatory and endothelial responses. Submitted.

Masson CJ, van Meijl LEC, Mensink RP. The effects of milk and milk constituents provided with a high-fat meal on postprandial markers for inflammation in overweight men. Submitted.

Masson CJ, Mensink RP. Milk Homogenization and Postprandial Metabolism in Overweight Men: a Randomized Study. Submitted.

Masson CJ, Plat J, Mensink RP, et al. Fatty acid- and cholesterol transporter protein expression along the human intestinal tract. Abstract. Atherosclerosis Supplements;11:78-78. 
CURRICULUM UITAE 
Christiaan Josef Masson was born on November $18^{\text {th }} 1983$ in Heerlen, the Netherlands. After he completed secondary school at the Bernardinus College in Heerlen in 2002 he started his study Health Sciences at Maastricht University in 2003, for which he obtained his bachelor's degree in 2006. In 2007 he obtained his master's degree for the European master of Metabolism and Nutrition at Maastricht University. In December of the same year he started his $\mathrm{PhD}$ research project at the Human Biology department of Maastricht University under supervision of prof. dr. ir. R.P. Mensink. In 2010 he was awarded with a travel grant for his oral and poster presentations at the International Symposium on Chylomicrons in Disease (ISCD). His research, described in this thesis, was supported by the Dutch Dairy Association. He conducted human studies to investigate the effects of constituents and the food matrix of dairy products on postprandial metabolism in overweight subjects, who are at risk for developing the metabolic syndrome and cardiovascular disease. 